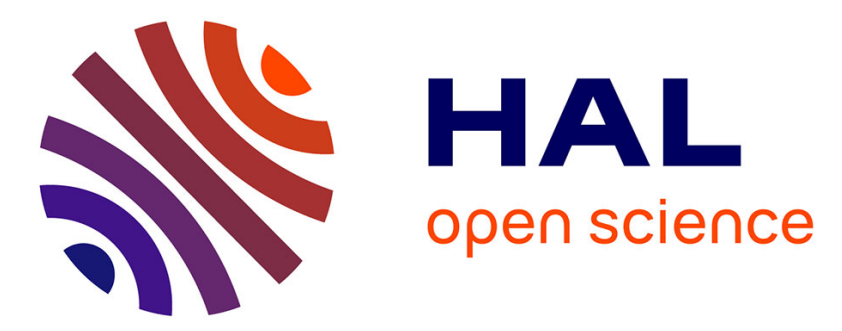

\title{
Pour une histoire instrumentale des savoirs ottomans : à quoi servaient les " livres tenus en haute estime" et autres précieux manuscrits conservés dans une bibliothèque de madrasa anatolienne (Burdur, seconde moitié du XVIIIe siècle)?
}

Olivier Bouquet

\section{To cite this version:}

Olivier Bouquet. Pour une histoire instrumentale des savoirs ottomans : à quoi servaient les " livres tenus en haute estime " et autres précieux manuscrits conservés dans une bibliothèque de madrasa anatolienne (Burdur, seconde moitié du XVIIIe siècle)?. Arabica, 2020, 67 (5/6), pp.502 - 592. 10.1163/15700585-12341575 . halshs-03200789

\section{HAL Id: halshs-03200789 \\ https://shs.hal.science/halshs-03200789}

Submitted on 30 Apr 2021

HAL is a multi-disciplinary open access archive for the deposit and dissemination of scientific research documents, whether they are published or not. The documents may come from teaching and research institutions in France or abroad, or from public or private research centers.
L'archive ouverte pluridisciplinaire HAL, est destinée au dépôt et à la diffusion de documents scientifiques de niveau recherche, publiés ou non, émanant des établissements d'enseignement et de recherche français ou étrangers, des laboratoires publics ou privés. 


\title{
Pour une histoire instrumentale des savoirs ottomans : à quoi servaient les « livres tenus en haute estime » et autres précieux manuscrits conservés dans une bibliothèque de madrasa anatolienne (Burdur, seconde moitié du XVIII $^{\mathrm{e}}$ siècle) ?
}

\author{
Olivier Bouquet \\ Université de Paris, Cess ma, Paris, France \\ olivier.bouquet@gmail.com
}

\section{Résumé}

Cet article décrit et analyse le contenu d'une bibliothèque de 106 ouvrages placés en waqf par Halīl Hamīd Pacha (1736-1785) dans une madrasa de Burdur, cité d'Anatolie méridionale dont ce haut dignitaire ottoman était originaire. Létude aborde

* La rédaction de cet article n'aurait pas été possible sans le précieux concours d'E. Ambros, İ. Erünsal, N. Michel, Ch. Müller, H. Reindl-Kiel, M. Roiland, R. Seignobos, M. Slama, I. Warscheid et K. Yıldız. J'adresse ma plus vive gratitude à D. Mekouar pour l'aide considérable qu'il m'a apportée dans la recherche bibliographique et pour le temps qu'il a consacré à l'identification de plusieurs titres d'ouvrage. Je remercie très chaleureusement N. Vatin pour sa relecture des translittérations de l'ottoman, L. Daaïf pour ses corrections des translittérations de l'arabe, Y. Aykan et R. Soler pour leurs suggestions et remarques et J.-Ch. Coulon pour le travail éditorial effectué sur la dernière version du manuscrit. J'ai beaucoup bénéficié des lumières de C. Mayeur-Jaouen en histoire religieuse et de références bibliographiques connues (hélas!) de très peu de chercheurs français. Je rends hommage aux personnels de la Direction des œuvres manuscrites de Konya ainsi que ceux de la Direction des archives des fondations pieuses d'Ankara qui m'ont accueilli en leurs murs et m'ont généreusement offert de consulter plusieurs des documents utilisés dans cet article. Je sais gré à Bekir Şahin, directeur de la Direction des œuvres manuscrites de Konya, H. Ali Ekinci, directeur de la Bibliothèque et du Musée de Burdur, et Birol Ülker, directeur de la Bibliothèque du Centre de recherches islamiques à Istanbul, de m'avoir communiqué respectivement une liste de 628 manuscrits anciennement conservés à Burdur («Burdur Kitapları Süleymaniye’den Konya'ya Devir-Teslim Listesi, 21-6-2012»), une liste d'ouvrages transférés à la Bibliothèque Dervīş Meḥmed Pacha et un tableau excel de manuscrits de Burdur. 
l'historicité des sciences islamiques en aval de la période médiévale, le rapport entretenu par le public des lecteurs avec des ouvrages de référence, mais aussi le devenir de productions scientifiques et littéraires dans des espaces de la «logosphère arabe » jadis tenus pour périphériques et désormais étudiés au prisme de dynamiques intellectuelles diversifiées. Elle examine le «modèle ottoman » des madrasas non plus sous l'angle des institutions ou des carrières comme c'est souvent le cas, mais sous celui, moins exploré par les spécialistes, des conditions pratiques de la transmission des savoirs. On sait certes qu'à la fin de l'époque moderne des champs de connaissance étaient fragilisés, alors que d'autres étaient plus activement arpentés. Mais on ignore encore largement comment, in situ, les étudiants des madrasas lisaient les textes et comment les enseignants annotaient et commentaient les manuels. Larticle aborde ces questions en examinant l'hypothèse selon laquelle le choix des ouvrages mis en waqf à Burdur ne correspondait pas seulement à l'importance que ceux-ci occupaient dans les hiérarchies des sciences islamiques ou au prestige des auteurs qui les avaient écrits, mais répondait directement à l'utilité qu'ils avaient aux yeux d'étudiants ottomans qui espéraient accéder aux carrières de $n \bar{a} i b$, enseignant ou mufti et des lettrés qui les formaient dans ce sens. Pour mesurer la validité de cette hypothèse, l'étude identifie précisément la place des commentaires dans le corpus et s'interroge sur la capacité du public à faire usage des manuscrits et donc à lire de l'arabe.

\title{
Mots clefs
}

madrasa ottomane, manuscrits, sciences islamiques, waqf, commentaires

\begin{abstract}
This article examines the contents of a library of 106 manuscripts Halī Hamīd Pasha (1736-1785) had donated as waqf in a madrasa of Burdur, a city of southern Anatolia the high Ottoman dignitary originated from. The study addresses the historicity of Islamic sciences after the medieval period, the relationship the public of readers established with reference works and the evolution of scientific and literary productions within the Ottoman "Arab logosphere" formerly held as peripherals and now studied through the prism of diversified intellectual dynamics. It scrutinizes the so-called "Ottoman model" of madrasas less through institutions and careers as specialists in the field usually do than in relation with practical conditions surrounding the transmission of knowledge. Truly, historians have shown to what extent during the 18th century some scientific fields were weakened while others were more actively surveyed. However, they have hardly investigated into how madrasa students read and assimilated reference works
\end{abstract}


and on how teachers annotated and commented on their textbooks. The article offers an insight in this topics by exploring the hypothesis according to which the choice of manuscripts Halìl Hamīd Pasha had donated not only corresponded to their reputation in the hierarchies of Islamic sciences or to the prestige of their authors, but practically responded to the usefulness they had in the eyes of Ottoman students who hoped to access the careers of $n \bar{a} i b$, teacher or mufti and the scholars who trained them in this direction. In order to measure the validity of this hypothesis, the study identifies the place of commentaries in the corpus and questions the ability of the public to use manuscripts and therefore read Arabic.

\section{Keywords}

Ottoman madrasa, manuscripts, Islamic sciences, waqf, commentaries

\section{Introduction}

Cet article décrit et analyse le contenu d'une bibliothèque de 106 ouvrages placés en vakf par Halīl Hamīd Pacha (1736-1785) dans une madrasa de Burdur, cité d'Anatolie méridionale dont ce haut dignitaire ottoman était originaire. Si je propose de le publier dans la revue Arabica, c'est qu'à l'exception de deux d'entre eux composés en persan $\left(\mathrm{n}^{\circ} 45,48\right)$ et de cinq autres écrits en turc ottoman $\left(n^{\circ} 6,102,104,105,106\right)$, la totalité des manuscrits cités furent rédigés en arabe ${ }^{1}$. Une telle répartition n'étonnera ni les historiens ottomanistes, ni leurs collègues arabisants ${ }^{2}$ : elle correspond à celles qui ont été identifiées dans des collections inventoriées, non seulement à Burdur, mais dans plusieurs

1 Au reste, Arabica a publié un article consacré à la reconstitution de la bibliothèque d'un mathématicien ottoman : Cécile Bonmariage, «La bibliothèque de Mustafa Sıdkı : contribution à l'étude d'une collection de manuscrits au XVIII'e siècle », Arabica, 63/5 (2016), p. 533-556.

2 Cependant, il n'est pas à exclure que plusieurs des manuscrits non identifiés ici soient rédigés dans une autre langue que l'arabe. Voir Orhan Bilgin, «Turkey», dans The World Survey of Islamic Manuscripts, éd. Geoffrey J. Roper, Londres, Al-Furqān Islamic Heritage Foundation, 1991-1994, 4 vols, III, p. 271-40o ; İsmail Erünsal, Ottoman Libraries: A Survey of the History, Development and Organization of Ottoman Foundation Libraries, Harvard, The Department of Near Eastern Languages and Literatures-Harvard University ( Sources of Oriental Languages and Literatures », 84; «Turkic sources», 74), 2008, p. 137. Sur les difficultés de déduire la langue d'un manuscrit (arabe, turc, bosnien) de la lecture du seul titre dans des inventaires après décès, voir Asim Zubčević, Book Ownership in Ottoman Sarajevo 1707-1828, thèse de doctorat, Université de Leyde, 2015, p. 158-159. 
bibliothèques anatoliennes ${ }^{3}$. Les références des manuscrits ne sont pas datées : leur étude n'apporte aucun éclairage particulier sur les modalités de constitution du patrimoine arabe des bibliothèques ottomanes ${ }^{4}$. Elle offre en revanche d'aborder l'historicité des sciences islamiques en aval de la période médiévale ${ }^{5}$, le rapport entretenu par le public des lecteurs avec des ouvrages de référence, mais aussi le devenir de productions scientifiques et littéraires dans des espaces de la «logosphère arabe» jadis tenus pour périphériques et désormais étudiés au prisme des dynamiques intellectuelles qui les traversent ${ }^{6}$. Elle pro-

3 Sur les bibliothèques de Burdur, voir M. Zeki Oral, «Mevcut Vesikalara Göre Burdur Kütüphaneleri ve Kitap Vakfiyeleri Vesikaları », Belleten, 24/93-96 (196o), p. 233-261; Bekir Şahin, « Geçmişten Günümüze Burdur Kütüphaneleri », Burdur Araştırmaları, 2/3 (2002), p. 51-65. Sur les manuscripts jadis conservés à Burdur, voir Ahmed Ateş, «Burdur-Antalya ve Havalisi Kütüphanelerinde Bulunan Türkçe, Arapça ve Farsça Bazı Mühim Eserler », İstanbul Üniversitesi Edebiyat Fakültesi Türk Dili ve Edebiyatı Dergisi, 2/3-4 (1948), p. 171-191 et, plus développé, un compte rendu détaillé avec des précisions sur des œuvres en turc, arabe et persan par Adnan Sadık Erzi paru dans Belleten, 13/49 (1949), p. 163-18o. Sur le catalogage des manuscrits arabes à l'époque républicaine, voir Hatice Aynur, « Türkiye Kütüphaneleri Arap Harflı Basma Kitap Katalogları Üzerine Bibliyografik Bir Değerlendirme (1929-2009) », dans İsmail Erünsal'a Armağan, éds Bilgin Aydın, Mustafa Birol Ülker et Hatice Aynur, Istanbul, Ülke Kitapları, 2014, II, p. 1097-1132. Pour une synthèse sur les bibliothèques ottomanes, voir İsmail Erünsal, Türk Kütüphaneleri Tarihi II : Kuruluştan Tanzimat'a Kadar Osmanlı Vakıf Kütüphaneleri, Ankara, Türk Tarih Kurumu, 1991.

4 À ce jour, le sujet du transfert des bibliothèques arabes par les conquérants ottomans a été peu examiné par les spécialistes. Konrad Hirschler, Medieval Damascus: Plurality and Diversity in Arabic Library. The Ashrafiya Library Catalogue, Édimbourg, Edinburgh University Press («Edinburgh Studies in Classical Islamic History and Culture »), 2016, p. 50-52, ainsi que le compte rendu de Renaud Soler dans Arabica, 65/1-2 (2018), p. 235-242, p. 239.

5 Sur la république des lettres envisagée comme "communauté textuelle» entre 648/1250 et 1226/1811, voir Muhsin J. al-Musawi, The Medieval Islamic Republic of Letters: Arabic Knowledge Construction, Notre Dame, University of Notre Dame Press, 2015, p. 1-9. Sur les enjeux de la périodisation, voir Konrad Hirschler et Sarah Bowen Savant, «Introduction - What is a Period? Arabic Historiography and Periodization », Der Islam, 91/1 (2014), p. 6-19. Pour le cas ottoman, voir Yavuz Aykan, « From the Hanafi Doxa to the Mecelle: The Mufti of Amid and Genealogies of the Ottoman Jurisprudential Tradition», dans Forms and Institutions of Justice: Legal Actions in Ottoman Contexts, éds Yavuz Aykan et Işık Tamdoğan, Istanbul, Institut français d'études anatoliennes, 2018, consultable en ligne : books.openedition.org/ ifeagd/2334, consulté le 5 juin 2019. Pour une étude de dynamiques historiographiques au moyen d'une approche régressive, voir Catherine Mayeur-Jaouen, « À la poursuite de la réforme: renouveaux et débats historiographiques de l'histoire religieuse et intellectuelle de l'islam, XV $\mathrm{X}^{\mathrm{XXI}}{ }^{\mathrm{e}}$ siècle », Annales : histoire et sciences sociales, 73/2 (2018), p. 317-358.

6 Philipp Bruckmayr, «The Šarh /Ḥäšiya Phenomenon in Southeast Asia from al-Sanūsī’s Umm al-Barāhīn to Malay Sifat Dua Puluh Literature », Mélanges de l'Institut dominicain d'études orientales, 32 (2017), p. 27-52, p. 46 ; John Voll, « Muḥammad Hayyā al-Sindī and Muhammad ibn 'Abd al-Wahhāb: An Analysis of an Intellectual Group in Eighteenth-Century Madīna », Bulletin of the School of Oriental and African Studies, 38/1 (1975), p. 32-39; Nehemia 
pose en outre d'examiner le «modèle ottoman » des madrasas non plus sous l'angle des institutions ou des carrières comme c'est souvent le cas, mais sous celui, moins exploré, des conditions pratiques de la transmission des savoirs?

En matière d'identification des pratiques culturelles, l'état de l'art est en effet peu avancé. Séparément plutôt que conjointement, les historiens des madrasas et les spécialistes des bibliothèques ont proposé des inventaires des ressources manuscrites ${ }^{8}$. Ils ont décrit selon quelles modalités ces institutions « usually contained a restricted range of a hundred or so preferred, 'canonical'

Levtzion, «Eighteenth Century Sufi Brotherhoods: Structural, Organisational and Ritual Changes", dans Islam: Essays on Scripture, Thought and Society. A Festschrift in Honour of Anthony H. Johns, éds Peter G. Riddell et Tony Street, Leyde-New York, Brill ( «Islamic Philosophy and Theology», 28), 1997, p. 147-16o; Asad Q. Ahmed et Margaret Larkin, «The Hāshiya and Islamic Intellectual History », Oriens, 41/3-4 (2013), p. 213-216; Bernd Radtke et Rex S. O'Fahey, «Neo-Sufism Reconsidered», Der Islam, 70/1 (1993), p. 52-87; Nehemia Levtzion et John Obert Voll, «Introduction », dans Eighteenth-Century Renewal and Reform in Islam, éds Nehemia Levtzion et John Obert Voll, Syracuse, Syracuse University Press, 1987, p. 3-20 ; Harbans Mukhia, « 'Medieval India': An Alien Conceptual Hegemony? », The Medieval History Journal, 1/1 (1998), p. 91-105, réédité dans Harbans Mukhia, Exploring India's Medieval Centuries: Essays in History, Society, Culture and Technology, New Delhi, Aakar Books, 2010, p. 31-48; Kirti N. Chaudhuri, Asia Before Europe: Economy and Civilisation of the Indian Ocean from the Rise of Islam to 1750, Cambridge, Cambridge University Press, 1990 (notamment sur la «structure topologique de l'islam», p. 49). Sur la «vision arabo-centrée de l'Orient ottoman », voir Mayeur-Jaouen, «À la poursuite de la réforme », p. 317-318, 346-348.

7 Gilles Veinstein n'avait pas intégré cet élément dans son article de synthèse sur les madrasas ottomanes: Gilles Veinstein, «Le modèle ottoman», dans Madrasa : la transmission du savoir dans le monde musulman, éds Nicole Grandin et Marc Gaborieau, Paris, Arguments, 1997, p. 73-83. Pour mesurer ce décalage, on consultera les sections bibliographiques distinguées par Mefail Hızlı dans son bilan sur l'historiographie des madrasas, « Anadolu'daki Osmanlı Medreseleri : Bir İcmal», Türkiye Araştırmaları Literatür Dergisi, 2/4 (2004), p. 371409, p. 374. Voir aussi Cahid Baltacı, XV.-XVI. Asırlarda Osmanlı Medreseleri: Teşkilat, Tarih, Istanbul, Marmara Üniversitesi İlahiyat Fakültesi Vakfi, 2005, I, p. 5-105 (aucune madrasa n'est citée concernant Burdur ; 2 pages seulement sont consacrées à l'éducation dans les bibliothèques des madrasas : ibid., I, p. 34-35); Yasemin Beyazıt, Osmanlı İlmiyye Mesleğinde İstihdam (XVI. Yüzyll), Ankara, Türk Tarih Kurumu, 2014; Hüseyin Demir, Die osmanischen Medresen: das Bildungswesen und seine historischen Wurzeln im Osmanischen Reich von 1331160o, Francfort-sur-le-Main, Peter Lang Verlag («Leipziger Beiträge zur Orientforschung », 17), 2005. Pour une critique des approches institutionnelles sur les oulémas ottomans, lire Ertuğrul Ökten, «Scholars and Mobility: A Preliminary Assessment from the Perspective of al-Shaqāyiq al-Nu'māniyya », Osmanlı Araştırmaları, 41 (2013), p. 55-70, p. 57-58.

8 À partir d'une sélection de 14 œuvres, Cevat İzgi présente le détail des programmes d'enseignement: Cevat İzgi, Osmanlı Medreselerinde İlim, Istanbul, İz yayıncılık, 1997, 2 vols, I [Riyazî İlimler] ; j'ai plus particulièrement examiné 5 d'entre eux qui concernent le XVIII ${ }^{\mathrm{e}}$ siècle : p. 69-77, p. 84-97, p. 102-105. Voir aussi Mustafa Bilge, İlk Osmanlı Medreseleri, Istanbul, Edebiyat Fakültesi Basımevi («İstanbul Üniversitesi Edebiyat Fakültesi yayınları», 3101), 1984, p. 40-63 (un grand nombre d'ouvrages de la liste y sont cités). Sur le contenu des enseignements des disciplines, lire Ömer Özyllmaz, Osmanlı Medreselerinin Eğitim Programları, Ankara, Kültür Bakanlığı, 2002 ; Baltacı, XV.-XVI. Asırlarda Osmanlı Medreseleri. 
(Arabic) texts related to grammar, logic, the law and other subjects taught in these institutions $»^{9}$. Ils ont démontré que les domaines intellectuels couverts par les livres placés en $v a k f$ dans les madrasas allaient au-delà du champ des disciplines islamiques ${ }^{10}$. Ce faisant, ils ont appliqué des «catégories bibliographiques» invariables, voire anhistoriques, sur l'ensemble de la période ottomane ${ }^{11}$ sans chercher à retracer les évolutions de la place respective des disciplines du 'ilm depuis la fondation des premières madrasas au viII ${ }^{\mathrm{e}} /$ $\mathrm{XIV}^{\mathrm{e}}$ siècle $^{12}$.

On sait certes qu'à la fin de l'époque moderne des champs de connaissance étaient fragilisés - mise au ban par des oulémas du XI $\mathrm{e}^{\mathrm{e}} / \mathrm{XVII}^{\mathrm{e}}$ siècle, la théologie

9 Jan Schmidt, compte rendu de İsmail E. Erünsal, Ottoman Libraries: A Survey of the History, Development and Organization of Ottoman Foundation Libraries, 2008, dans Wiener Zeitschrift für die Kunde des Morgenlandes, 103 (2013), p. 496-499, p. 497.

10 İ. Erünsal, contre les perspectives développées par A. Adıvar (Erünsal, Ottoman Libraries, p. 49-50).

11 Voir a contrario l'enquête quantitative, périodisée et comparée conduite par Orlin Sabev, «Okuyan Taşralı Bir Toplum: Rusçuk Müslümanlarının Kitap Sevgisi (16951786) », Balkanlar'da İslam Medeniyeti Uluslararası Üçüncü Sempozyum Tebliğleri, Bükreş, Romanya/1-5 Kasım 2006, Istanbul, IRCICA, 2011, II, p. 575-607. Voir aussi Fahri Unan, «The Ottoman Ulema: Their Understanding of Knowledge and Scholarly Contributions », dans The Turks, Ankara, Yeni Türkiye Yayınları, 2002, III [The Ottomans], p. 841-850; İzgi, Osmanlı Medreselerinde İlim; İhsan Fazlıŏlu, «Osmanlılar: İlim ve Kültür», Türkiye Diyanet Vakfi İslam Ansiklopedisi, 23 (2007), p. 548-556. Emmanuelle Chapron, "Catégories de l'entendement éditorial et ordre des livres : les livres d'éducation dans les catalogues de libraires du XVIII e siècle », dans L'annonce faite au lecteur: la circulation de l'information sur les livres en Europe, $16^{e_{-1}} 8^{e}$ siècles, éds Annie Charon, Sabine Juratic et Isabelle Pantin, Louvain, Presses universitaires de Louvain («L'atelier d'Érasme : histoires, littératures, livres »), 2017, p. 243-265, p. 3.

12 Ekmeleddin İhsanoğlu se dit très sceptique sur les possibilités d'une telle démarche: Ekmeleddin İhsanoğlu, «Ottoman Educational and Scholarly-Scientific Institutions », dans History of the Ottoman State, Society and Civilisation, éd. id., Istanbul, Ircica, 2002, p. 357-515, p. 383. Voir aussi Shahab Ahmed et Nenad Filipović, «The Sultan's Syllabus: A Curriculum for the Ottoman Imperial Medreses Prescribed in a Fermān of Qānūnī I Süleyman, Dated 973 (1565)», Studia Islamica, 98-99 (2004), p. 183-218, p. 191 (liste et transcription de 39 ouvrages, dont 12 de tafsìr, 12 de hadīt et 12 de fiqh, p. 207). Le tableau des enseignements brossé par İ.H. Uzunçarşılı pose problème en ce qu'il ne tient pas compte des évolutions constatées depuis la période classique : İ.H. Uzunçarşıll, Osmanlı Devletinin İlmiye Teşkilatı, Ankara, Türk Tarih Kurumu, 1965, p. 19-31. Voir aussi Fahri Unan, Kuruluşundan Günümüze Fâtih Külliyesi, Ankara, Türk Tarih Kurumu, 2003. Pour une prise en compte des évolutions des classifications scientifiques aux XVII ${ }^{\mathrm{e}}$-XIX ${ }^{\mathrm{e}}$ siècles, voir Francesca Bellino, «Arabic Encyclopaedias and Encyclopaedism between the Seventeenth and Nineteenth Centuries: Forms, Functions, Intersections of Adab and Modernity», dans Adab and Modernity: A «Process of Civilization»?, éd. Catherine Mayeur-Jaouen, Leyde-Boston, Brill (« Islamic Literatures: Texts and Studies», 3), 2019, p. 123-167. 
spéculative (kaläm) suscitait encore d'importantes productions ${ }^{13}$-, alors que d'autres étaient plus activement arpentés (l'histoire, l'astronomie ou les mathématiques) ${ }^{14}$. Mais on ignore encore largement comment, in situ, les étudiants des madrasas lisaient les textes, ni comment les enseignants annotaient et commentaient les manuels. À feuilleter les pages de manuscrits conservés aux archives de Konya, à entrapercevoir toute la richesse des annotations marginales, tantôt diagonales parallèles ordonnées, tantôt concentrations désorganisées, tantôt indications brèves et espacées, on se pose mille questions sur le travail de la main et de la pensée qui guidait celle-ci ${ }^{15}$.

Désireux d'aborder plusieurs de ces questions, j'examinerai l'hypothèse selon laquelle le choix des ouvrages mis en vakf à Burdur ne correspondait pas seulement à l'importance que ceux-ci occupaient dans les hiérarchies des sciences islamiques ou au prestige des auteurs qui les avaient écrits, mais répondait directement à l'utilité qu'ils avaient aux yeux d'étudiants ottomans qui espéraient accéder aux carrières de juge, enseignant ou mufti et des lettrés qui

13 Le recueil de Bursalı Meḥmed Țāhir 'Oșmānlı Müellifleri, Istanbul, Mațbaca-ı 'āmire, 1333/1914-1915, 3 vols, compterait environ 500 œuvres de kalām: Hülya Terzioğlu, «Celâleddîn ed-Devvânî’nin İsbât-ı Vâcib Anlayışı ve Osmanlı Düşünce Dünyasına Etkileri », İnsan ve Toplum Bilimleri Araştırmaları Dergisi, 7/1 (2018), p. 330-343, p. 331, p. 338: pour des exemples de ces gloses. Sur les condamnations portées au kaläm par al-Nābulusī, voir Khaled El-Rouayheb, Islamic Intellectual History in the Seventeenth Century: Scholarly Currents in the Ottoman Empire and the Maghreb, Cambridge, Cambridge University Press, 2015, p. 290-294. Sur sa pensée et son milieu intellectuel, voir Lejla Demiri et Samuela Pagani (éds), Early Modern Trends in Islamic Theology, 'Abd al-Ghanī al-Nābulusī and His Network of Scholarship, Tübingen, Mohr Siebek («Sapientia Islamica », 1), 2019. Pour une étude de l’œuvre de Muḥammad al-Aqkirmānī (m. 1174/176o), voir Mykhaylo M. Yakubovych, «Muhammad al-Aqkirmānī and his Iqd al-Lacālī: The Reception of Ibn Sīnā in Early Modern Ottoman Empire», Osmanlı Araştırmaları, 41 (2013), p. 197-217. Voir aussi Mustafa Said Yazıcıoğlu, Le kalâm et son rôle dans la société turco-ottomane aux XV $V^{e}$ et XVI ${ }^{e}$ siècles, Ankara, ministère de la Culture, 199o, p. 68-69, 269270 ; Kenan Yakuboğlu, Osmanlı Medrese Eğitimi ve Felsefesi, Istanbul, Gökkubbe, 2006. L'intérêt qu'un dignitaire comme Koca Rāg̀ıb Pacha portait au kalām surpassait largement celui que ses collègues accordaient à la discipline: Henning Sievert, «Eavesdropping in the Pasha's Salon: Usual and Unusual Readings of an Eighteenth-Century Ottoman Bureaucrat », Osmanlı Araştırmaları, 41 (2013), p. 159-195, p. 176-177. Voir aussi Zubčević, Book Ownership in Ottoman Sarajevo 1707-1828, p. 181.

14 Orlin Sabev, «Bulgaristan'da Osmanlı Vakıf Kütüphanelerinde Bir Örnek : Sofya Müftüsü Ebubekir Efendi Kütüphanesi (1777)», dans Balkanlarda Osmanlı Vakıfları ve Eserleri Uluslararası Sempozyumu, Ankara, Vakıflar Genel Müdürlüğü Yayınları, 2012, p. 297-303, p. 299.

15 Par exemple: Ms Konya, Konya Yazma Eserler Bölge Müdürlüğü [= Direction régionale des œuvres manuscrites de Konya], 3884, 3936, 4449 et 4498. 
les formaient dans ce sens ${ }^{16}$. Pour mesurer la validité de cette hypothèse, je déterminerai la place des commentaires (plus d'un tiers des titres cités) dans le corpus et je m'interrogerai sur la capacité du public à faire usage des manuscrits et donc à lire de l'arabe. Je le ferai avec les moyens qui sont les miens (je lis l'ottoman de ces manuscrits) et avec l'aide de collègues arabisants (je n'en comprends pas l'arabe). Je pars du principe qu'« il faut bien s'installer à la pointe de son savoir ou à la pointe de son ignorance - c'est la même chose pour avoir quelque chose à dire $»^{17}$.

\section{Une collection de manuscrits}

Les spécialistes ont pris l'habitude de désigner sous l'appellation «bibliothèques de $v a k f »$ des collections de livres placées sous régime de mainmorte dans deux cadres institutionnels différents. Dans le premier, des membres de la famille impériale, des hauts dignitaires ou des lettrés faisaient don de manuscrits à des institutions islamiques prééxistentes (complexes islamiques, madrasas, couvents, mosquées, écoles $)^{18}$. Dans le second, ils fondaient des bibliothèques dans des édifices construits à cette fin et rétribuaient des

16 La recherche d'un bénéfice que devront en tirer des « étudiants en sciences » est explicitement évoquée dans la vakfiyye de la bibliothèque Köprülü d'Istanbul : Müjgân Cunbur, « Kütüphane Vakfiyelerinden Notlar», Erdem, 1/3 (1985), p. 711-743, p. 718. Sur le principe d'utilité comme finalité des collections de livres, voir Houari Touati, L'armoire à sagesse: bibliothèques et collections en Islam, Paris, Aubier («Collection historique»), 2003, p. 1617, p. 324-325, à partir de la lecture de Krzysztof Pomian, Collectionneurs, amateurs et curieux, Paris, Venise, XVI ${ }^{e}$-XVIII ${ }^{e}$ siècle, Paris, Gallimard («Bibliothèque des histoires »), 1987, p. 231-291. Sur la manière dont le paradigme d'utilité s'impose dans les bibliothèques occidentales du XVIII ${ }^{\mathrm{e}}$ siècle, voir Frédéric Barbier, Histoire des bibliothèques : d'Alexandrie aux bibliothèques virtuelles, Paris, Armand Colin («U. Histoire»), 2013, p. 197-224. Pour une approche instrumentale des bibliothèques, voir Emmanuelle Chapron, Mémoire de synthèse. Travailler avec les livres, XVIII ${ }^{e_{-X X I}}{ }^{e}$ siècle, Université Paris I PanthéonSorbonne, 2016, p. 24-25. Sur les métiers de la 'ilmiyye, voir Gilles Veinstein, «Les Ottomans: fonctionnarisation des clerc, cléricalisation de l'État? », dans Histoire des hommes de Dieu dans l'islam et le christianisme, éds Dominique Iogna-Prat et Gilles Veinstein, Paris, Flammarion, 2003, p. 179-202.

17 L'Abécédaire de Gilles Deleuze, interview Claire Parnet, réal. Pierre-André Boutang, Paris, Éditions Montparnasse (« Regards »), 2004, N comme neurologie.

18 Oral Onur, Edirne Vakıf Kütüphaneleri, Istanbul, Acar, 1986; Uba Çavdar, «Vakıf Kütüphaneleri », Vakıf Dergisi Özel Sayısı, 2006, p. 54-57; İsmail E. Erünsal, «Ottoman Foundation Libraries: Their History and Organization », Osmanlı Araştırmaları, 30 (2007), p. 31-86 ; Faruk Bilici, «Les bibliothèques vakıf-s à Istanbul au XVI ${ }^{\mathrm{e}}$ siècle, prémices de grandes bibliothèques publiques », Revue des mondes musulmans et de la Méditerranée, 
personnels spécialisés à partir des fonds dégagés par leur $v a k f$. On considère généralement que la première des bibliothèques dites «indépendantes » (müstaḳil ${ }^{19}$ ) fut fondée par Köprülü Fāẓll Mușțafà Pacha en vertu d'une charte (vakfiyye) datée de $1678^{20}$. Dans les deux siècles suivants, elles se multiplièrent sans faire pour autant disparaître les bibliothèques d'institution ${ }^{21}$. Dans la seconde moitié $d u \mathrm{XII}^{\mathrm{e}} / \mathrm{XVIII}^{\mathrm{e}}$ siècle, plusieurs d'entre elles furent créées dans des provinces à l'initiative de dignitaires qui en étaient issus ou avaient à en assurer le gouvernement ${ }^{22}$. Les donateurs de manuscrits se répartissaient entre les collectionneurs en quête « de beaux livres », les lettrés avides d'en parcourir toutes les pages, les amateurs de bonnes affaires et les hommes soucieux de réaliser une ouvre pieuse et utile - le vakf de livres promettait des compensations dans l'au-delà ${ }^{23}$. On sait que des dignitaires profitaient de leur passage par les directions territoriales pour s'approprier des ouvrages rares qui sommeillaient dans la poussière des siècles passés, alors que d'autres envoyaient des chargés de mission pour les y débusquer ${ }^{24}$. On raconte qu'un des derniers lettrés ottomans de haute volée, 'Alī Emīrī (m. 1924), avait accepté un poste au Yémen - une destination peu recherchée parmi les employés de l'État - pour la seule raison qu'il voulait consulter un précieux manuscrit qui s'y trouvait ${ }^{25}$.

87-88 (1999), p. 39-59, en particulier p. 44-47 pour une liste de 40 fondateurs de bibliothèques dont 9 grands vizirs.

19 Erünsal, Türk Kütüphaneleri Tarihi II, p. 61.

20 İsmail E. Erünsal, « The Development of Ottoman Libraries from the Conquest of Istanbul (1453) to the Emergence of the Independent Library », Belleten, 6o/227 (1996), p. 93-125; id., Ottoman Libraries, p. 45-54.

21 Zubčević, Book Ownership in Ottoman Sarajevo 1707-1828, p. 119. Pour une présentation de plusieurs d'entre elles en fonction sous le règne de Mahmud I'r (r. 1143/1730-1168/1754), voir Hatice Aynur, «I. Mahmûd'un (ö. 1754) Kütüphaneleri ve Tarih Manzumeleri », dans İsmail Erünsal'a Armağan, II, p. 681-734.

22 Erünsal, Ottoman Libraries, p. 198.

23 Il s'agit du 'ilm nājic dont parle le hadith, évoquant ce qui reste d'un homme après sa mort. Sur les compensations liées aux livres de targib et tarhïb, voir Youssef Eche, Les bibliothèques arabes publiques et semi-publiques en Mésopotamie, en Syrie et en Égypte au Moyen Âge, Damas, Institut français de Damas, 1967, p. 302. Sur les modalités d'acquisition de manuscrits, voir Lale Uluç, «Ottoman Book Collectors and Illustrated Sixteenth Century Shiraz Manuscripts », Revue des mondes musulmans et de la Méditerranée, 87-88 (1999), p. 85-107, p. 88-89; Zubčević, Book Ownership in Ottoman Sarajevo 1707-1828, p. 210. Sur le « collectionnisme » et la recherche de «beaux livres » à l'époque médiévale, voir Touati, L'armoire à sagesse, p. 21-30, p. 245-248.

24 Erünsal, Ottoman Libraries, p. 133; Sievert, «Eavesdropping in the Pasha's Salon », p. 163.

25 Jean Deny, «Ali Emiri Efendi », Journal asiatique, 204 (1924), p. 375-379, p. 376. 
Les livres étaient d'un prix élevé et les manuscrits coûteux à reproduire ${ }^{26}: s^{\prime}$ ils n'étaient pas toujours annotés, au moins étaient-ils parcourus et feuilletés ${ }^{27}$.

La bibliothèque dont il est question dans le présent article relève de la première catégorie: c'était un lieu «de diffusion des sciences pour l'amour de Dieu », comme le précise la charte de la fondation (vakfyyye) ; c'était une madrasa située dans le quartier de Recep Çelebi de Burdur. Associée à la mémoire d'un ancien ouléma, Çeşmecizāde, elle accueillait quelques poignées d'étudiants ${ }^{28}$. Halīl Hạīì avait passé une partie de son enfance à Burdur, avant de suivre son père à Istanbul où ce dernier s'était installé comme marchand. Adolescent, il avait été recruté au divan de la Sublime Porte. Au fil d'une carrière d'une trentaine d'années, il s'était élevé dans la hiérarchie de la Porte, en était devenu l'un des plus importants dignitaires, avant d'en prendre la direction comme grand vizir entre décembre 1782 et mars 1785 . Halīl Ḥamīd était resté attaché à Burdur. Les enseignants de la ville étaient réputés, mais ils manquaient de ressources. Le dignitaire avait souhaité leur venir en aide par une donation de 106 livres. Ce faisant, il sacrifiait à un usage établi : en général, les collections de taille réduite (10o à 300 manuscrits) ne justifiaient pas la construction d'un

26 Sur le coût de la copie de manuscrits, voir İ. Erünsal, Kütüphanecilikle İlgili Osmanlıca Metinler ve Belgeler I, Istanbul, 1990 (rééd.), p. 78 ; id., Osmanlılarda Sahaflı ve Sahaflar, Istanbul, Timaş, 2013, p. 171-172. Sur le prix du papier au XVIII ${ }^{\mathrm{e}}$ siècle, voir O. Ersoy, Onsekizinci ve Ondokuzuncu Yüzyıllarda Türkiye'de Kâğıt, Ankara, Ankara Üniversitesi Basımevi, 1963, p. 19-20. Sur la valeur de manuscrits indiquée dans des inventaires après décès des $\mathrm{X}^{\mathrm{e}} / \mathrm{XVI}^{\mathrm{e}}$ et $\mathrm{XII} \mathrm{e}^{\mathrm{e}} / \mathrm{XVIII}{ }^{\mathrm{e}}$ siècles, voir respectivement N. Göyünç, «Tarih Başlıklı Muhasebe Defterleri », Osmanlı Araştırmaları, 10 (1990), p. 1-37, 25-27 et Nelly Hanna, In Praise of Books: A Cultural History of Cairo's Middle Class, Sixteenth to the Eighteenth Century, Syracuse, Syracuse University Press («Middle East Studies Beyond Dominant Paradigms »), 2003, p. 91-93; Zubčević, Book Ownership in Ottoman Sarajevo 1707-1828, p. 198-201. Sur l'ornementation de manuscrits anciennement conservés à la Bibliothèque Halīl Hamīd Pacha d'Isparta, voir Sema Etikan, Isparta Halil Hamid Paşa İl Halk Kütüphanesinden Seçilen Yazma Eserlerde Görülen Tezyini Unsurlar, mémoire de master, Université Süleyman Demirel, 2013. Pour une présentation détaillée de décorations de manuscrits d'une bibliothèque de grand vizir contemporaine de celle de Halīl Ḥamīd Pacha, voir Ali Fuat Baysal, Akseki Yeğen Mehmet Paşa Kütüphanesi Tezhipli Kitaplar Albümü, Konya, Palet Yayınları, 2017.

27 Orlin Sabev, «Private Book Collections in Ottoman Sofia, 1671-1833 (Preliminary Notes) », Études balkaniques, 1 (2003), p. 34-82, p. 46 ; Francis Richard, «Lecteurs ottomans de manuscrits persans du XVI ${ }^{\mathrm{e}}$ au XVIII ${ }^{\mathrm{e}}$ siècles », Revue des mondes musulmans et de la Méditerranée, 87-88 (1999), p. 79-83, p. 83. Sur les livres recherchés dans le seul but d'être réunis, voir Touati, L'armoire à sagesse, p. 12-13.

28 «ḥasbī neşr-i 'ulūm eden Çeşmecizāde medresesinde» (vakffiyye datée du 1 receb 1198/21 mai 1784, Vakıflar Genel Müdürlüğü, vGM-D-1929); Yusuf Ekinci, Burdur, Ankara, 1995, p. 112 ; M. Sadık Akdemir, «Osmanlı Arşiv Belgeleri Iş̧̆̆ı Altında XIX. Yüzyıl Burdur Vakıfları », SDÜ İlahiyat Fakültesi Dergisi, 18 (2007), p. 91-118, p. 103, 105. 
nouvel édifice ; elles étaient installées dans des institutions préexistentes ${ }^{29}$. La donation consistait exclusivement en manuscrits : à l'exception de l'entreprise conduite par İbrahim Müteferrika entre 1728 et 1742, la Porte n'autorisait pas l'impression d'ouvrages en caractères arabes ${ }^{30}$. Un chiffre en dit long: entre 1729 et 1802, seuls 45 livres furent imprimés à Istanbul, dont un seul entre 1746 et $1782^{31}$. Autorisés à pratiquer leur culte dans le cadre de la dimma, des sujets non musulmans connectés à des ateliers européens s'étaient efforcés de multiplier les supports de diffusion auprès de leurs coreligionnaires. Mais les livres gravés dans des presses juives, grecques ou arméniennes ne devaient en rien concerner les musulmans. Les oulémas se refusaient à voir des imprimés franchir les portes des madrasas.

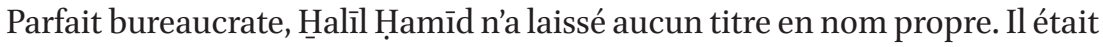
davantage connu pour lire des notes administratives à longueur de journée que pour compulser la littérature islamique. Cependant, il admirait les savants et respectait leurs livres. Tenait-il cette disposition de son père, bibliothécaire, semble-t-il, d'un grand notable de Burdur, Çelik Mehmed Pacha? Ou l'avait-il développée au fil de sa formation et de sa carrière, au contact d'un immense lettré, le grand vizir Meḥmed Rāg̉ıb Pacha (1699-1763) ? Pourquoi alors n’ai-je retrouvé que des corans dans les inventaires après-décès et inventaires de fin d'exercice le concernant ${ }^{32}$ ? Parce que Halīl Ḥamīd avait fait don de ses livres ${ }^{33}$.

29 Erünsal, Ottoman Libraries, p. 48.

30 Ekmeleddin İhsanoğlu, Hatice Aynur, «Yazmadan Basmaya Geçiş : Osmanlı Basma Kitap Geleneğinin Doğuşu (1729-1848)», Osmanlı Araştırmaları, 22 (2003), p. 219-255. Pour une récente mise au point sur la question, voir Orlin Sabev, Waiting for Müteferrika: Glimpses of Ottoman Print Culture, Boston, Academic Studies Press («Ottoman and Turkish Studies»), 2018.

31 Jale Baysal, «Turkish Publishing Activities Before and After the New Alphabet», Anatolica, 8 (1981), p. 115-131, p. 121-122.

32 Archives du Premier Ministre, Istanbul, MAD.d 9718, TS MAD 2295, TS MAD 2302 ; Olivier Bouquet, « Un grand vizir dans sa maison : édition de trois inventaires après décès (1785) », Turcica, 47 (2016), p. 187-236 ; id., « Un grand vizir dans son palais : édition d'un inventaire de fin d'exercice (1785)», Turcica, $5^{2}$ (2020), p. 163-217. Dans un échantillon de 36 inventaires de bureaucrates du milieu du XvinI ${ }^{\mathrm{e}}$ siècle, H. Sievert a compté que tous contenaient au moins trois livres, la majorité variant entre 11 et 509 (Sievert, « Eavesdropping in the Pasha's Salon », p. 169).

33 Dans un inventaire de vizir dressé en 1700-1701, les seuls livres cités sont des corans: Amanda Philipps, «Ali Paşa and His Stuff: An Ottoman Household in Istanbul and Van », dans Living the Good Life: Consumption in the Qing and Ottoman Empires of the Eighteenth Century, éds Elif Akçetin et Suraiya Faroqhi, Leyde-Boston, Brill («Rulers \& Elites », 13), 2018, p. 90-112, p. 106-107. Sur la quasi-absence de livres dans un inventaire palatial dressé en 1505, voir J. Michael Rogers, «An Ottoman Palace Inventory of the Reign of Bayazid II », dans Comité international d'études pré-ottomanes et ottomanes, VIth Symposium, Cambridge, 1-4 VII 1984, éds Jean-Louis Bacqué-Grammont et Emeri Johannes Van Donzel, Istanbul, IFEA («Varia Turcica », 4), 1987, p. 39-53, p. 41. 
Il était courant de procéder ainsi : à la même époque, en 1777, le mufti de Sofia transféra de précieux manuscrits à la bibliothèque qu'il venait de fonder, en sorte que l'historien bulgare Orlin Sabev n'a trouvé trace d'aucun d'ouvrage dans les inventaires après décès consultés ${ }^{34}$. Bien des pachas en firent autant ${ }^{35}$.

Je fais l'hypothèse que Halīl Ḥamīd avait accumulé des manuscrits avant de décider de s'en séparer - selon le site officiel du musée de Burdur, la bibliothèque fut installée dans la madrasa en $1770^{36}$. Quelques années plus tard, j'ignore quand exactement, le dignitaire renouvela l'opération à Isparta, ville voisine où sa famille maternelle était installée, cédant cette fois-ci un nombre de livres quatre fois supérieur, chiffre correspondant aux standards de l'époque pour un serviteur ottoman de son rang ${ }^{37}$. Halīl Hamīd était alors dans la phase la plus élevée de sa carrière et disposait par conséquent de moyens financiers supérieurs. En outre, il attachait plus d'importance à cette collection : à Burdur, les gens de la madrasa étaient en charge de livres placés dans une armoire (1 ère catégorie) ; à Isparta, un personnel directement salarié par le $v a k f$ du pacha entretenait des livres conservés dans un bâtiment pensé et construit comme une bibliothèque ( $2^{\text {nde }}$ catégorie). Je suppose que Halīl Ḥamīd aura conservé une partie de ses manuscrits pour son propre usage et/ou dans la perspective de procéder à une donation ultérieure (il est possible que les livres restants aient été confisqués lors de sa révocation, ce qui arrivait aussi, y compris pour ceux d'entre eux placés en $v a k f^{38}$ ).

34 Sabev, «Bulgaristan'da Osmanlı Vakıf Kütüphanelerinde Bir Örnek», p. 298-299. Sur la difficulté qu'il y a à utiliser des inventaires après décès pour déduire le nombre exact de livres possédés au cours d'une vie, voir Orlin Sabev, «The First Ottoman Turkish Printing Enterprise: Success or Failure?», dans Ottoman Tulips, Ottoman Coffee: Leisure and Lifestyle in the Eighteenth Century, éd. Dana Sadji, Londres, I.B. Tauris, 2007, p. 63-89, p. 75. Erünsal, Ottoman Libraries, p. 131-133.

36 https://burdur.kutuphane.gov.tr/TR-259810/tarihcemiz.html, consulté le 1 mai 2020. Je n'ai trouvé nulle part ailleurs la confirmation de cette date. Elle est en contradiction avec celle avancée par İ. Erunsal : 1782 (Erunsal, Türk Kütüphaneleri Tarihi, p. 109).

37 Dans la première moitié du XII $/ \mathrm{XVIII}^{\mathrm{e}}$ siècle, rares sont les collections mises en $v a k f$ par des hauts dignitaires qui dépassent 500 voire 1000 manuscrits, telles celles de Şehīd 'Alī Pacha (1715), Dāmād 'Alī Pacha (1720), Dāmād İbrāhīm Pacha (1730) et Re'īüu-l-küttāb Muștafà Efendī (1747): Ayşen Aldoğan, «Şehit Ali Paşa Kütüphanesi », Türkiyemiz, 35 (1981), p. 1-7, 42-43, p. 7 ; Erünsal, Ottoman Libraries, p. 131-132. À Sarajevo, les 17 collections les plus importantes identifiées par Zubčević dans des inventaires dressés entre 1707 et 1828 vont de 88 à 410 volumes (Zubčević, Book Ownership in Ottoman Sarajevo 17071828, p. 235-236). Établie en 1782, la bibliothèque du grand vizir Yeğen Mehmed Pacha est dotée de 322 manuscrits (Baysal, Akseki Yeğen Mehmet Paşa Kütüphanesi Tezhipli Kitaplar Albümü).

38 L'exemple de la bibliothèque de Dāmād İbrāhīm Pacha est souvent cité : à sa mort en 1730, 9oo manuscrits furent confisqués (Uluç, « Ottoman Book Collectors and Illustrated Sixteenth Century Shiraz Manuscripts», p. 89-9o). À la suite de l'exécution du précité Şehīd 'Alī Pacha en 1716, une partie de ses livres fut conservée au Palais et une autre fut 
Lors de leur enregistrement dans la charte (vakfyyye) en 1784, les manuscrits de Burdur étaient au nombre de $106^{39}$. Par la suite, le fond connut des variations. Il ne comptait plus que 72 ouvrages en 1881: aurait-il subi les effets du temps, les agressions du feu, les dommages de l'eau ou les secousses des tremblements de terre (très fréquents dans la région), ajoutés à une dégradation générale des bibliothèques de vakf agravée par le désintérêt persistant des pouvoirs publics pour les richesses des bibliothèques provinciales ${ }^{40}$ ? Entre 1898 et 19o3, le nombre d'ouvrages passa à $120^{41}$ : la collection aurait-elle alors bénéficié de l'apport d'autres fondations actives ou en déshérence? Si tel fut le cas, elle ne fut pas substantiellement enrichie : en 1960, elle comptait 117 volumes ${ }^{42}$. Un bâtiment fut construit pour abriter la collection. Mais il était en bois et finit par s'écrouler. Le terrain fut vendu et les livres furent délocalisés dans d'autres bibliothèques de la ville ${ }^{43}$ - en 1960, M. Zeki Oral évoque un ensemble de 3208 manuscrits conservés à Burdur ${ }^{44}$. Selon le directeur du musée et de la bibliothèque de Burdur que j'ai interrogé à ce sujet lors d'une visite effectuée en février 2016, la principale bibliothèque de la ville, celle de Dervīş Mehmed Pacha, aurait compté jusqu'à 4500 ouvrages (manuscrits et imprimés ${ }^{45}$ ). Après l'instauration de la République turque en 1923,

mise en vente (Aldoğan, « Şehit Ali Paşa Kütüphanesi », p. 7). Sur les mises en vakf décalées de collections situées dans diverses résidences, comme autant d'arrangements en vue d'une réunion des collections à terme, voir le cas de Şehīd 'Alī Pacha (ibid., p. 2). Sur les tentatives de sultans de reconstituer des bibliothèques dispersées suite au partage entre héritiers, voir Bilici, «Les bibliothèques vakıf-s à Istanbul au XVI e siècle », p. 42 (2 112 manuscrits récupérés sur une estimation de 7 ooo possédés par Mü’eyyedzāde, no 82 ). Vakfiyye datée du 1 receb 1198/21 mai 1784 (Vakıflar Genel Müdürlüğü, VGM-D-1929).

40 İsmail E. Erünsal, «Ottoman Foundation Libraries in the Age of Reform: The Final Period », Libri, 54 (2004), p. 247-255.

41 https://burdur.kutuphane.gov.tr/TR-25981o/tarihcemiz.html, consulté le 15 juillet 2020.

42 Oral, « Mevcut Vesikalara Göre Burdur Kütüphaneleri ve Kitap Vakfiyeleri Vesikaları », p. 236.

43 Ibid., p. 233. Sur le devenir des édifices d'autres bibliothèques de Burdur, voir Hacer Sibel Ünalan, Anadolu'daki Türk Kütüphaneleri, Istanbul, İsAM yayıları, 2012, p. 284-294.

44 Oral, «Mevcut Vesikalara Göre Burdur Kütüphaneleri ve Kitap Vakfiyeleri Vesikaları », p. 248.

45 Bekir Şahin, « Katalogta yer Almayan ve Ortaya Yeni Çıkan Burdur Şer'iye Sicili », I. Burdur Sempozyuтu: Bildiriler, 16-19 Kasım 2005, Burdur, Mehmet Akif Ersoy Üniversitesi, 2007, p. 50-54, p. 53. Entretien avec H. Ali Ekinci, Burdur, le 22 février 2016. Le directeur de la bibliothèque de Burdur m’a communiqué une liste de 295 ouvrages donnés par Yücel Bulgur, de la famille Pirkulzāde, à la Bibliothèque du grand vizir Dervīş Mehmed Pacha. B. Şahin a produit une liste de 1515 ouvrages de cette bibliothèque à partir d'un inventaire daté de 1267/1850-1851 établi selon les disciplines scientifiques suivantes : tafsīr (118), figh (243), ma'ānì (104), naḥw (196), hadith (65), etc. (Şahin, « Katalogta yer Almayan ve Ortaya 
l'ordre fut donné aux bibliothèques de $v a k f$ de transmettre à Ankara des listes des ouvrages $(\text { fihrist })^{46}$. Ces listes furent conservées dans un bâtiment, mais celui-ci brûla en $1944^{47}$. À des dates que j'ignore, les livres furent transférés principalement à la Bibliothèque Süleymaniye d'Istanbul (pour les manuscrits) et à la Bibliothèque nationale d'Ankara (également pour les imprimés) ${ }^{48}$. Aujourd'hui, les manuscrits des Bibliothèques de Burdur sont conservés par la Direction des manuscrits de Konya (collection $\mathrm{n}^{\circ}$ 11). Ils sont répertoriés dans le catalogue général du Türkiye Yazmaları Toplu Kataloğu (тÜYAток) ${ }^{49}$. Mais les bibliothèques d'origine des manuscrits ne sont pas spécifiées. Aussi, lors de la mission que j'ai effectuée en mars 2016 à Konya, je n'ai pas été en mesure

Yeni Çıkan Burdur Şer'iye Sicili», p. 50-54). Selon Osman G. Özgüdenli, la bibliothèque municipale de Burdur comptait 2312 manuscrits (Özgüdenli, «Persian Manuscripts i. in Ottoman and Modern Turkish Libraries », Encyclopaedia iranica, 2005, http://www.iranicaonline.org/articles/persian-manuscripts-1-ottoman, consultéle 26 juin 2019 ; l'auteur ne précise malheureusement pas la date d'inventaire). Lors d'un repérage effectué en 1947, Ahmed Ateş y a consulté un corpus de 1500 manuscrits (Ateş, «Burdur-Antalya ve Havalisi Kütüphanelerinde Bulunan Türkçe, Arapça ve Farsça Bazı Mühim Eserler », p. 171).

46 Sur l'usage des listes et catalogues de bibliothèques à l'époque républicaine, voir Hüseyin Türkmen, Türkiye Kütüphaneleri Yazma Eser Katalogları: 1923-20o6, Istanbul, Kitabevi, 2010.

47 Pour un inventaire des listes de manuscrits de bibliothèques dont certains furent ensuite imprimés, voir Nimet Bayraktar, «Yazma ve Basma Kütüphane Fihristleri », Türk Dünyası Araştırmaları, 21 (1982), p. 127-159. Celle de Halīl Ḥamīd n’y figure pas. En revanche, la Direction des œuvres manuscrites d'Ankara conserve trois fihrist de la Bibliothèque Halīl Ḥamīd Pacha d'Isparta, datés de 1826, 1906 et n.d. TÜYATOK, Isparta, Ankara, Milli Kütüphane Basımevi («Kataloglar Dizisi », 17), 2000, p. 1-2.

48 En 2012, 628 manuscrits de Burdur conservés à la Bibliothèque Süleymaniye furent transférés à la Direction des œuvres manuscrites de Konya. Son directeur, B. Şahin, a eu la gentillesse de me communiquer la liste de ces manuscrits, à l'occcasion d'une mission effectuée sur place en 2016. Je l'en remercie vivement. Plusieurs des titres du corpus y figurent. Mais les bibliothèques d'origine des manuscrits n'étant pas indiquées, il est impossible de déterminer ceux d'entre eux qui correspondent aux manuscrits de la collection Halīl Hamīd Pacha.

49 En 1978, un projet d'inventaire des manuscrits islamiques à long terme, le programme du тÜYАток, fut lancé par le ministère de la Culture : Barbara Flemming, «The Union Catalogue of Manuscripts in Turkey: Türkiye Yazmaları Toplu Kataloğu (TÜYATOK)», Manuscripts of the Middle East, 1 (1986), p. 109-110. Mais il a progressé lentement faute, notamment, d'un budget suffisant et d'un personnel qualifié. Les références des manuscrits dans les catalogues sont souvent incomplètes. Pour un bilan sur la période 19892002 et une riche bibliographie à mettre à jour pour la décennie qui suit, voir Hatice Aynur, «Türkiye'de Türkçe Yazma Eserlerin Kataloglanması Üzerine Bir Değerlendirme 1989-2002 ", Journal of Turkish Studies, 26/1 (2002), p. 37-52. Pour un bilan plus récent sur la numérisation des catalogues, voir $i d$., « Türkiye Yazmaları Toplu Kataloğu », Türkiye Diyanet Vakfi İslam Ansiklopedisi, 41 (2012), p. 597-598. 
d'identifier les ouvrages de la Bibliothèque de Halīl Hamīd Pacha ${ }^{50}$. J'ai préféré concentrer mes recherches sur les manuscrits de l'autre bibliothèque du pacha, celle d'Isparta, pour la raison inverse qu'ils sont répertoriés comme tels dans le catalogue du тÜYAток. J'ai consulté les versions numérisées d'une cinquantaine d'entre eux. Je souhaite y consacrer prochainement une étude. Pour ce qui est des manuscrits de Burdur, j'ai exploité la charte de la fondation pieuse du pacha. J'ai obtenu une copie numérisée de l'exemplaire conservé à la Direction générale des fondations pieuses d'Ankara ${ }^{51}$. Les fac-similés des folios concernant la bibliothèque sont reproduits plus bas. La liste des ouvrages cités est l'objet de la présente étude ${ }^{52}$.

\section{Des livres à l'usage d'étudiants de madrasa}

Plus de la moitié des œuvres citées datent de l'époque pré-ottomane (55 au total), étalées entre les premières générations de musulmans (tafsìr attribué

50 Selon H. Ali Ekinci, le transfert des livres à Konya aurait été achevé dans les années 2000, à l'exception des imprimés de la bibliothèque Pirkulzāde, conservés dans la bibliothèque du musée. Dans le catalogue TÜYATOK Burdur I, p. v, il est indiqué que 1687 manuscrits répertoriés dans la İl Halk Kütüphanesi de Burdur (indiqués 15 H.K.) et 795 manuscrits issus de la Halil Hamid Paşa İl Halk Kütüphanesi d'Isparta (indiqués 32 H.K.) furent transférés à Konya en 1994.

51 À comparer à la liste des 78 ouvrages mis en vakf par un grand vizir antérieur, Darendeli Meḥmed Pacha : Vahit Türk, « Darendeli Mehmed Paşa Kütüphanesinde Bulunan Türkçe Yazmalar», dans Firat Havzası Yazma Eserler Sempozyumu: 5-6 Mayıs 1986, Bildiriler, éd. Tuncer Gülensoy, Elazığ, Firat Üniversitesi, 1987, p. 211-218; Ahmed Akgündüz et al., Darende Tarihi, Malatya, Seyyid Osman Hulusi Efendi Vakfi Somuncu Baba Araştırma ve Kültür Merkezi, 2002, p. 486-49o.

52 Les ouvrages sont cités selon le système de translittération adopté par Nicolas Vatin, Initiation à l'ottoman, Paris, EHEss («Études turques et ottomanes. Documents de travail », 5), 1996, p. 10-11. Sur la translittération de l'ottoman, voir Eleazar Birnbaum, «The Transliteration of Ottoman Turkish for Library and General Purposes », Journal of the American Oriental Society, 87 (1967), p. 122-156. À noter les particularités de translittération de plusieurs caractères arabes:

\begin{tabular}{lll}
\hline Caractère & Arabe & Ottoman \\
\hline \multirow{ث}{c}{} & $\underline{\mathrm{t}}$ & $\underline{\mathrm{s}}$ \\
$\dot{\tau}$ & $\mathrm{h}$ & $\underline{\mathrm{h}}$ \\
$\dot{j}$ & $\underline{\mathrm{d}}$ & $\underline{\mathrm{z}}$ \\
$ض$ & $\mathrm{~d}$ & $\mathrm{z}$ \\
$\dot{b}$ & $\mathrm{z}$ & $\dot{\mathrm{z}}$ \\
$\mathrm{G}$ & $\mathrm{q}$ & $\mathrm{k}$ \\
\hline
\end{tabular}


à Ibn 'Abbās, m. ca 68/687; nº 3) et les derniers lettrés mamelouks (al-Suyūṭī, m. 911/1505; $\mathrm{n}^{\circ} 23,41,5^{2}$ ). Le reste date de l'époque ottomane (34 ouvrages), du $\mathrm{X}^{\mathrm{e}} / \mathrm{XVI}^{\mathrm{e}}$ siècle et du XI $\mathrm{e}^{\mathrm{e}} / \mathrm{XVII}^{\mathrm{e}}$ siècle pour les trois quarts d'entre eux ${ }^{53}$. La production de l'époque médiévale est encore plus marquée si l'on prend en compte les sujets traités dans les manuscrits : tous puisent de près ou de loin dans la littérature des premiers siècles de l'islam. Deux tiers environ des ouvrages de l'époque ottomane sont produits par des lettrés turcophones, principalement des membres de la ilmiyye qui pratiquaient également l'arabe et le persan - un auteur du corpus (Münşī, m. ca 1001/1593; nº 9) doit son nom de plume à la facilité qu'il avait de rédiger dans les « trois langues » (elsine-i s selās $e$ ). Quant au tiers restant, il est composé pour moitié de productions de lettrés arabophones de Syrie ( $\mathrm{n}^{\circ} 87, \mathrm{n}^{\circ}$ 101), de Palestine ( $\mathrm{n}^{\circ}$ 98), d'Égypte ( $\mathrm{n}^{\circ}$ 10, 23), du Kurdistan $\left(n^{\circ} 99\right)$, d'Iran ( $\left.n^{\circ} 66\right)$ et du Khorasan $\left(n^{\circ} 13,24,28\right)$.

De telles répartitions confirment plusieurs études sur les collections des madrasas comme reflets des curricula imposés par l'appareil administratif de judicature et d'enseignement ('ilmiyye ${ }^{54}$ ):1) l'importance accordée aux savants de l'époque médiévale que les lettrés ottomans considéraient comme des auteurs classiques indispensables à la formation des étudiants ${ }^{55} ; 2$ ) la place réservée aux lettrés turcophones intégrés ou liés aux cadres de la ilmiyye et associés au renforcement de celle-ci au sein de l'État au cours des $\mathrm{X}^{\mathrm{e}} / \mathrm{XVI}^{\mathrm{e}}-\mathrm{XI}{ }^{\mathrm{e}} / \mathrm{XVII}^{\mathrm{e}}$ siècles ; 3 ) une ouverture réduite aux productions des savants arabophones de l'Empire et des pays voisins (seuls deux auteurs non ottomans sont cités pour ce qui est de l'époque moderne).

À Burdur comme à Isparta, Halīl Hamīd fait don de «beaux livres relatifs aux sciences de l'exégèse, du hadith, du droit, de la lexicologie et des sciences supérieures » (fünündan fenn-i tefsìr ve hadis ve fikh ve luğat ve 'ulüm-i 'aliyyeye

53 J'ai retenu les dates les plus informées, celles des décès des auteurs cités : XIV ${ }^{\mathrm{e}}$ siècle (1); $\mathrm{XV}^{\mathrm{e}}$ siècle $(4)$; $\mathrm{XVI}^{\mathrm{e}}$ siècle $(13)$; XVII ${ }^{\mathrm{e}}$ siècle $(8) ; \mathrm{XVIII}^{\mathrm{e}}$ siècle $(2)$.

54 Voir Hüseyin Atay, « Fatih-Süleymâniye Medreseleri Ders Programları ve İcazet-nameler », Vakıflar Dergisi, 13 (1981), p. 171-235; id., Osmanlılarda Yüksek Din Eğitimi: Medrese Programlart-İcazetnâmeler-Islahat Hareketleri, Istanbul, Dergâh, 1983; İhsan Ezherli, «Osmanlı Medreseleri ve Eğitim Metodları », Diyanet Iş̧leri Başkanlığı Dergisi, 7/70-71 (1968), p. 64-67. Pour un répertoire des institutions d'enseignement du hadith, voir Ahmet Gül, Osmanlı Medreselerinde Eğitim-Öğretim ve Bunlar Arasında Dâru'l-Hadîslerin Yeri, Ankara, Türk Tarih Kurumu, 1997 ; Sabev, « Bulgaristan'da Osmanlı Vakıf Kütüphanelerinde Bir Örnek », p. 300-303.

55 Erünsal, Ottoman Libraries, p. 2 ; «The concept of 'Classical' authors remained alien to the Ottoman Turks for a long time» : Johann Strauss, «Who Read What in the Ottoman Empire (19th-2oth Centuries)?», Middle Eastern Literatures, 6/1 (2003), p. 39-76, p. 48. C'est peut-être le cas pour la littérature envisagée par J. Strauss, mais moins pour les programmes de madrasas. 
dāir kütüb-i nefise-i ma'dūde $\left.{ }^{56}\right)$ : autant de domaines en effet couverts par le corpus. Les trois sciences dites «supérieures» (tafsirr, hadith et fiqh) constituent les 'ulüm-i 'aliyye, domaine des sciences chariatiques ou sciences de la révélation ('ulüm-i şer'ìyye) - plusieurs auteurs, tel Țaşköprüzāde (m. 968/1561 ; $\mathrm{n}^{\mathrm{o}} 53$ ), y ajoutent la théologie que d'autres lettrés, tel Saçaḳllzāde (m. 1145/1732), écartent pour en revanche y intégrer les ' $a q \bar{a} ' i d^{57}$. Dans les bibliothèques de $v a k f$, elles sont clairement circonscrites et séparées des autres disciplines ${ }^{58}$. Ici, elles bénéficient d'une quinzaine d'ouvrages chacune, soit près de la moitié du corpus. Enseignées à des degrés divers dès les premiers niveaux du cursus, plus nombreuses, considérées comme auxiliaires (Hilfswissenschaften), c'est-à-dire préparatoires à l'étude des précédentes, et intitulées selon des classifications variables dans les catalogues des bibliothèques, les 'ulüm-i àliyye (șarf, naḥw, 'aqā̉id, manțiq, adab, balägat, kalām) font l'objet de donations plus dispersées ${ }^{59}$.

$5^{6}$ Vakfiyye datée du 27 octobre 1783 , p. 5 o (exemplaire des descendants de Halīl Ḥamīd Pacha).

57 Fahri Unan, «Taşköprülüzâde’nin Kaleminden XVI. Yüzyılın 'İlim’ ve ‘Âlim’ Anlayışı», Osmanlı Araştırmaları, 17 (1997), p. 149-264, p. 240-251. Les définitions scientifiques de l'encyclopédiste ottoman furent en partie inspirées des classifications de Ibn al-Akfānī : Jan Just Witkam, «Ibn al-Akfānī (m. 749/1348) and His Bibliography of the Sciences », Manuscripts of the Middle East, 2 (1987), p. 37-41, p. 40. Sur l'intégration des 'aqā’id parmi les sciences religieuses, voir Stefan Reichmuth, «Bildungskanon und Bildungsreform aus der Sicht eines islamischen Gelehrten der Anatolischen Provinz: Muḥammad al-Sājaqlī (Saçaqlı-zāde, gest. um 1145/1733) und sein Tartīb al-ulūm», dans Words, Texts and Concepts Cruising the Mediterranean Sea: Studies on the Sources, Contents and Influences of Islamic Civilization and Arabic Philosophy and Science Dedicated to Gerhard Endress on His Sixty-fifth Birthday, éds Rüdiger Arnzen et Jörn Thielmann, Louvain-Dudley, Peeters («Orientalia Lovaniensia Analecta», 139), 2004, p. 493-520, 500. Sur les classifications de Saçaklızāde, voir aussi Bellino, « Arabic Encyclopaedias and Encyclopaedism between the Seventeenth and Nineteenth Centuries », p. 142-144.

58 İ. Erünsal, «Kuruluşundan Tanzimatta Kadar Osmanlı Vakıf Kütüphanelerinde Yapılan Kataloglama Çalışmaları », Journal of Turkish Studies, 6 (1982), p. 97-110, p. 109.

59 Les distinctions disciplinaires exposées par Uzunçarşılı (Osmanlı Devletinin İlmiye Teşkilatı, p. 20-23) doivent être à la fois complétées par les résultats d'études détaillées de curricula, telles celles proposées par İzgi (Osmanlı Medreselerinde İlim, I, p. 163-183), Yazıcıoğlu (Le kalâm et son rôle dans la société turco-ottomane aux XV ${ }^{e}$ et XVI ${ }^{e}$ siècles, p. 5458) ou Demir (Die osmanischen Medresen, p. 66-72, p. 82-85; pour une liste de manuels classés par discipline) et révisées en fonction des classifications des lettrés du XII $/ \mathrm{XVIII}^{\mathrm{e}}$ siècle (Reichmuth, «Bildungskanon und Bildungsreform aus der Sicht eines islamischen Gelehrten der Anatolischen Provinz», p. 507), lesquelles classifications exigent d'être à leur tour examinées dans l'épaisseur de leur historicité (Bellino, «Arabic Encyclopaedias and Encyclopaedism between the Seventeenth and Nineteenth Centuries», p. 131, pour l'identification de « vagues » successives dans l'émergence de l'encyclopédisme ottoman). 
Les commentaires dominent l'inventaire. Ce sont des outils de compréhension des textes à l'usage des étudiants. Ce sont des instruments de travail mis à la disposition des enseignants: des varia $\left(\right.$ mecmú $\left.^{\prime} a\right)$ assemblent plusieurs des commentaires d'une œuvre considérée comme importante dans le cursus $\left(n^{\circ} 66,67\right)$. Des ouvrages de base sont explicitement destinés à l'enseignement en madrasa $\left(\mathrm{n}^{\circ} 61,62\right)$. Conçus comme des « auxiliaires » pédagogiques (mu'in, $\mathrm{n}^{\circ} 81$ ) et destinés à la formation de futurs $n \bar{a} i b s$ et muftis, des manuels très concis s'en tiennent au traitement de cas particuliers ( $\left.n^{\circ} 83\right)$. «Unificateurs » d'opinions hanéfites, des compendia regroupent les arguments des juristes les mieux à même de parvenir au règlement des problèmes auxquels les professionnels seront régulièrement confrontés dans l'exercice de leurs fonctions $\left(n^{\circ} \text { 90, 93 }\right)^{60}$. Des traités (risāle) accompagnent les étudiants dans la découverte de tel ou tel champ d'étude, à la fois spécifique et très arpenté, de réflexion (la théologie par exemple, $\mathrm{n}^{\circ}$ 66), ainsi que des anthologies et ouvrages d'érudition littéraire produits par des auteurs prolifiques ( $\left.\mathrm{n}^{\circ} 39\right)$. Pour compléter ces ressources, sont mis à leur disposition quantité de lexiques, dictionnaires d'arabe $\left(\mathrm{n}^{\circ} 57,58,59\right)$ et glossaires spécialisés dans une discipline, ou la terminologie de celle-ci : locutions usitées dans le figh (no 60 ) ou les hadiths $\left(\mathrm{n}^{\circ}{ }^{6}\right)$ et expressions assez problématiques et «étranges » pour devoir être explicitées $\left(\mathrm{n}^{\circ} 55\right)$.

À l'évidence, Halīl Ḥamīd pense aux étudiants lorsqu'il fait don de ses livres : un commentaire (no 64) du Miftạh al-'ulūm d'al-Sakkākī (m. 626/1229; no 33) est une introduction indispensable à l'apprentissage de l'éloquence (balagat $\left.{ }^{61}\right)$, quand on sait que l'ouvrage, aussi pionnier fut-il au Moyen Âge, aussi prestigieux demeura-t-il sous les Ottomans, « était trop mal présenté, trop obscur et parfois trop plein de contradictions pour être d'un usage pratique pour la plupart des gens qui étudiaient la rhétorique ${ }^{62}$. De même, autant en matière d'exégèse coranique le Tafsìr al-ğalälayn $\left(\mathrm{n}^{\mathrm{o}} 5\right)$ est l'un des ouvrages les plus accessibles du fait de son style bref et concis et de sa taille réduite, autant celui d'al-Bayḍāwī (m. ca 685/1286; nº 1), placé au cœur de la discipline, est trop difficile pour être abordé sans l'aide de commentaires adaptés. Dont acte : Halīl Ḥamīd Pacha fait don d'une demi-douzaine d'entre eux ( $\mathrm{n}^{\circ}$ 10-16).

6o Yavuz Aykan, Rendre la justice à Amid: procédures, acteurs et doctrines dans le contexte ottoman du XVIII ${ }^{e}$ siècle, Leyde, E.J. Brill («The Ottoman Empire and its Heritage », 6o), 2016, p. 229.

61 Philipp Hallden, «Rhetoric», dans Medieval Islamic Civilization: An Encyclopedia, éd. Josef W. Meri, New York-Londres, Routledge, 20o6, I, p. 679-681.

62 Seeger A. Bonebakker, «al-Ma‘̄āī wa-l-bayān », $E I^{2}$. 
L'inventaire ressemble à ceux qu'on trouve dans des chartes d'autres bibliothèques des $\mathrm{XI}^{\mathrm{e}} / \mathrm{XVII}^{\mathrm{e}}-\mathrm{XII} \mathrm{e}^{\mathrm{e}} / \mathrm{XVIII}^{\mathrm{e}}$ siècles, de Kayseri à Sarajevo, de Rhodes à Konya, en passant par Sofia et Merzifon ${ }^{63}$. Les ouvrages sont recensés les uns à la suite des autres, comme le seraient les biens d'un inventaire après décès ${ }^{64}$. Prenons quelques titres au fil du texte: un manuel d'eschatologie $\left(n^{\circ} 43\right)$, un traité de médecine ( $\left.\mathrm{n}^{\circ} 44\right)$, un recueil de biographies $\left(\mathrm{n}^{\circ} 45\right)$, une étude sur le Prophète ( $\left.\mathrm{n}^{\circ} 46\right)$, un ouvrage d'adab ( $\left.{ }^{\circ} 47\right)$ et une histoire générale ( $\left.{ }^{\circ} 48\right)$. Des classiques de la littérature islamique sont cités ensemble qui n'ont de commun que leur caractère compilatoire : la somme sur les disciplines linguistiques d'al-Sakkākī (Miftāḥ al-ulūm, no 33 ) précède le Kitāb al-Ag̉anī, œuvre la plus importante d'Abū l-Farağ al-Iṣfahānī (m. 356/967; no 37), recueil de poèmes mis en musique agrémenté de commentaires détaillés.

C'est également le propre des inventaires: comme ils le feraient pour des ustensiles de même type ou des tissus de même provenance, les scribes procèdent à des regroupements ${ }^{65}$. Par genres: recueils de litanies et de prières $\left(n^{\circ} 30,31,32\right)$, compilations de fatwas $\left(n^{\circ} 79-85\right)$, commentaires de théologie ( $\left.\mathrm{n}^{\circ} 61-62 ; 65-66\right)$. Par type d'ouvrage : glossaires et dictionnaires $\left(\mathrm{n}^{\circ} 55^{-60}\right)$. Par écoles de droit: ouvrages de savants hanbalites ( $\mathrm{n}^{\mathrm{o}} 77_{-78)}$. Ils rendent

63 Cunbur, «Kütüphane Vakfiyelerinden Notlar»; Mehmet Çayırdağ, «Kayseri'de Vakıf Kütüphaneleri ve Matbah Emini Hacı Halil Efendi Kütüphanesi», Vakıflar Dergisi, 20 (1988), p. 265-288 (contient plusieurs inventaires tirés de vakfiyye); Zubčević, Book Ownership in Ottoman Sarajevo 1707-1828; Bekir Şahin, Rodos Fethi Pasa Vakfi: Hafız Ahmed Ağa Kütüphanesi Yazma Eserler Kataloğu, Istanbul, i̇sAR, 2013; Adnan Gürbüz, «Merzifonlu Kara Mustafa Paşa'nın Merzifon Vakıfları», Merzifonlu Kara Mustafa Paşa Uluslararası Sempozyumu, 8-11 Haziran 200o, Ankara-Merzifon Vakfi, T.C. Kültür Bakanlığı, 200o, p. 319-327, p. 323 ; Müjgan Cunbur, «Yusuf Ağa Kütüphanesi ve Kütüphane Vakfiyesi », Ankara Üniversitesi Dilve Tarih-Coğrafya Fakültesi Tarih Bölümü Tarih Araştırmaları Dergisi, 1/1 (1963), p. 203-217; Sabev, «Bulgaristan'da Osmanlı Vakıf Kütüphanelerinde Bir Örnek»; Kenan Yıldız, «Sanatkâr Bir Devlet Adamından Geriye Kalanlar : Esad Muhlis Paşa'nın Terekesi », dans Yavuz Argıt Armağanı, éd. Mustafa Birol Ülker, Istanbul, 2010, p. 209-264.

64 Sur les livres comme biens mobiliers au même titre que les armes, outils ou animaux, voir Ahmet Akgündüz, İslâm Hukukunda ve Osmanlı Tatbikatında Vakıf Müessesesi, Ankara, Türk Tarih Kurumu Basımevi, 1988, p. 150-151.

65 Uluç, «Ottoman Book Collectors and Illustrated Sixteenth Century Shiraz Manuscripts », p. 89-9o ; Sabev, « Bulgaristan'da Osmanlı Vakıf Kütüphanelerinde Bir Örnek », p. 300-303 (des regroupements pour le tafsìr, le hadith, le fiqh et les 'aqä’id); dans les deux cas, les inventaires débutent avec les corans et les livres de tafsìr ; İ. Erünsal a repéré des chartes dans lesquelles les livres étaient classés par discipline (Erünsal, Ottoman Libraries, p. 147). Sur les regroupements dans les inventaires de biens, voir Bouquet, « Un grand vizir dans sa maison». 
également compte de liens qui unissent des textes entre eux: les commentaires respectifs des deux volumes de l'opuscule de grammaire d'Ibn al-Ḥăğib (m. 646/1249) se font suite $\left(\mathrm{n}^{\mathrm{o}} 75,76\right)$; le dictionnaire arabe de Muhammad b. Abū Bakr al-Rāzī (m. 666/1267-1268; no 57) est mentionné avant les Șihạh d'al-Ğawharī (m. ca 396/1005; $\left.{ }^{\circ} 5^{8}\right)$ à partir desquels il fut en partie composé. Mais ces regroupements sont arbitraires et fluctuants ${ }^{66}$. Cherchez l'intrus : dans le défilé des grandes sommes de tafsìr par lequel débute l'inventaire, s'invite une étude du Lețāiffnāme de Bursalı Lāmi'ī Çelebi (no 6), œuvre satirique qui n'a rien d'exégétique - peut-être les scribes l'ont-ils inscrite à cet endroit de la liste pour la seule raison que le titre débute par tafsìr (commentaire $)^{67}$. Si un consensus existait sur la caractérisation des grandes œuvres et les titres sous lesquels il convenait de les noter, on sait que les scribes avaient souvent des difficultés à classer les manuscrits en fonction de l'organisation interne et du «profil thématique $\left(K\right.$. Hirschler) propres à chaque bibliothèque ${ }^{68}$.

Il est probable qu'un catalogue avait été dressé séparément de la liste de la vakfiyye comme cela se faisait pour un nombre croissant de collections du $\mathrm{XII}^{\mathrm{e}} / \mathrm{XVIII}^{\mathrm{e}}$ siècle - il est établi que ce fut le cas à la bibliothèque d'Isparta ${ }^{69}$; et il est possible que les livres avaient été classés autrement in situ selon les nomenclatures en vigueur dans les madrasas ${ }^{70}$. Celles-ci étaient le résultat des entrelacements produits entre les classifications des sciences islamiques médiévales (iḥs ā̉ al-ulūm), les distinctions proposées par des savants ottomans comme Muṣlị̣ al-Dīn Muștafà (m. 893/1488), Birgivī Meḥmed Efendī (m. 981/1573) ou Țaşköprüzāde ( $\mathrm{n}^{\circ}$ 53), les règles de catalogage fixées dans la seconde moitié du $\mathrm{X}^{\mathrm{e}} / \mathrm{XVI}^{\mathrm{e}}$ siècle et les programmes d'enseignement imposés dans des firmans ou résumés dans des traités ${ }^{71}$. Sans cesse affinées aux XI ${ }^{\mathrm{e}}$ /

66 Erünsal, Ottoman Libraries, p. 158 (pour des exemples de livres inscrits dans des catégories étrangères à leur discipline de référence) ; $i d$., « Kuruluşundan Tanzimatta Kadar Osmanlı Vakıf Kütüphanelerinde Yapılan Kataloglama Çalışmaları » (sur le catalogage dans les bibliothèques de $v a k f$ ).

67 Je remercie E. Ambros pour ses éclaircissements sur cette œuvre.

68 Erünsal, «Ottoman Foundation Libraries », p. 77 ; Hirschler, Medieval Damascus, p. 103.

69 TÜYATOK, Isparta, p. 2.

70 Erünsal, «Kuruluşundan Tanzimatta Kadar Osmanlı Vakıf Kütüphanelerinde Yapılan Kataloglama Çalışmaları», p. 105; id., «Ottoman Foundation Libraries», p. 77 ; id., Ottoman Libraries, p. 157 ; id., "Catalogues and Cataloguing in the Ottoman Libraries », Libri, 37/4 (1987), p. 333-349 (reproduit dans Ottoman Libraries, p. 145-164). Pour une étude très détaillée d'un catalogue de bibliothèque, voir Hirschler, Medieval Damascus, p. 64-86.

71 Witkam, «Ibn al-Akfānī (m. 749/1348) and His Bibliography of the Sciences », p. 37-41; Godefroid de Callataÿ et Baudouin Van den Abeele (éds), Une lumière venue d'ailleurs: héritages et ouvertures dans les encyclopédies d'Orient et d'Occident au Moyen Âge, Turnhout-Louvain, Brepols («Réminisciences», 9), 2008; Gerhard Endress (éd.), Organizing Knowledge:Encyclopaedic Activities in the Pre-Eighteenth Century Islamic World, 
$\mathrm{XVII}^{\mathrm{e}}-\mathrm{XII} / \mathrm{eVIII}{ }^{\mathrm{e}}$ siècles, les classifications et sous-classifications étaient livrées au caractère arbitraire du choix des bibliothécaires ${ }^{72}$. Elles étaient et demeurent des cotes mal taillées, car le figh intégrait des normes dérivées d'autres disciplines - à la condition de toujours rester la source suprême de légitimation de ces normes ${ }^{73}$-, des autobiographies incluaient des matériaux très similaires à ceux trouvés dans des manuels de soufisme ${ }^{74}$, des sīra $\left(\mathrm{n}^{\circ}{ }_{40}\right)$ puisaient aux données réunies dans les recueils de hadiths ( $\left.\mathrm{n}^{\circ} 46\right)$, des manuels soufis incorporaient des éléments de tafsìr $\left(\mathrm{n}^{\circ} 47\right)$, des dictionnaires se référaient au principe d'authenticité des transmissions de données lexicographiques sur le modèle des recueils d'al-Buhārī (m. 256/870) et de Muslim (m. 261/875; $\left.\mathrm{n}^{\circ} 58\right)$, quand des commentaires d'ouvrage de théologie étaient pour moitié consacrés à des questions philosophiques $\left(n^{\circ} 61\right)$. Plus encore, des œuvres citées dans la liste pourraient être résolument qualifiées de transdisciplinaires :l'étude de tafsīr hanbalite de Sirāğ al-Dīn b. Ādil al-Ḥanbalī (m. après $\left.880 / 1475 ; \mathrm{n}^{\circ} 74\right)$ traite d'une multitude de sujets, oscillant entre réflexion terminologique (l'i 'rāb, différence dans la finale du mot) et interprétation des versets à partir du figh ou du kaläm. Au IX $/ \mathrm{XV}^{\mathrm{e}}$ siècle en Égypte et en Syrie, puis de nouveau au $\mathrm{XI}^{\mathrm{e}} / \mathrm{XVII}^{\mathrm{e}}$ siècle, les interpénétrations se multipliaient entre la littérature du hadith, la pensée légale et l'adab soufi ${ }^{75}$.

Leiden-Boston, Brill («Islamic Philosophy, Theology, and Science», 61), 2006 ; Hirschler, Medieval Damascus (chapitre 2); Atay, Osmanlılarda Yüksek Din Eğitimi, p. 6o-72 ; Unan, «Taşköprülüzâde’nin Kaleminden XVI. Yüzyllın ‘İlim' ve ‘Âlim’ Anlayışı »; Ekmeleddin İhsanoğlu, «Institutionalisation of Science in the Medreses of Pre-Ottoman and Ottoman Turkey », dans Turkish Studies in the History of Philosophy of Science, éds Gürol Irzlk et Güven Güzeldere, Dordrecht-New York, Springer («Boston Studies in the Philosophy of Science », 244), 2005, p. 265-283, p. 278-280 ; Erünsal, «Ottoman Foundation Libraries », p. 76-77.

72 Ibid., p. 77 ; id., «A Brief Survey of the Development of Turkish Library Catalogues», Libri, $5^{1}$ (2001), p. 1-7, p. 2-3; id., «Kuruluşundan Tanzimatta Kadar Osmanlı Vakıf Kütüphanelerinde Yapılan Kataloglama Çalışmaları », p. 107, 109; id., Ottoman Libraries, p. 159 (l'auteur repère trois sous-classifications dans le catalogage des ouvrages de tafsïr de la bibliothèque Meḥmed Rāġıb Pacha).

73 Baber Johansen, « Coutumes locales et coutumes universelles aux sources des règles juridiques en droit musulman hanéfite », Annales islamologiques, 27 (1993), p. 29-35, p. 29.

74 Michael Winter, Society and Religion in Early Ottoman Egypt: Studies in the Writings of 'Abd al-Wahhāb al-Sha'rānī, New Brunswick, Transaction Books («Studies in Islamic Culture and History »), 1982, p. 7 .

75 Éric Geoffroy, Le soufisme en Égypte et en Syrie sous les derniers Mamelouks et les premiers Ottomans: orientations spirituelles et enjeux culturels, Damas, Institut français de Damas, 1995; Catherine Mayeur-Jaouen, «La Sira halabiyya (1633): la Vie du Prophète comme épiphanie», Arabica (à paraître). Je remercie l'auteur de m'avoir communiqué cet article. 
L'inventaire débute par les disciplines placées au sommet du ${ }^{\prime} l m^{76}$. À une exception près déjà évoquée $\left(\mathrm{n}^{\circ} 6\right)$, les 16 premiers titres de la liste de la charte - je ne suis pas en mesure d'identifier avec certitude le titre $n^{\circ} 11$ - correspondent à des études de tafsirr, réparties entre 8 ouvrages de référence et 6 gloses (ḥaş̧iye) destinées à la fois à préserver et à transmettre les connaissances de ces ouvrages ${ }^{77}$. Connus, recensés et vénérés, les commentateurs (müfessir) occupent une place centrale dans la littérature ottomane et leurs écrits sont généralement cités en tête de liste ${ }^{78}$. Viennent ensuite des livres consacrés à la tradition prophétique (16 titres). Les clercs ottomans pensent comme al-Suyūṭî : que c'est «la plus noble des sciences » ${ }^{79}$. L'intérêt qu'ils lui portent s'est accentué tout au long du XI ${ }^{\mathrm{e}} / \mathrm{XVII}^{\mathrm{e}}$ siècle : au cour des programmes d'enseignement en madrasa, les hadiths sont entourés d'un attachement dévotionnel revigoré au Prophète et servent de modèle de légitimation aux traditions soufies $^{80}$. Employés partout en terre d'Islam depuis les débuts du genre, les recueils de référence $\left(\mathrm{n}^{\circ} 18,19\right)$ sont complétés d'autres ouvrages, certes plus tardifs et moins vénérés, mais très populaires $\left(n^{\circ} 17\right)$. S'y ajoute tout ce qui relève de la sira $\left(\mathrm{n}^{\circ} 40\right)$, du modèle prophétique $\left(\mathrm{n}^{\circ} 20\right)$ et des louanges du Prophète dont certaines sont ciblées (sur des traits de personnalité et d'apparence, $\mathrm{n}^{\mathrm{o}} 28$ ). Soulignons la présence des sunan/sünen $\left(\mathrm{n}^{\mathrm{0}} 21,22\right)$ qui compilent

76 La pratique a été repérée ailleurs (Sabev, « Bulgaristan'da Osmanlı Vakıf Kütüphanelerinde Bir Örnek», p. 300 ; Uluç, « Ottoman Book Collectors and Illustrated Sixteenth Century Shiraz Manuscripts », p. 89).

77 Zubčević, Book Ownership in Ottoman Sarajevo 1707-1828, p. 174-176.

78 Hellmut Ritter, « Ayasofya Kütüphanesinde Tefsir İlmine Ait Arapça Yazmalar », Türkiyat Mecmuası, 7-8 (1945), p. 1-93; Muhammed Abay en a répertorié 276 : Muhammed Abay, Osmanlı Dönemi Müfessirleri, Bursa, Uludağ Üniversitesi Sosyal Bilimler Enstitüsü, 1992 ; id., «Osmanlı Döneminde Yazılan Tefsir ile İlgili Eserler Bibliyografyası », Divan İlmi Araştırmalar Dergisi, 6 (1999), p. 249-303 ; Ziya Demir, Osmanlı Müfessirleri ve Tefsir Calışmaları (Kuruluştan X/XVI. Asrın Sonuna Kadar), Istanbul, Ensar, 2006, p. 324-330.

79 Sur la «culture canonique» forgée autour des grands recueils de hadiths, voir Jonathan Brown, The Canonization of al-Bukhārī and Muslim, Leiden-Boston, Brill («Islamic History and Civilization», 69), 2007, p. 33, 42-46. Sur la place des hadiths dans la culture religieuse ottomane, lire Mehmet Emin Özafşar, « Osmanlı Ĕ̆itim, Kültür ve Sanat Hayatında Hadis », dans Türkler, éds Hasan Celâl Güzel, Kemal Çiçek et Salim Koca, Ankara, Yeni Türkiye, 2002, XI, p. 356-369.

8o Salih Karacabey, «Osmanlı Medreselerinin Son Dönemi'nde Hadis Öğretimi », Uludăg Üniversitesi İlahiyat Fakültesi Dergisi, 8/8 (1999), p. 149-169, p. 151-152; id., « Hadis Öğretiminde Medrese ve Daru'l-Hadislerin Yeri», Uluslararası Katılımlı Sempozyum: Anadolu'da Hadis Geleneği ve Daru'l-Hadisler, 30 Nisan-1 Mayıs 2011, Samsun, Çankırı Belediyesi, 2011, p. 217-243, p. 227-23o. 
des décisions juridiques $(a q w \bar{a} l)$ en plus des recueils biographiques de grands traditionnistes $\left(\mathrm{n}^{\circ} 26\right)$.

Troisième discipline des sciences supérieures, le fiqh est cité dans les mêmes proportions (16 titres). Il domine le champ intellectuel ottoman : il vient en tête des productions des enseignants de la prestigieuse madrasa Șahn-1 șemān fondée sous Mehmed II (r. 855/1451-886/1481). C'est la matière la plus étudiée dans les cursus publiés par les spécialistes ${ }^{81}$ et la discipline la plus citée dans des listes de manuscrits de bibliothèques ${ }^{82}$ et dans des inventaires de biens ${ }^{83}$. Sont mentionnés deux des quatre livres de base muteber (tenus en haute estime) appelés dans le figh hanéfite mutūn al-arba'a (no 89, 96). Comme il se doit, les deux sections du figh sont représentées: les «fondements du droit » (ușūl al-fiqh, no $68-69^{84}$ ) ou jurisprudence théorique ${ }^{85}$ et les «branches du droit » (furū $\bar{c}^{c}$ l'incontournable commentaire de Ḥaskafī, $\mathrm{n}^{\circ}$ 101) ou exposition

81 Entre 1470 et 1730 (Unan, « The Ottoman Ulema », p. 847).

82 C'est la discipline la plus représentée dans les bibliothèques de Halīl Hamīd Pacha à Isparta (101 des $5^{82}$ manuscrits; Hikmet Turan Dağlıoğlu, «Isparta'da Halil Hamid Paşa Kütüphanesi », ÜN - Isparta Halkevi Mecmuası, 8/91-92 [1941-1942], p. 1301-1303, p. 1302), de Dervīş Meḥmed Pacha à Burdur (243 des 1515 ouvrages d'un inventaire dressé en 18501851 ; Şahin, « Katalogta yer Almayan ve Ortaya Yeni Çıkan Burdur Şer'iye Sicili », p. 51), du mufti de Sofia en 1777 (30 ouvrages parmi 159 titres ; Sabev, « Bulgaristan'da Osmanlı Vakıf Kütüphanelerinde Bir Örnek», p. 299) et de Yūsuf Ag̉a à Konya en 1796 (sur 75 o ouvrages, 112 de figh, 63 de tafsìr et 76 de hadith ; İzzet Sak, Kadı Sicilleri Işı̆̆ında Konya'da Yapılan Vakıflar (1650-1910), Konya, Konya Büyükşehir Belediyesi, 2012, p. 235-236).

83 Jane Hathaway, «The Wealth and Influence of an Exiled Ottoman Eunuch in Egypt: The Waqf Inventory of Abbas Agha », Journal of the Economic and Social History of the Orient, 37/4 (1994), p. 293-317, p. 311 ; Sabev, « Okuyan Taşralı Bir Toplum », p. 581-583 ; Zubčević, Book Ownership in Ottoman Sarajevo 1707-1828, p. 177.

84 La discipline concerne l'identification des sources du droit et les principes généraux de l'herméneutique qui permettent d'extrapoler les règles à partir de la révélation (Norman Calder, «Ușūl al-fiḳh », $\left.E I^{2}\right)$. Christian Müller traduit l'expression par «legal hermeneutics » ou « hermeneutical approach to sacred origins » : Christian Müller, «Mamluk Law: A Reassessment», dans Ubi sumus? Quo vademus? Mamluk Studies - State of the Art, éd. Stephan Conermann, Göttingen, V\&R Unipress-Bonn University Press («Mamluk Studies », 3), 2013, p. 263-283, p. 269-270.

85 «Rechtsprinzipien» (Reichmuth, «Bildungskanon und Bildungsreform aus der Sicht eines islamischen Gelehrten der Anatolischen Provinz », p. 503). On trouvera une synthèse sur l'ușūl dans Youcef Soufi, «The Historiography of Sunni Usul a-fiqh », dans The Oxford Handbook of Islamic Law, éds Anver M. Emon et Rumee Ahmed, New York, Oxford University Press, 2018, p. 249-270, et une présentation éclairante sur l'époque ottomane dans Abdurrahman Atçl, « Greco-Islamic Philosophy and Islamic Jurisprudence in the Ottoman Empire (1300-160o): Aristotle's Theory of Sciences in Works on Ușul al-Fiḳh », Osmanlı Araştırmaları, 41 (2013), p. 33-54, p. 40-44. 
des normes ${ }^{86}$. En matière de $u s ̦ u ̄ l$, les jurisconsultes ottomans ont discuté et redéployé des théories scientifiques dont la discipline avait jusqu'alors fait usage ${ }^{87}$. Un débat est en cours : selon Guy Burak, la «taxinomie tripartite des textes» (textes d'autorité, commentaires, collections de fatwas) se serait effacée au profit d'un « corpus juridique impérial assez standardisé ${ }^{88}$. Si, pour cet auteur, les textes du figh hanéfite tirent leur autorité du prestige de la dynastie qui projette sur eux une « conscience du canon », pour Yavuz Aykan, cette autorité dérive, pratiquement plus qu'idéologiquement, de la capacité des muftis provinciaux à produire des opinions casuistiques ${ }^{89}$.

Le madhab le plus cité est le hanéfisme. Cela fait sens en Anatolie où l'État ottoman n'en reconnait officiellement nul autre, alors qu'ailleurs dans l'Empire la Porte garantit les conditions d'une « flexibilité pragmatique » (Y. Aykan) en fonction des affaires traitées ${ }^{90}$. Cela dit, en Anatolie également, l'exercice pratique du droit rend possible les changements de $m a d h a b^{91}$. D'où, sans doute, la présence d'ouvrages comparatifs $\left(n^{\circ} 86,87\right)$ dans la collection. D'où également la mention d'une étude de tafsìr hanbalite (al-Lubāb par Ibn 'Ādil, $\left.\mathrm{n}^{\circ} 74\right)$ : non seulement, celle-ci traite de nombreux problèmes théologiques et linguistiques qui vont au-delà de l'exercice exégétique, mais elle prend largement en compte les œuvres de juristes d'autres madhab - peut-être est-ce pour cette raison

86 «Exposition systématique de normes juridiques» (Müller, «Mamluk Law», p. 270 ; ma traduction de l'anglais).

87 Abdurrahman Atçıl, «Mobility of Scholars and Formation of a Self-Sustaining Scholarly System in the Lands of Rūm during the Fifteenth Century », dans Islamic Literature and Intellectual Life in Fourteenth and Fifteenth-Century Anatolia, éds Andrew C.S. Peacock et Sara Nur Ylldız, Würzburg, Ergon («Istanbuler Texte und Studien », 34), 2016, p. 315-332.

88 Guy Burak, The Second Formation of Islamic Law: The Hanafi School in the Early Modern Ottoman Empire, New York, Cambridge University Press (« Cambridge Studies in Islamic Civilization »), 2015, p. 143-144, mes traductions de l'anglais.

89 Compte rendu par Yavuz Aykan de Guy Burak, The Second Formation of Islamic Law, dans International Journal of Middle East Studies, 48/4 (2016), p. 793-795, p. 795.

$90 \quad$ Sur le cas de la Syrie, voir Bruce Masters, «Ottoman Policies Toward Syria in the 17th and 18th Centuries », dans The Syrian Land in the 18th and 19th Century, éd. Thomas Philipp, Stuttgart, Franz Steiner Verlag («Berliner Islamstudien », 5), 1992, p. 11-26, p. 17-18. Pour une comparaison avec les flexibilités observées à l'époque mamelouke, voir Yossef Rapoport, «Legal Diversity in the Age of Taqlīd: The Four Chief Qādīs under the Mamluks », Islamic Law and Society, 10/2 (2003), p. 210-228.

91 Aykan, Rendre la justice à Amid, p. 168, contre la thèse d'un « refusal to allow any 'conversion' to another madhhab in Anatolia and the Balkans »: Haim Gerber, Islamic Law and Culture 1600-1840, Leiden, Brill («Studies in Islamic Law and Society», 9), 1999, p. 69. Sur la notion de «textes cosmopolites » à partir de l'étude du cas du madhab zaydite, voir Brinkley Morris Messick, Sharīa Scripts: A Historical Anthropology, New York, Columbia University Press, 2018, p. 100-133. 
qu'on en trouvait de nombreuses copies en milieu hanéfite? Notons aussi la présence d'ouvrages du rite hanbalite, à commencer par une hagiographie de son fondateur présumé (Aḥmad b. Hanbal, m. 241/855) composée par le savant de Bagdad, Aḥmad b. 'Ālī l-Ǧawzì (m. 597/12o1; nº 36). Plus remarquable encore est la mention de son Talbìs Iblīs ( $\left.\mathrm{n}^{\circ}{ }_{78}\right)$, «l'une des œuvres majeures du Hanbalisme de combat » (Henri Laoust), particulièrement hostile aux tarīqas. On connaît la capacité intégratrice du figh ottoman: au milieu du $\mathrm{x}^{\mathrm{e}} / \mathrm{XvI}^{\mathrm{e}}$ siècle, alors que Dede Cöngī (m. 975/1567) nourrit ses travaux juridiques aux sources de plusieurs madhab, sa doxa jurisprudentielle est catégorisée comme hanéfite ${ }^{92}$. Se pourrait-il que, deux siècles plus tard, dans un contexte de propagande anti-wahhabite, les juristes ottomans soient enjoints par le pouvoir impérial de répondre à la diffusion d'une nouvelle doxa hanbalite ${ }^{93}$ ? Ou faut-il y voir les derniers feux d'une «culture de l'ambiguïté » à étudier par-delà les cadres arabes au sein desquels Thomas Bauer l'a récemment examinée ${ }^{94}$ ?

Nulle bibliothèque sans recueils de fatwas ( 7 dont 4 ottomans). Le genre est riche et divers ${ }^{95}$. Des recueils contiennent les fatwas d'un mufti en particulier. D'autres sont des compilations organisées selon les catégories légales en usage, sur le modèle des divisions propres aux manuels de $f i q h^{96}$. Ainsi, dans la bibliothèque précitée du mufti de Sofia (1777), ces recueils arrivent en deuxième position après les ouvrages de droit ${ }^{97}$. Ils sont rédigés en arabe, sinon dans un turc stylisé, le cas échéant flanqués de traductions en arabe ( $\left.n^{\circ} 81\right)$. On y retrouve des caractères linguistiques et des éléments de composition et d'organisation

92 Yavuz Aykan, «A Legal Concept in Motion: The 'Spreader of Corruption' (sā'i bìl-fesād) from Qarakhanid to Ottoman Jurisprudence», Islamic Law and Society, 26/3 (2018), p. 1-19, p. 4.

93 Samer Traboulsi, «An Early Refutation of Muhammad ibn 'Abd al-Wahhāb’s Reformist Views », Die Welt des Islams, 42/3 (2002), p. 373-415.

94 Thomas Bauer, Die Kultur der Ambiguität: Eine andere Geschichte des Islams, Berlin, Verlag der Weltreligionen, 2011. Pour un élargissement des perspectives à d'autres cultures islamiques et notamment aux «floraison(s) ottomane(s)», voir le compte rendu de Catherine Mayeur-Jaouen, dans Arabica, 64/1 (2017), p. 115-127.

95 On trouvera un répertoire détaillé d'environ 160 collections de fatwas recueillies par des şeyhü-l-islām, muftis provinciaux, enseignants, juges et scribes dans Şükrü Özen, «Osmanlı Döneminde Fetva Literatürü », Türkiye Araştırmaları Literatür Dergisi, 3/5 (2005), p. 249-378.

96 Colin Imber, «Eleven Fetvas of the Ottoman Sheikh ul-Islam 'Abdurrahim », dans Islamic Legal Interpretation: Muftis and Their Fatwas, éds Muhammad Khalid Masud, Brinkley Messick et David S. Powers, Cambridge, Harvard University Press, 1996, p. 141-149, p. 141. Sabev, «Bulgaristan'da Osmanlı Vakıf Kütüphanelerinde Bir Örnek», p. 299. 
de manuels de droit et ouvrages de fur $\bar{u}^{-98}$ : ces recueils étaient en effet conçus pour répondre directement aux problèmes juridiques soulevés dans les cas examinés dans les tribunaux ( $\left.n^{\circ} 81,83\right)$, étant entendu que les fatwas n'avaient de valeur exécutoire que dès lors qu'elles étaient intégrées au litige examiné99. D'où l'intérêt grandissant que les spécialistes leur portent depuis une quinzaine d'années ${ }^{100}$. On sait qu'une grande partie de ces recueils étaient constitués à Istanbul avant d'être diffusés dans l'Empire ${ }^{101}$ : à Amīd par exemple, la majorité des fatwas des muftis se référaient aux opinions des grands şeyh̆̈̈-l-islām, collectées après leur mort par leur chef de bureau (fetvā eminni) - plusieurs compendia sont ici cités : Ebu-s-su'ūd (m. 982/1574 ; nº 8), Sa'dī Çelebi (m. 945/1538; no 12), Bayrāmzāde ( ca 10o1/1593; no 15) et Kemālpaşazāde (m. 940/1534; $\left.\mathrm{n}^{\mathrm{o}} 91\right)^{102}$. On sait également que l'exercice du droit ottoman impliquait la participation d'autres acteurs que les « auteurs-juristes », pour reprendre le terme de Wael B. Hallaq ${ }^{103}$. Des muftis provinciaux (kenar müftileri) consultaient des textes de furū $\bar{c}^{\mathrm{p}}$ our rédiger leurs propres fatwas. Forts de leur expérience dans les tribunaux, ils produisirent des recueils dont certains furent reconnus pour leur fiabilité104.

Nulle bibliothèque sans ouvrages biographiques. À l'instar de leurs prédécesseurs, des lettrés ottomans s'attachent à rendre compte de la succession ininterrompue de générations qui ont témoigné de l'expérience islamique

98 Ömer Faruk Köse, The Fatwa Collection of an Ottoman Provincial Mufti, Vani Mehmed Efendi (d. 1685), master d'histoire, Université de Boğaziçi, Istanbul, 2015, p. 18.

99 Y. Aykan, contre les propositions de L. Peirce, H. Gerber ou G. Burak. Je le remercie d'en avoir discuté avec moi.

100 H. Necati Demirtaş, Açıklamalı Osmanlı Fetvâlar I : Fetâvâ-yı Ali Efendi, Çatalcalı Ali Efendi, Istanbul, Kubbealtı Neşriyâtı, 2011, 2 vols ; Pehlül Düzenli, Ma'rûzât :Şeyhülislâm Ebussuûd Efendi, Istanbul, Klasik, 2013; Süleyman Kaya, Betül Algın, Zeynep Trabzonlu et Asuman Erkan (éds), Behcetül-fetâvâ: Şeyhülislam Yenişehirli Abdullah Efendi, Istanbul, Klasik («Osmanlı hukuk tarih », 5 ; « Osmanlılarda hukuk ve tolum », 3), 2012 ; Süleyman Kaya (éd.), Fetâvâ-yı Feyziye: Şeyhülislam Feyzullah Efendi, Istanbul, Klasik («Osmanlılarda hukuk ve toplum », 2), 2009 ; Süleyman Kaya et Mustafa Demiray (éds), Netîcetül-fetâvâ : Şeyhülislam Fetvaları, Istanbul, Klasik (« Osmanlı hukuk tarihi », 9 ; « Osmanlılarda hukuk ve toplum », 6), 2014; Pehlül Düzenli, Şeyhülislâm Ebussuûd Efendi ve Fetvâları, Istanbul, Osmanlı Araştırmaları Vakfi, 2012.

101 Burak, The Second Formation of Islamic Law, p. 16o-161.

102 Aykan, Rendre la justice à Amid, p. 178, p. 229; Aykan, «From the Hanafi Doxa to the Mecelle», p. 9 .

103 Wael B. Hallaq, « The Author-Jurist and Legal Change in Traditional Islamic Law », Recht van de Islam, 18 (2001), p. 31-75 ; id., An Introduction to Islamic Law, Cambridge-New York, Cambridge University Press, 2009, p. 10.

104 Köse, The Fatwa Collection of an Ottoman Provincial Mufti, Vani Mehmed Efendi (d. 1685), p. 19 (pour une bibliographie des thèses et masters consacrés à des recueils de fatwas). 
vécue à partir des origines ${ }^{105}$ : d'où la présence du Nafahăt al-uns ( $\left.\mathrm{n}^{\mathrm{o}} 45\right)$, le riche recueil de biographies de mystiques du dernier grand poète persan du Moyen Âge, Mawlānā Ğāmī (m. 898/1492). À partir de la seconde moitié du xe/ $\mathrm{XVI}^{\mathrm{e}}$ siècle, des savants inscrivent les généalogies d'autorité et les textes du figh au service de la jurisprudence impériale ${ }^{106}$. En outre, ils rattachent le genre aux autres disciplines scientifiques et littéraires et l'érigent en branche à part entière de l'historiographie ${ }^{107}$. C'est dans cette tradition islamique que s'inscrit un Ṭaşköprüzāde qui, dans la première moitié $\mathrm{du} \mathrm{x}^{\mathrm{e}} / \mathrm{XVI}^{\mathrm{e}}$ siècle, répertorie les vies de centaines d'oulémas et de cheikhs dans ses Parcelles anémones $\left(\mathrm{n}^{\mathrm{o}} 53\right)^{108}$. À la fin du XI ${ }^{\mathrm{e}} / \mathrm{XVII}^{\mathrm{e}}$-début du XII $/ \mathrm{XVIII}^{\mathrm{e}}$ siècle, le genre biographique est redéployé vers les recueils en série de hauts dignitaires (Reihenbiographien von Würdenträgen $)^{109}$.

Pour ce qui est de la théologie, trois des auteurs principaux de la discipline sont cités (al-Ğurğānī, m. 816/1413-1414, no 61 ; al-Taftāzānī, m. 792/139o, nº 62 ; al-Dawānī, m. 908/1502-1503, no 66), alors qu'aucune place n'est laissée aux productions non hanéfites - ce qui est bien différent du fiqh, comme on a vu. Quant aux autres sciences, elles bénéficient de la présence d'un ouvrage au moins : rhétorique (bayāa $\left.n^{110}, \mathrm{n}^{\mathrm{o}} 33,64\right)$, profession de foi ('aqā̉id, $\mathrm{n}^{\circ}$ 65), logique (manțiq, $\left.\mathrm{n}^{\mathrm{o}} 73\right)$, adab ${ }^{111}\left(\mathrm{n}^{\mathrm{o}} 35,47,51\right)$, sira $\left(\mathrm{n}^{\mathrm{o}} 28,40\right)$, histoire $\left(\mathrm{n}^{\circ} 48\right.$, $\left.5^{2}\right)$, médecine $\left(n^{\circ} 44\right)$, cosmographie $\left(n^{\circ} 5^{\circ}\right)$, astronomie $\left(n^{\circ} 71\right.$, très employé), sciences naturelles $\left(\mathrm{n}^{\circ} 67\right)$ et poésie, à condition qu'elle soit savante - quand bien même mettrait-elle directement en cause les prétentions vertueuses et

105 Ibrahim Hafsi, «Recherches sur le genre "Ṭabaqāt" dans la littérature arabe », Arabica, 23/3 (1976), p. 227-265, p. 233.

106 Burak, The Second Formation of Islamic Law, p. 12, p. 71-100.

107 Barbara Kellner-Heinkele, «Osmanische Biographiensammlungen », Anatolica, 6 (19771978), p. 171-194, p. 171, p. 173 .

108 Barbara Flemming, «Glimpses of Turkish Saints: Another Look at Lami'i and Ottoman Biographers », Journal of Turkish Studies, 18 (1994), p. 59-74; Burak, The Second Formation of Islamic Law, p. 94-98.

109 Kellner-Heinkele, «Osmanische Biographiensammlungen», p. 171, p. 173; Olivier Bouquet, «Biographies, autobiographies et pouvoir sultanien, de Soliman le Magnifique à Abdülhamid II », Annales islamologiques, 46 (2012), p. 273-289.

110 Bayān: "procédé discursif qui fournit les moyens grâce auxquels on obtient une clarté parfaite du discours, une expression limpide». Marie Bernand, «Bayān selon les Ușūliyyūn », Arabica, 42/2 (1995), p. 145-16o, p. 145-146.

111 «Les différents concepts d'adab définissent des normes de comportement, notamment liés à des emplois ou des fonctions, d'une part, ou bien s'appliquent à une connaissance de la langue, culture générale morale et littéraire, d'autre part. Deux champs lexicaux séparés que personne, à part Kâtib Celebi dans le Kašf al-z̧unūn, ne lie à l'époque ottomane». Catherine Mayeur-Jaouen, «Deux livres pionniers sur les ego-documents dans les littératures du Moyen-Orient à l'époque moderne et contemporaine », Arabica, 6o/3-4 (2013), p. 385-40o, p. 391. 
l'hypocrisie d'autorités religieuses, nimbée d'une fascinante aura mystique, celle de Ḥăfıż (m. 792/139o; $\left.\mathrm{n}^{\circ} 104,105,106\right)$ correspond à ce point au piétisme du temps qu'elle a toute sa place en madrasa ${ }^{112}$. La culture religieuse du temps est en effet animée d'un soufisme empreint d'une conscience de la sunna plus aiguë113 - parmi les auteurs de la liste, notons la présence d'éminents cheikhs, prédicateurs, oulémas, historiens et penseurs soufis ( $\left.\mathrm{n}^{\circ} 20,23,31,45,47,102\right)$. Elle est également marquée par l'apparition de nouvelles formes cognitives d'attachement à la «Voie muhammadienne» (țarīqa muhammadiyya ${ }^{114}$ ). Affirmée depuis le $\mathrm{XI}^{\mathrm{e}} / \mathrm{XVII}^{\mathrm{e}}$ siècle au moyen de vecteurs renforcés que sont les manuels de prières $\left(\mathrm{n}^{\circ} 30,31,32\right)$ et les recueils d'anecdotes édifiantes ou de raretés religieuses ( $\mathrm{n}^{\mathrm{o}} 100$ ), la diffusion d'une devotio moderna gagne les bureaucrates du siècle suivant ${ }^{115}$.

Loin de révéler aucune surprise, l'inventaire témoigne d'un classicisme sans pli $^{116}$. Connus et populaires, les titres cités se sont imposés au fil des siècles, grands classiques aussi présents dans les madrasas anatoliennes que le sont les Larousse et Robert dans les bibliothèques municipales françaises ${ }^{117}$. Certes, des ouvrages très employés dans les cursus (le Tafsìr d'Abū l-Layt al-Samarqandī, m. 373/983-984, notamment) et des auteurs incontournables dans les licences

112 Ahmed Ateş, İstanbul Kütüphanelerinde Farsça Manzum Eserler, Istanbul, Devlet Kitapları, 1968.

113 Bernd Radtke, «Sufism in the 18th Century: An Attempt at a Provisional Appraisal», Die Welt des Islams, $36 / 3$ (1996), p. 326-364, p. 360-361; Derin Terzioğlu, «Sufis in the Age of State-Building and Confessionalization», dans The Ottoman World, éd. Christine Woodhead, Londres, Routledge, 2012, p. 86-99 ; Rachida Chih et Catherine Mayeur-Jaouen, «Introduction: le soufisme ottoman vu d'Égypte», dans id. (éds), Le soufisme à l'époque ottomane, $X V I^{e}-X V I I{ }^{e}$ siècle, Le Caire, IFAO, 2010, p. 1-55, p. 2, p. 31.

114 Radtke et O’Fahey, «Neo-Sufism Reconsidered», p. 64-71 (pour des éléments de définition et une synthèse historiographique); Stefan Reichmuth, « Aspects of Prophetic Piety in the Early Modern Period », Archives de sciences sociales des religions, 178 (2017), p. 129150, p. 140-141.

115 Sievert, «Eavesdropping in the Pasha's Salon», p. 173; Chih et Mayeur-Jaouen, «Introduction », p. 30 ; Mayeur-Jaouen, « La Sirra halabiyya».

116 Pour une comparaison avec une liste de 159 livres d'une bibliothèque inventoriée en 1777, voir Sabev, «Bulgaristan'da Osmanlı Vakıf Kütüphanelerinde Bir Örnek», p. 300-303. Voir aussi Aynur, «I. Mahmûd'un (ö. 1754) Kütüphaneleri ve Tarih Manzumeleri », p. 743-734.

117 Pour une comparaison avec les processus de «classicisation» d'œuvres pédagogiques, voir Emmanuelle Chapron, «Comment Robinson Crusoé est entré au collège : carrières littéraires et fabrique d'un classique au XVIII ${ }^{\mathrm{e}}$ siècle», Revue Historique, 680 (2016), p. $763-784$. 
d'enseignement (iğăza/icāzet) ne figurent pas danslaliste (al-Ġazālī, m.5०5/1111, ou Ibn al-Arabī, m. 638/1240, par exemple ${ }^{118}$ ), mais les disciplines principales sont représentées par leurs plus beaux monuments ${ }^{119}$ : pour la Tradition prophétique, le Ğāmic al-ṣaḥ̄h d'al-Buhāāī (no $\left.{ }^{\circ} 18\right)$, riche de ses milliers de traditions sélectionnées et classées, conçu comme le livre le plus important après le Coran et placé à la tête des recueils de traditions sunnites avec son alter ego, l'autre plus «authentique » recueil de tous les temps, à savoir le compendium de Muslim $\left(\mathrm{n}^{\mathrm{o}} 19\right)^{120}$; dans le domaine de l'exégèse, al-Bayḍāwī aurait suscité plus de 250 commentaires et études ${ }^{121}$ - si les bureaucrates possèdent un ouvrage de tafsir dans leur bibliothèque, c'est celui-ci ${ }^{122}$; en jurisprudence, le Multaqā d'al-Ḥalabī (m. 956/1549) est à l'origine d'un commentaire indépassable et inégalé : tant par la rigueur de sa composition que par la richesse des cas traités, al-Ḥaskafî (m. 1088/1677; n $^{\circ}$ 101) surplombe les autres manuels ${ }^{123}$; en rhétorique, voici l'incontournable Miftạh al-úūm d'al-Sakkākī (no $\left.{ }^{\circ} 33\right)$, à partir duquel s'est édifiée la plus grande partie de la discipline ${ }^{124}$. Halīl Hamìd et ses gens le savent bien : qu'un étudiant assimile cette poignée d'ouvrages et il aura fait l'essentiel du travail que ses maîtres attendent de lui. Déposés dans un même meuble, une armoire précise la charte, ces 106 livres matérialisent un lieu de savoir à la fois circonscrit et infini, un «trésor de la sagesse » 125 .

Cela peut sembler logique que les auteurs les plus importants du corpus soient cités au titre de leur maître-ouvrage : Ḩāzin al-Bag̉dādī (m. 741/1340-1341) pour son tafsìr ( $\mathrm{n}^{\mathrm{o}} 2$ ), al-Hुafāğ̄i (m. 1069/1658-1659) pour son commentaire du tafsìr d'al-Bayḍāwī (no 10), al-Suhrawardī (m. 632/1234-1235), l'un des plus importants soufis de l'islam sunnite, pour un manuel, généraliste et exhaustif,

118 Unan, Kuruluşundan Günümüze Fâtih Külliyesi, p. 372 ; Sievert, «Eavesdropping in the Pasha's Salon », p. 173. Pour une réévalution de l'influence d'Ibn 'Arabī aux XVII ${ }^{\mathrm{e}}-\mathrm{XVIII}{ }^{\mathrm{e}}$ siècles, voir El-Rouayheb, Islamic Intellectual History in the Seventeenth Century, p. 306-307.

119 Sur les ouvrages spécialisés considérés comme les plus importants dans les bibliothèques médiévales de Damas, voir Eche, Les bibliothèques arabes publiques et semi-publiques en Mésopotamie, en Syrie et en Égypte au Moyen Âge, p. 293-299.

120 James Robson, «al-Bukhārī», $E I^{2}$; M. Yaşar Kandemir, «El-Câmiu's-sahîh », Türkiye Diyanet Vakfi İslam Ansiklopedisi, 7 (1993), p. 114-123; Gautier H.A. Juynboll, « Muslim b. al.-Ḥadjādj », $E I^{2}$; M. Yaşar Kandemir, «El-Câmiu's-sahîh », Türkiye Diyanet Vakfi İslam Ansiklopedisi, 7 (1993), p. 124-129; İzgi, Osmanlı Medreselerinde İlim, I, p. 166, 169. Sur la notion d'authenticité dans les recueils de hadiths et les sïra, voir Mayeur-Jaouen, « La Sïra halabiyya».

121 İsmail Cerrahoğlu, «Envârü't-tenzîl ve esrârü't-te'vîl », Türkiye Diyanet Vakfi İslam Ansiklopedisi, 11 (1995), p. 26o-261.

122 Sievert, «Eavesdropping in the Pasha's Salon », p. 176.

123 Şükrü Selim Has, «The Use of Multaqa'-abḥur in the Ottoman Madrasas and in Legal Scholarship », Osmanlı Araştırmaları, 7-8 (1988), p. 393-418.

124 Bilge, İlk Osmanlı Medreseleri, p. 55-56.

125 Touati, L'armoire à sagesse, p. 18. 
qui a influencé des millions de croyants dans leur pratique religieuse ( $\left.n^{\circ} 47\right)$, ou encore al-Ṣafĩ (m. 939/1532-1533) pour son Rašahăt consacré aux soufis naqšbandis $\left(\mathrm{n}^{\circ} 102\right)$. D'autres lettrés sont mentionnés, tantôt pour la seule œuvre qu'on leur connaisse (le Kitāb al-lubāb d'Ibn 'Ādil, $n^{\circ}$ 74), tantôt pour une étude rarement citée dans une production par ailleurs modeste: Bayrāmzāde et son commentaire d'al-Bayḍāwī ( $\left.\mathrm{n}^{\mathrm{o}}{ }_{15}\right)$, alors que cet auteur est généralement associé à une étude de sémantique (ma'ānì). D'autres savants figurent au titre d'une contribution majeure: Hwānd Amīr (m. 942/1535-1536) pour sa grande histoire générale de l'Iran ( $\left.{ }^{\circ}{ }^{4} 8\right)$; al-Muțarrizī (m. 610/1213) pour son lexique juridique ( $\left.\mathrm{n}^{\circ} 55\right)$; al-Ğawharī (m. ca 396/1005) pour son diction-

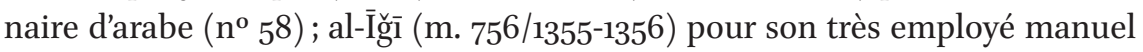
de théologie (no 61) ; Mollā Hü̈rsev (m. 885/148o) pour son œuvre dogmatique (no 68) ; Kaậizāde (m. ca 835/1432) pour son commentaire de manuel d'astronomie $\left(\mathrm{n}^{\mathrm{o}} 71\right)$. À l'inverse, des polygraphes sont cités pour un livre secondaire de leur corpus (Lāmi'î Çelebi, m. 938/1531-1532, no 6 ; al-Bag̉awì, m. 516/1122, no 7 ; al-Suyūṭī, no 41 ; Abū l-Layț al-Samarqandī, no 43 ; al-Ša 'rānī, m. 973/15651566, no 51; al-Zamahšarī, m. 538/1143-1144, no 56 ; Kemālpaşazāde, no ${ }^{\circ} 1$ ), tandis que d'autres, principalement distingués par une activité intellectuelle particulière, ont également produit des commentaires variés dans d'autres disciplines : maître du rubāi dans la littérature turque, le poète 'Azmīzāde Hâaletī (m. 1040/1631) est cité ici au titre d'un commentaire de figh ( $\left.n^{\circ} 69\right)$, alors que le juriste chaféite al-Ǧārabardī (m. 746/1345-1346) est mentionné pour le commentaire qu'il a proposé de la célèbre étude de morphologie d'Ibn al-Ḥāğib $\left(\mathrm{n}^{\mathrm{o}} 75\right)$.

Si les ouvrages de la liste ne sont pas toujours les plus prestigieux et si les auteurs mentionnés ne sont pas les plus incontournables dans les classements des sciences islamiques, au moins sont-ils considérés comme des écrits utiles aux yeux de pédagogues soucieux de mettre à la disposition de leurs meilleurs étudiants, futurs nāàibs, enseignants et muftis provinciaux, des instruments de travail tenus pour dignes de foi en dépit des erreurs qui y ont été repérées - on en trouverait même dans le célèbre dictionnaire d'al-Ğawharī $\left(\mathrm{n}^{\circ} 5^{8}\right)$. Si le commentaire d'al-Ḥaskafî ( $\left.n^{\circ} 101\right)$ s'impose en madrasa, c'est qu'il sert de manuel de référence autant aux oulémas qui y enseignent qu'aux cadis qui rendent leur jugement dans les tribunaux ${ }^{126}$. C'est aussi que les enseignants utilisent des textes qu'ils ont eux-mêmes lus et appris dans leurs années de formation, selon des méthodes pédagogiques associées à de prestigieuses chaînes de transmission (silsile) indiquées dans leurs licences d'enseignement - les plus solides d'entre elles se rattachent à des maîtres et des auteurs tels al-Rāzī l-Taḥtānī

126 Has, «The Use of Multaqa'l-abhur in the Ottoman Madrasas and in Legal Scholarship », p. 403-405. 
(m. 766/1364; no 73), al-Taftāzānī (no 62, 65) ou al-Ğurğānī (no 61) (n) $^{127}$. Ce serait une double différence avec l'époque mamelouke : le concept de «livres de haute réputation » (kütüb-ı mu'tebere) gouverne les classifications ottomanes; des firmans imposent aux étudiants et aux enseignants qui les forment d'étudier les disciplines et leurs instruments dans un certain ordre ${ }^{128}$; il est attendu des muftis qu'ils fassent usage des livres les plus considérés du fiqh (kütüb-ı mu'teberāt-l fikhiye) et qu'ils les citent dans leurs fatwas ${ }^{129}$. Les ouvrages imposés dans les autres disciplines varient selon les rangs des madrasas (définies en fonction des salaires quotidiens des enseignants, 20 aspres [yirmili], 30 aspres [otuzlu], etc.). Ainsi, dans les madrasas à 30 aspres, le commentaire du Miftāh al-uuùm habituellement retenu en cours de rhétorique est celui d'al-Taftāzānī ( $\left.\mathrm{n}^{\circ} 64\right)$, alors que celui d'al-Ǧurğānī ( $\mathrm{n}^{\circ}$ 61) est employé dans les mosquées à 40 aspres $^{130}$. Si c'est le commentaire d'al-Ḥaskafì ( ${ }^{0}{ }^{0}$ 101) que Halīl Ḥamīd Pacha met à la disposition des étudiants, c'est qu'il s'agit du plus employé, au point d'être traduit et commenté en turc dès le $\mathrm{XI}{ }^{\mathrm{e}} / \mathrm{XVII}^{\mathrm{e}}$ siècle ; c'est aussi qu'il se distingue par le regard critique qu'il pose sur les sources de la littérature hanéfite. Néanmoins, parmi la cinquantaine de commentaires suscités par le Multaqā, d'autres études auraient pu également convenir ${ }^{131}$. En vérité, les commentaires disponibles sont assez nombreux pour que les autorités de la 'ilmiyye laissent les enseignants choisir ceux d'entre eux qu'ils préfèrent étudier ${ }^{132}$.

127 Sur l'étude de ces auteurs dans les premières madrasas ottomanes, voir Bilge, İlk Osmanlı Medreseleri, p. 43. Pour des exemples de silsile indiquées dans les icāzetnāme rattachées à des maîtres dont plusieurs sont signalés ici (tel Dawanī, no 66), voir Ebül'ulâ Mardin, Huzûr Dersleri, Istanbul, İsmail Akgün Matbaası, 1966, II et III, p. 645-76o ; Yakuboğlu, Osmanlı Medrese Eğitimi ve Felsefesi, p. 53-54, p. 56, p. 59-70. Pour des silsile d'icāzetnāme de jurisconsultes et théologiens, voir Atay, «Fatih-Süleymâniye Medreseleri Ders Programlanı ve İ́azet-nameler », p. 197-200 ; id., Osmanlılarda Yüksek Din Eğitimi, p. 116128. Voir aussi Has, «The Use of Multaqa'-abhur in the Ottoman Madrasas and in Legal Scholarship », p. 395-396.

128 Sur la canonisation de textes de droit validée par le souverain en 1565, voir Ahmed et Filipović, «The Sultan's Syllabus»; Burak, The Second Formation of Islamic Law, p. 124-125, 133 .

129 Pehlül Düzenli, « Osmanlı Fetvâsında 'Muteber Kaynak' ve 'Müftâ Bih Mesele' Problemi », Türkiye Araştırmaları Literatür Dergisi, 11/22 (2013), p. 9-78; Aykan, Rendre la justice à Amid, p. 171.

130 Baltacı, XV.-XVI. Asırlarda Osmanlı Medreseleri, I, p. 87-88; Uzunçarşılı, Osmanlı Devletinin İlmiye Teşkilatı, p. 50-51.

131 Şükrü Selim Has, « Mülteka'l-ebhur », Türkiye Diyanet Vakfi İslam Ansiklopedisi, 31 (2006), p. 549-552.

132 Mefail Hızl, « Osmanlı Medreselerinde Okutulan Dersler ve Eserler », Uludağ Üniversitesi İlahiyat Fakültesi Dergisi, 17/1 (2008), p. 25-46, p. 41. 
Ne négligeons pas, Halīl Ḥamīd ne les négligeait pas, les productions littéraires ottomanes et leurs grands auteurs: Mollā Hüsrev, qualifié par le sultan Fātiḥ Meḥmed, au titre de ses études de figh (no 68), de «Abū Ḥanīfa de son temps » ${ }^{133}$; Hạâletī, non seulement le maître du rubā̄ĭ, je l'ai dit, mais un auteur et traducteur de traités religieux qui avait puisé un immense savoir dans les 4000 volumes de sa bibliothèque qu'il annotait constamment ${ }^{134}$ celle de Mü’eyyedzāde (m. 922/1516; no 82) franchit le nombre jamais atteint jusqu'alors de 7 ooo volumes ${ }^{135}$; Kemālpaşazāde ( $n^{\circ}$ 91), auteur d'une œuvre considérable rédigée en arabe, turc et persan, en histoire, droit, théologie, philosophie, grammaire et poésie ; Ebu-s-su ūd ( ${ }^{\circ}$ 8), admiré par ses contemporains pour son savoir et son éloquence, lui «l'orateur des exégètes » (hațīb al-mufassirin $)^{136}$ - des biographes n'hésitent pas à placer son commentaire au niveau des exégèses d'al-Zamahššrī $\left(n^{\circ}{ }_{5}^{6}\right)$ et d'al-Bayḍāwī $\left(n^{\circ} 1\right)^{137}$.

Tout de même, à l'échelle de l'Islam, que pèse l'œuvre d'Ebu-s-su'ūd face à celle de l'imposant al-Suyūțī $\left(n^{\circ} 23,41,5^{2}\right)$ - le lettré cairote se dit l'auteur de 300 ouvrages, mais les historiens Ibn Iyās (m. ca 930/1524) et Wağīh al-Dīn 'Abd al-Raḥmān b. al-Šaybānī l-Šāfici connu comme Ibn al-Daybac (m. 944/1537) lui en attribuent respectivement le double et le triple ${ }^{138}$. Sans parler des immensément prolifiques Ibn al-Ǧawzī (n $\left.{ }^{\text {o }} 3^{6}\right)^{139}$ et Qārī $\left(\mathrm{m} .1014 / 1605 ; n^{\circ} 24\right)^{140}$. Au

133 M. Hüdai Şentürk, Künhül'-Ah̆bār, II, Fätịh Sulțān Meḥmed Devri, 1451-1481, Ankara, Türk Tarih Kurumu, 2003, p. 187-188.

134 Halûk İpekten, « Azmîzâde Mustafa Hâletî », Türkiye Diyanet Vakfı İslam Ansiklopedisi, 4 (1991), p. 348-349.

135 Tayyib Gökbilgin, « Müeyyed-zâde », dans İslam Ansiklopedisi, dir. Adnan Adıvar et al., Istanbul, Maarif Basımevi, 1950-1986, 13 vols, VIII [1979], p. 786-79o, p. 79 o.

${ }_{13} 6$ Shuruq Naguib, «Guiding the Sound Mind: Ebu's-su'ūd's Tafsir and Rhetorical Interpretation of the Qur'an in the Post-Classical Period», Osmanlı Araştırmaları, 42 (2013), p. 1-52, p. 4.

137 Colin Imber, Ebu's-su'ud: The Islamic Legal Tradition, Stanford University Press («Jurists: Profiles in Legal Theory »), 1997, p. 11, 18.

138 Jean-Claude Garcin, «Histoire, opposition politique et traditionaliste dans le Husn al-muhạḍarat de Suyūṭī », Annales islamologiques, 7 (1967), p. 33-9o, p. 38 ; Éric Geoffroy, «Al-Suyūțī», $E I^{2}$.

139 Il prétend avoir écrit deux mille volumes (Eche, Les bibliothèques arabes publiques et semi-publiques en Mésopotamie, en Syrie et en Égypte au Moyen Âge, p. 284).

140 Patrick Franke, «The Ego of the Mullah: Strategies of Self-Representation in the Works of the Meccan Scholar 'Alī al-Qārī (d. 16o6) », dans Many Ways of Speaking about the Self: Middle Eastern Ego Documents in Arabic, Persian, and Turkish (14th-2oth Century), éds Ralf Elger et Yavuz Köse, Wiesbaden, Harrassowitz («Mîzân », 18), 2010, p. 185-200, p. 187-188 (pour une typologie de 124 de ses travaux). 
bout des chaînes de transmission du savoir, que représente le commentaire (pas assez exceptionnel pour être identifié) d'un résumé (le Ğāmic al-ṣagīir d'al-Munāwī, m. 1031/1621-1622; no 23) d'une œuvre à la fois majeure et inachevée, le Ğam'al-ğawāmi', dernière grande compilation de la tradition prophétique léguée par le même al-Suyūṭi ? À l'échelle ottomane, vu d'Istanbul, peut-être a-t-on surestimé le poids d'Ebu-s-su'ūd, sans cesse rappelé, idéologiquement plus que pratiquement, à son statut de «plus connu des şeyhülislam ottomans $»^{141}$ et à son $\operatorname{tafsĭ}\left(\mathrm{n}^{\circ} 8\right)$, «le tefsir le plus célébre écrit à l'époque ottomane »142 ? Peut-être a-t-on sous-estimé à l'inverse l'ampleur des contributions de Mollā Hüusrev (salué par une fatwa signée de la main du précédent), non seulement dans la réflexion théorique en matière d'ușūl al-figh ${ }^{143}$, mais également dans l'exercice, pratique et provincial, du droit ottoman? En tout cas, les spécialistes n'ont pas fini de mesurer l'importance de son Gurar al-ạkām $\left(\mathrm{n}^{\mathrm{o}} 86\right)^{144}$.

C'est entendu: aux yeux du public des lecteurs et des fondateurs de bibliothèques, les dépôts de l'époque moderne n'ont ni la pureté ni la solidité des roches médiévales. Halīl Hamīd qui veut de «beaux livres » pour sa madrasa le pense certainement: il privilégie les seconds dans sa donation. Faut-il souligner davantage encore cet écart par la prise en compte de la nature des ouvrages? Le contraste, en effet, est plus net encore si l'on regarde les choses ainsi : côté pré-ottoman, 11 commentaires sur 55 titres; côté ottoman, 22 commentaires sur 33 titres. Autrement dit, comme écrivains de langue arabe, les Ottomans figurent ici davantage comme des glosateurs et des interprètes que comme des auteurs de compositions «originales» $\left(t e^{\prime} l i f f\right)$. Encore, ces dernières ont un caractère compilatoire : quatre recueils de fatwas $\left(\mathrm{n}^{\circ} 79,81,82\right.$, 83), deux ouvrages de tafsìr ( $\left.\mathrm{n}^{\circ} 8,9\right)$, un manuel de soufisme ( $\left.\mathrm{n}^{\circ}{ }^{1}\right)$, un recueil de țabaqāt ( $\mathrm{n}^{\circ} 53$ ), un manuel de fiqh ( $\left.\mathrm{n}^{\circ} 86\right)$, un ouvrage d'ușūl (no 68 ) et un dictionnaire arabe-turc ( $\left.{ }^{\circ} 59\right)$.

Bipartition des périodes, bipartition des savants? À mettre en valeur la polymathie des auteurs de l'époque médiévale, à citer ces jurisconsultes qui sont aussi traditionnistes, ces grammairiens qui sont aussi historiens et ces théologiens qui sont aussi philosophes, on se détourne d'autant plus des

\footnotetext{
141 Colin Imber, «Ebussuud », dans Dictionnaire de l'Empire ottoman, éds François Georgeon, Nicolas Vatin et Gilles Veinstein, Paris, Fayard, 2015, p. 388.

142 Unan, «The Ottoman Ulema », p. 848 ; ma traduction.

143 Sur ses contributions, voir Atçll, « Greco-Islamic Philosophy and Islamic Jurisprudence in the Ottoman Empire (1300-160o)», p. 43-45.

144 Y. Aykan s'y emploie actuellement. Je le remercie d'en avoir discuté avec moi.
} 
lettrés ottomans qui, à force d'être à ce point stambouliotes de l'Empire ${ }^{145}$, en seraient devenus des provinciaux de l'Islam, en marge de configurations dynamiques du savoir portées par des traditionnistes et des soufis actifs du Yémen à l'Égypte ${ }^{146}$. Irrémédiablement "pétrifiés » dans un « highly conservative 'establishment' » engoncé dans « l'institutionnalisation du privilège » ${ }^{147}$, les grands mollas du XII ${ }^{\mathrm{e}} / \mathrm{XVIII}{ }^{\mathrm{e}}$ siècle se seraient écartés pour de bon de l'idéal du savant omniscient ('alìm-i kül) que leurs prédécesseurs s'étaient assigné dans les premières madrasas ottomanes d'Anatolie occidentale, à la fois pôles d'attraction de scientifiques orientaux et lieux de formation de lettrés locaux de Rūm ${ }^{148}$. En vérité, peu de lignées de savants naissent des dynasties de grands oulémas - on aperçoit ici deux d'entre elles, les Kara Dāvūdzāde ( ${ }^{\circ}$ 73) et les Minḳārīzāde $\left(n^{\circ} 79\right)^{149}$. Ces traits dominants sont confirmés par plusieurs études ${ }^{150}$. Mais à lire le détail de l'inventaire de la bibliothèque de Burdur, on met le doigt sur des réalités culturelles différentes.

En ce jadis siècle de déclin des lettres ottomanes redoré, il y aura bientôt trente ans, en siècle d'Aufklärung islamique, des productions intellectuelles manifestent le dynamisme d'une activité scripturaire fortement imprégnée des logiques complémentaires (les appuis mutuels entre traditions prophétiques et confrériques) de transmissions du ${ }^{i} \mathrm{~lm}^{151}$. Les grands oulémas sont sans doute

145 Sur les origines géographiques des grands mollas, voir Madeleine Zilfi, « Elite Circulation in the Ottoman Empire: Great Mollas of the Eighteenth Century »,Journal of the Economic and Social History of the Orient, 26 (1983), p. 318-363, p. 324-326.

146 Francis Robinson, «Ottoman-Safawids-Mughals: Shared Knowledge and Connective Systems », Journal of Islamic Studies, 8/2 (1997), p. 151-184, p. 173.

147 Madeleine Zilfi, The Politics of Piety: The Ottoman Ulema in the Postclassical Age (1600180o), Minneapolis, Bibliotheca Islamica («Studies in Middle Eastern History », 8), 1988, p. 51, p. 54 .

14827 madrasas ottomanes furent construites au VIII $/ \mathrm{XIV}^{\mathrm{e}}$ siècle et 96 au IX $/ \mathrm{XV}^{\mathrm{e}}$ siècle (Atçll, «Mobility of Scholars and Formation of a Self-Sustaining Scholarly System in the Lands of Rūm during the Fifteenth Century », p. 318; Gül, Osmanlı Medreselerinde Eğitim-Öğretim ve Bunlar Arasinda Dâru'l-Hadîslerin Yeri, p. 36-57).

149 Yllmaz Öztuna, Devletler ve Hânedanlar: Türkiye (1074-1990), Ankara, Kültür ve Turizm Bakanlığı, 2005, II, p. 779-780.

150 Zilfi, «Elite Circulation in the Ottoman Empire», p. 320, p. 326-327; Denise Klein, Die osmanischen Ulema des 17. Jahrhunderts: Eine geschlossene Gesellschaft?, Berlin, Klaus Schwartz («Islamkundliche Untersuchungen», 274), 2007, p. 90-97 (pour une étude quantitative de la mobilité sociale et géographique d'oulémas du XI $/ \mathrm{XVII}^{\mathrm{e}}$ siècle).

151 Pour une mise au point sur le débat autour des positions de Reinhard Schulze, « Das islamische achtzehnte Jahrhundert: Versuch einer historiographischen Kritik », Die Welt des Islams, 30/1(1990), p.140-159, voir Radtke, « Sufism in the 18th century »;Stefan Reichmuth, «Arabic Literature», Die Welt des Islams, 42/3 (2002), p. 281-288; Mayeur-Jaouen, «À la poursuite de la réforme », p. 341-343. Sur la «stagnation » de la théologie philosophique à partir du $\mathrm{x}^{\mathrm{e}} / \mathrm{XVI}^{\mathrm{e}}$ siècle, voir W. Montgomery Watt, Islamic Philosophy and Theology, 
moins productifs que par le passé152. Mais partout dans l'Empire, on analyse et on commente des ouvrages lus à plusieurs. Partout, on copie et on annote les écrits d'auteurs importants, certes prolifiques (al-Bābartī, m. 786/1384, dont on connaît au moins une quarantaine d'œuvres), mais célèbres avant tout pour tel commentaire (celui du Hidāya, ${ }^{\circ}$ 92) ${ }^{153}$. Ils ne comptent pas pour rien ces pédagogues répertoriés dans les țabaqāt au titre principal de leurs annotations analytiques ou synthétiques, tel un Kara Sinān dont le commentaire ( $\mathrm{n}^{\circ}$ 99) s'ajoute aux très nombreuses gloses suscitées par le Wiqāya de Șadr al-Šarī‘a (m. 747/1346-1347 $)^{154}$. Il faut les citer ces éveilleurs désireux de placer leur vaste érudition au service de jeunes talents qui cherchent à percer (Mü’eyyedzāde, $n^{o} 82$; İbn Kemāl, no 91$)^{155}$.

Tout travail apporte sa pierre à l'édifice de la tradition islamique : même noyés dans la masse des centaines de commentaires et études suscités par le monument exégétique d'al-Bayḍāwīis6, les gloses de la sourate 6 («Les bestiaux») par Bostān Çelebi (m. 977/1569-1570; no 16) et de la sourate 7 («Les redans ») par Bayrāmzāde ( $\left.{ }^{\circ} 15\right)$ éclairent les jeunes et moins jeunes gens qui, à l'approche du grand œuvre, s'inquiéteraient de la longueur du chemin à accomplir vers la «Voie muhammadienne » ${ }^{157}$. Il est du reste intéressant de se demander, note Asad Q. Ahmed, pourquoi tel commentateur a choisi de se

Édimbourg, Edinburgh University Press, 1985, p. 133-134. Pour un examen critique de cette théorie, voir El-Rouayheb, Islamic Intellectual History in the Seventeenth Century, p. 347349 ; Lejla Demiri et Samuela Pagani, « 'Abd al-Ghanī al-Nābulusī and the Intellectual and Religious History of the 17th and 18th Century World of Islam », dans Early Modern Trends in Islamic Theology, éds Demiri et Pagani, p. 2.

$15^{2}$ Voir les indications chiffrées entre la fin du $\mathrm{IX}^{\mathrm{e}} / \mathrm{XV}^{\mathrm{e}}$ siècle et le XII $/ \mathrm{XVIII}^{\mathrm{e}}$ siècle produites par F. Unan pour la Șaḥn Medresesi (Kuruluşundan Günümüze Fâtih Külliyesi, p. 359-366; id., «The Ottoman Ulema», p. 846-847). Sur les disciplines et auteurs enseignés dans cette madrasa voir Unan, Kuruluşundan Günümüze Fâtih Külliyesi, p. 322-356.

153 Sur les pratiques de copie et de prise de notes, voir Tülün Değirmenci, «Bir Kitabı Kaç Kişi Okur? Osmanlı'da Okurlar ve Okuma Biçimleri Üzerine Bazı Gözlemler», Tarih ve Toplum Yeni Yaklaşımlar, 13/253 (2011), p. 7-43, p. 37-39.

154 Şükrü Özen, «Sadrüşşerîa », Türkiye Diyanet Vakfi İslam Ansiklopedisi, 35 (2008), p. 427431, p. 429 .

155 F. Unan a répertorié 290 enseignants au sein de la Șahnn Medresesi qui auraient rédigé des travaux écrits (520 au total) dans les trois dernières décennies du $\mathrm{IX}^{\mathrm{e}} / \mathrm{XV}^{\mathrm{e}}$ siècle et au $\mathrm{X}^{\mathrm{e}} /$ $\mathrm{XVI}^{\mathrm{e}}$ siècle (Unan, «The Ottoman Ulema», p. 846).

${ }_{15} 6$ Plus de 25 o selon İsmail Cerrahoğlu, «Envârü’t-tenzîl ve esrârü't-te'vîl », Türkiye Diyanet Vakfi İslam Ansiklopedisi, 11 (1995), p. 26o-261.

157 J'ai déjà évoqué les multiples commentaires suscités par l'œuvre d'al-Bayḍawī. Brockelmann en dénombre sept: Carl Brockelmann, Geschichte der arabischen Litteratur, Leyde, E.J. Brill, 1937-1949, SII, p. 308, 322, 529, 639, 647, 65o, 659 . 
concentrer sur tel texte ou sur telle partie d'un texte en particulier ${ }^{158}$. De même qu'il est intéressant de comprendre, ajoute Harun Anay, «pourquoi certains commentaires sont devenus très connus; pourquoi un grand nombre de personnes ont ressenti le besoin d'écrire un commentaire sur telle ouvre ${ }^{159}$. Chercher à répondre à ces questions implique d'évaluer les livres non pas seulement à l'aune de la solidité de leur réputation et à la mesure du degré de leur excellence littéraire, mais à l'échelle de leur degré de diffusion - du commentaire de la sourate 67 («La royauté », $n^{\circ} 12$ ) par Sā'dì Çelebi, on trouvait des copies partout, de Damas à Bagdad, en passant par Le Caire ou Sarajevo -; et, par voie de conséquence, de déterminer le rôle que jouaient ces études et commentaires dans la vie des Ottomans, dans la pratique des obligations rituelles comme dans l'exercice de la justice - c'est la démarche d'un nombre croissant d'historiens du droit comme du soufisme ${ }^{160}$. On mesure alors que les textes les plus « créatifs » ne sont pas nécessairement les plus « influents » et vice-versa ${ }^{161}$. On se dit qu'il serait injuste de projeter une distinction si tranchée sur l'ensemble des savants des temps ottomans et de présupposer que ceux-ci se contentèrent de reproduire ce qui existait avant eux, comme si les travaux de Lāmi'ī Çelebi ( $n^{\circ}$ 6) n'étaient rien d'autre que les adaptations en turc des productions de 'Abd al-Raḥmān Ğāmīin' ${ }^{162}$.

Imaginons plutôt la possibilité d'une histoire des échanges culturels, au Proche-Orient, en Asie centrale et au-delà̀ ${ }^{163}$. Prenons ce commentaire de İbn

158 Asad Q. Ahmed, « Post-Classical Philosophical Commentaries/Glosses: Innovation in the Margins », Oriens, 41/3-4 (2013), p. 317-348, p. 320.

159 Harun Anay, «Bir Osmanlı Düşüncesinden Bahsetmek Mümkün mü ? », Dergâh :Edebiyat Sanat Kültür Dergisi, 6/76 (1996), p. 12-14, p. 13, ma traduction du turc.

16o Baber Johansen, « Legal Literature and the Problem of Change», dans Islam and Public Law, éd. Chibli Mallat, Londres, Graham and Trotman («Arab and Islamic Laws Series »), 1993, p. 31-47 ; Gerber, Islamic Law and Culture 1600-1840, p. 97-104 ; Chih et Mayeur-Jaouen, «Introduction », p. 21.

161 "A commentary is "influential" when it enjoys a wide distribution. A simple measure for this is to see how many manuscript copies survived and how much the text was cited by later authors. Corollary: the restricted commentary tradition forms the backbone of the commentary tradition; they are the most widely circulated and read texts of this set, and thus the most influential. This does not imply they are the most creative texts of the commentary tradition». L.W.C. (Eric) Van Lit, « Commentary and Commentary Tradition: The Basic Terms for Understanding Islamic Intellectual History », Mélanges de l'Institut dominicain d'études orientales, $3^{2}$ (2017), p. 3-26, p. 19.

162 Günay Kut Alpay, « Lamiî Chelebi and His Works », Journal of Near Eastern Studies, 35/2 (1976), p. 73-93; Nuran Tezcan, « Câmî-i Rûm Olarak Lâmiî Çelebi », Journal of Turkish Studies, 33/2 (2009), p. 159-179.

163 Cette possibilité est illustrée par le très remarquable article de Hamid Algar, «Jāmī and the Ottomans », dans Jāmī in Regional Contexts: The Reception of 'Abd al-Raḥmān Jāmì's Works in the Islamicate World, ca. 9th/15th-14th/2oth Century, éds Thibaut d'Hubert et 
Melek (m. ap. 821/1418-1419; $\mathrm{n}^{\circ}$ 63) apporté aux Mašārīq al-anwār al-nabawiyya d'al-Ṣāgāaī (m. 650/1252). Il offre un accès nouveau à ce qui est la première contribution médiévale indienne à la littérature du hadith, façonnée à partir des recueils d'al-Buhārī et Muslim $\left(\mathrm{n}^{\circ}{ }_{18}\right.$, 19), à un grand nombre d'oulémas ottomans des siècles suivants qui en multiplient les copies. Dans la continuité des siècles passés, une «littérature de contact» se déploie, nourrie des apports d'une «confrontation à l'autre ${ }^{164}:$ au VII ${ }^{\mathrm{e}} / \mathrm{XIII}^{\mathrm{e}}$ siècle, les bibliothèques des madrasas anatoliennes étaient riches d'écrits de savants d'Iran et du Turkestan ${ }^{165} ;$ au IX $/ \mathrm{XV}^{\mathrm{e}}$ siècle, des oulémas venus d'Asie centrale jouèrent un rôle majeur dans l'islamisation des villes nouvellement conquises par les Ottomans ${ }^{166}$. Dans les siècles qui suivent, leurs commentaires se diffusent dans les nouvelles madrasas ${ }^{167}$. Circulations ou mises en contact, comme on veut: quel est le lien entre une région de l'Inde (le Deccan), un bourg de la Haute-Égypte (Esna) et une ville de l'Anatolie méridionale (Burdur)? Le fait que le commentaire du savant Dawlatābādī (m. 849/1445), originaire de la première, rédigé sur le grand traité d'Ibn al-Ḥăğib $\left(n^{\circ}{ }_{76}\right)$ natif du deuxième, se retrouve dans une madrasa de la troisième. Dans l'autre sens, voici le manuel d'astronomie $\left(\mathrm{n}^{\mathrm{o}}{ }^{71}\right)$ du mathématicien bursiote Mūsā Kạạīzāde Rūmī qui se distingua par sa participation à la mise en place de l'observatoire de Samarkande dans la première moitié $\mathrm{du} \mathrm{IX}^{\mathrm{e}} / \mathrm{XV}^{\mathrm{e}}$ siècle. Bref, il y a dans cette collection de manuscrits de Burdur les signes d'« une pensée ottomane » 168 qu'il faut prendre au sérieux. Y résonnent les échos d'un nouveau monde

Alexandre Papas, Leyde-Boston, Brill («Handbuch der Orientalistik. 1. Abt., Der Nahe und der Mittlere Osten», 128), 2018, p. 63-135. Voir aussi Ökten, «Scholars and Mobility»; Atçl, «Mobility of Scholars and Formation of a Self-Sustaining Scholarly System in the Lands of Rūm during the Fifteenth Century». Sur le devenir d'une "communauté internationale de lettrés sunnites» $\mathrm{aux} \mathrm{X}^{\mathrm{e}} / \mathrm{XVI}^{\mathrm{e}}-\mathrm{XII}^{\mathrm{e}} / \mathrm{XVIII}^{\mathrm{e}}$ siècles, voir Robinson, «Ottoman-Safawids-Mughals», p. 157-162. Comme exemple d'intellectuel du XII ${ }^{\mathrm{e} /}$ $\mathrm{XVIII}^{\mathrm{e}}$ siècle connecté à des réseaux étendus de l'Inde à l'Afrique de l'Ouest, voir Stefan Reichmuth, The World of Murtadā al-Zabìdī: 1732-91: Life, Networks and Writings, Oxford, Gibb Memorial Trust, 2009.

164 Pour une comparaison avec une situation proche-orientale, voir Denise Aigle, « Les pays du Levant au carrefour des systèmes de représentation : perspectives d'Orient et d'Occident », dans Le Bilād al-Šām face aux mondes extérieurs : la perception de l'Autre et la représentation du Souverain, éd. ead., Damas-Beyrouth, Presses de l'Ifpo, 2012, p. 11-37, p. 13.

165 Sur «l'iranisation commençante» des Turcs dans l'Asie mineure musulmane au viI ${ }^{\mathrm{e}}$ / XIII ${ }^{\mathrm{e}}$ siècle, voir Claude Cahen, La Turquie pré-ottomane, Istanbul, IFEA («Varia Turcica », 7), 1988, p. 208-214.

166 Bilge, İlk Osmanlı Medreseleri, p. 102-115.

167 Dans l'Empire safavide également: Robinson, « Ottoman-Safawids-Mughals », p. 154-155.

168 Anay, «Bir Osmanlı Düşüncesinden Bahsetmek Mümkün mü ? », p. 12. 
(worldliness $\left.{ }^{169}\right)$ qui méritent d'être écoutés $\left(\mathrm{n}^{0}{ }^{31}\right)$. Comme dans le cas malais, des textes importants « eurent une vie après la mort (commentée) au-delà de la logosphère arabe ${ }^{170}$.

Il n'est pas difficile de comprendre pourquoi les lettrés ottomans ont valorisé à ce point la production de commentaires et de gloses, pourquoi des auteurs tel Birgili Kara Halīl Efendī (m. 1123/1711; n $\left.{ }^{\circ} 73\right)$ y ont consacré tout leur temps et épuisé les réserves de leur énergie intellectuelle ${ }^{172}$. D’abord, ils ont utilisé ces commentaires comme autant d'outils pédagogiques: en classe, des notes sont prises à partir d'un cours oral ou de la lecture d'un texte, car la lecture et l'écriture sont enseignées et pratiquées ensemble ${ }^{173}$; ces notes font ensuite la matière ultérieure d'un commentaire; des commentaires sont collationnés pour servir de manuels; puis, dans les marges de ces manuels, des annotations (hăşsiye) sont ajoutées ${ }^{174}$; à leur tour, elles sont utilisées pour constituer un manuel supplémentaire, reproduit ou non; des commentaires et des gloses d'époques différentes sont lus et font l'objet de discussions prolongées ${ }^{175}$. L'important est de lire et d'écrire - de lire ensemble, d'écrire ensemble - des

169 Reichmuth, «Arabic Literature », p. 282, mes traductions de l'anglais.

170 Bruckmayr, «The Šarh /Ḥāšiya Phenomenon in Southeast Asia from al-Sanūsì's Umm al-Barāhin to Malay Sifat Dua Puluh Literature», p. 46, ma traduction de l'anglais.

171 Des collègues (Ahmed et Larkin, « The Ḥāshiya and Islamic Intellectual History », p. 213) choisisent de traduire šarh et hăş̧iya par commentaire, tout en reconnaissant que les deux termes sont synonymes. À l'instar d'İ. Erünsal («Ottoman Foundation Libraries », p. 77) et de C. Mayeur-Jaouen (que je remercie pour ses indications), je traduis šarh par commentaire et hāšizya (qui peut aussi avoir le sens de postscriptum ou d'annotation) par glose. Je remercie Y. Aykan d'en avoir discuté avec moi. Voir Zubčević, Book Ownership in Ottoman Sarajevo 1707-1828, p. 158-159 (traduit hāašiya par « supercommentaire » ou « commentaire de commentaire »); Tevfik Rüştü Topuzoğlu, « Hâşiye », Türkiye Diyanet Vakfı İslam Ansiklopedisi, 16 (1997), p. 419-422 (avec une présentation par genres; plusieurs des gloses du corpus y sont présentées); Sedat Şensoy, «Şerh», Türkiye Diyanet Vakfi İslam Ansiklopedisi, 38 (2010), p. 555-558. Sur les relations entre teliff, hạş̧iye et şerh dans la littérature ottomane, voir Anay, « Bir Osmanlı Düşüncesinden Bahsetmek Mümkün mü ? », p. 13.

172 El-Rouayheb, Islamic Intellectual History in the Seventeenth Century, p. 23-24.

173 Konrad Hirschler, The Written Word in the Medieval Arabic Lands: A Social and Cultural History of Reading Practices, Édimbourg, Edinburgh University Press, 2013, p. 94.

174 Pour une approche de notes manuscrites de divers types comme sources documentaires, voir Andreas Görke et Konrad Hirschler (éds), Manuscript Notes as Documentary Sources, Beyrouth-Würzburg, Orient Institut-Ergon («Beiruter Texte und Studien », 129), 2011.

175 Abdullah Yormaz, «Muhalif Bir Metin Nasıl Okunur? Osmanlı Medreseleri'nde Hidâyetü'l-Hikme », DÎVÂN İlmî Araştırmalar, 18 (2005), p. 175-192, p. 192. 
textes; et chacun se fait alors auteur, car « les auteurs n'écrivent pas des livres: non, ils écrivent des textes que d'autres transforment en objets manuscrits » ${ }^{176}$. Ensuite, des lettrés ottomans ont employé les commentaires afin d'assurer la domination de curricula et prolonger les chaînes d'autorité dont ils se voulaient les garants. Ce faisant, ils se sont inscrits dans la continuité des sciences islamiques : le Šarh al-'aqā'id composé par al-Taftāzānī (nº 65$)$, commentaire d'une forme abrégée de credo, les 'Aqā̉id du savant maturidite Nağm al-Dīn al-Nasafì (m. 537/1142), ont été commentés par des dizaines de lettrés et très largement enseignés en madrasa ${ }^{177}$. À leur tour, les commentaires des commentaires ${ }^{178}$ ont suscité de nouveaux commentaires (des super-super-commentaires ${ }^{179}$ ): Birgili Kara Halīl Efendī $\left(\mathrm{n}^{\mathrm{o}} 73\right) \rightarrow$ Hā̌šiya 'alā Šarh Mațāli' al-anwār de Kara Dāvūd (m. 948/1541) $\rightarrow$ Šarḥ Maṭāli' al-anwār de Maḥmūd b. 'Abd al-Raḥmān al-Iṣfahānī (m. 749/1349) $\rightarrow$ Mațāli' al-anwār, ouvrage de logique de Sirāğ al-Dīn al-Urmawī (m. 682/1283). Il est en revanche plus difficile d'interpréter les enjeux qui entourent les arborescences de l'autorité scientifique.

Longtemps, il a été dit que les šarh et ḥāšiya n'avaient « rien d'original ou d'innovant», qu'ils témoignaient d'une «stagnation et d'un déclin des traditions intellectuelles islamiques ${ }^{180}$, que la connaissance des corpus se perdait dans l'immense littérature biographique, que le savoir s'abîmait dans la fragilité des chaînes de transmission et que les empilements de commentaires, dérivés et répétitifs, étaient autant d'obstacles à l'interprétation d'œuvres originales ${ }^{181}$. Même écrit par l'important Kemālpaşazāde, le commentaire de

176 Roger Chartier, Culture écrite et société : l'ordre des livres : XIV -XVIII e siècle, Paris, Albin Michel («Bibliothèque Albin Michel. Histoire»), 1996, p. 140.

177 Kātip Çelebi en répertorie 5o gloses (Yakuboğlu, Osmanlı Medrese Eğitimi ve Felsefesi, p. 163-168).

178 Sur la «généalogie des textes», voir Brinkley Morris Messick, The Calligraphic State: Textual Domination and History in a Muslim Society, Berkeley, University of California Press («Comparative Studies on Muslim Societies », 16), 1993, p. 176.

179 Van Lit, « Commentary and Commentary Tradition», p. 17.

180 Ahmed et Larkin, « The Ḥāshiya and Islamic Intellectual History », p. 213 (mes traductions de l'anglais). Sur la culture du commentaire comme indice d'absence de renouvellement de la pensée, voir Gustave E. von Grunebaum (éd.), Classicisme et déclin culturel dans l'histoire de l'islam: actes du symposium international d'histoire de la civilisation musulmane, Bordeaux, 1956, Paris, Maisonneuve, 1957 ; Watt, Islamic Philosophy and Theology, p. 134. Pour une discussion critique, voir Bruckmayr, «The Šarh /Hā̌šiya Phenomenon in Southeast Asia from al-Sanūsīs Umm al-Barāhīn to Malay Sifat Dua Puluh Literature », p. 29; Chih et Mayeur-Jaouen, «Introduction», p. 9-13, p. 21-22 ; al-Musawi, The Medieval Islamic Republic of Letters, p. 97-99.

181 Sur les critiques des pratiques de commentaire en sciences islamiques dans la culture écrite ottomane des $\mathrm{XIII}^{\mathrm{e}} / \mathrm{XIX}^{\mathrm{e}}$-XIV $^{\mathrm{e}} / \mathrm{XX}^{\mathrm{e}}$ siècles, voir İsmail Kara, "'Unuttukların Hatırla!' Şerh ve Haşiye Meselesine Dair Birkaç Not », Dîvân, 15/28 (2010), p. 1-67. 
l'incontournable al-Hidāya d'al-Margīnānī (m. 593/1196-1197; no 91) ne faisait, au bout du compte, que s'ajouter aux dizaines de gloses et surcommentaires précédents ${ }^{182}$, voisinant dans les armoires des bibliothèques avec les commentaires d'autres classiques, d'al-Niqāya de Șadr al-Šarī'a (no 89) au manuel de figh d'al-Qudūrī (m. 428/1037; al-Muhtașar), en passant par le Kanz al-daqā̉iq d'al-Nasafì (no $\left.{ }^{\circ} 6\right)$. En matière de figh, les muftis recouraient à des chaînes de renvoi pour authentifier les sources du droit et légitimer la transmission du savoir juridique en conformité avec les cadres de la doctrine hanéfite ${ }^{183}$. Il fallait en tirer les conclusions nécessaires: dans la foulée de Nağm al-Dīn al-Ṭarsūsī (m. 758/1357; nº 9o), le jurisconsulte hanéfite Huayr al-Dīn al-Ramlī (m. 1081/1671) recommandait de privilégier les textes d'autorité (mutūn) aux commentaires et aux recueils de fatwas ${ }^{184}$.

On voit désormais les choses autrement: pour les lecteurs qui les manipulent, les hypertextes ne sont pas nécessairement perçus comme inférieurs aux hypotextes (pour reprendre les distinctions proposées, parmi d'autres spécialistes, par Eric Van Lit ${ }^{185}$ ). Ils enrichissent au contraire l'œuvre commentée, non pour créer de nouvelles normes, mais pour pérenniser la tradition et « adapter les "anciennes" normes en fonction des circonstances changeantes de l'histoire ${ }^{186}$. Un commentateur insistera ainsi sur tel chapitre, en phase avec les enjeux du temps, pour laisser de côté des développements qui, à ses yeux, n'ont plus la pertinence d'antan ${ }^{187}$. Les Matālic al-anwār précités sont très employés pendant le siècle qui suit leur rédaction, à la suite de quoi il n'en est plus étudié que la première partie qui expose les problèmes introductifs, l'acquisition des conceptions (tașawwurāt) et surtout le commentaire qu'en

182 Brockelmann, Geschichte der arabischen Litteratur, I, p. 644-649.

183 Aykan, Rendre la justice à Amid, p. 176, 221. Sur la question des textes d'autorité et le développement d'une «Canon Consciousness » en contexte impérial hanéfite, voir Burak, The Second Formation of Islamic Law, p. 130-135.

184 Guy Burak, The Abü Haniffah of His Time: Islamic Law, Jurisprudential Authority and Empire in the Ottoman Domains (16th-17th Centuries), PhD, New York University, 2012, p. 241.

185 El-Rouayheb, Islamic Intellectual History in the Seventeenth Century, p. 33-34 au sujet de Dawānī ( $\mathrm{n}^{\circ}$ 66) et de Isfarāyīnī ( $\mathrm{n}^{\circ}$ 13); Mayeur-Jaouen, «La Sìra ḥalabiyya »; Van Lit, "Commentary and Commentary Tradition », p. 4-5, p. 13-14.

186 Sur l'entretien et la revification des sciences légales par les šurūḥ, voir Éric Chaumont, «L'autorité des textes au sein du šāfíisme ancien», Mélanges de l'Institut dominicain d'études orientales, 32 (2017), p. 54-62, p. 59. Sur le «shurūh phenomenon» comme réponse à des exigences de « 'cultural script' to fit into acceptable cultural norms » en théologie, voir al-Musawi, The Medieval Islamic Republic of Letters, p. 111-112.

187 Van Lit, "Commentary and Commentary Tradition», p. 6; George Saliba, Islamic Science and the Making of the European Renaissance, Cambridge, The MIT Press («Transformations »), 2007, p. 241 ; Ahmed, « Post-Classical Philosophical Commentaries/ Glosses », p. 345 . 
propose al-Rāzī l-Taḥtān̄ī188. Parfois, le commentaire est plus que cela encore : un prolongement voire un dépassement de l'œuvre. Les 'Aqā’id al-Nasafi ( $n^{\circ}$ 65) sont un catéchisme chargé d'éclairer rationnellement les aspects du credo et de l'eschatologie (à commencer par le caractère incréé du Coran). Ils portent également les conceptions maturidites de la foi contre la critique ašarite. Ils enrichissent les thématiques traitées par al-Nasafī (attributs de Dieu, relations entre l'homme et Dieu, vie après la mort, prophétie) des réflexions ontologiques puisées chez Avicenne qui font alors des émules chez des auteurs du IXe/Xve siècle, chez Bedr el-Dīn Simavlī (m. 819/1416) notamment ${ }^{189}$. C'est la raison pour laquelle le commentaire est plus commenté que l'œuvre au service de laquelle il se place. Ainsi le Šarh al-'aqā̇id d'al-Taftāzānī (n $n^{\circ}$ 65) continue de dominer le discours théologique en Asie centrale comme dans l'Empire ottoman jusqu'à l'époque contemporaine ${ }^{190}$. Car sans doute porte-t-il en lui une dimension universelle, un islam à la fois hanéfite dans ses pratiques religieuses et maturidite dans ses croyances, qui correspond à l'esprit de lettrés de la Samarcande du VIII ${ }^{\mathrm{e}} / \mathrm{XIV}^{\mathrm{e}}$ siècle comme aux orientations des oulémas anatoliens du XII $\mathrm{X}^{\mathrm{e}} / \mathrm{XVIII}^{\mathrm{e}}$ siècle $^{191}$.

Si l'on reprenait une distinction développée par plusieurs spécialistes, on dirait que les auteurs ottomans sont plutôt du côté du šarh que du matn ${ }^{192}$. Mais cela reviendrait à oublier que : 1) les auteurs d'œuvres qui pourraient passer pour originales entretiennent un dialogue étroit avec leurs prédécesseurs dont ils adoptent, critiquent ou rejettent les propositions de manière évidente ou implicite ${ }^{193} ; 2$ ) des œuvres, de grandes œuvres, ont également des fonctions

188 Khaled el-Rouayheb, «Ahmad al-Mallawi (d. 1767): Commentary on the Versification of the Immediate Implications of Hypothetical Propositions », dans The Oxford Handbook of Islamic Philosophy, éds Khaled el-Rouayheb et Sabine Schmidtke, New York, Oxford University Press, 2016, p. 514-515.

189 Sur le changement des «primary concerns » des mütakallimūn, voir Nathan Spannaus, «Theology in Central Asia», dans Oxford Handbook of Islamic Theology, éd. Sabine Schmidtke, New York, Oxford University Press, 2016, p. 588.

190 Ibid., p. 589.

191 Sur l'attachement de lettrés turcs et ottomans, tel Meḥmed Birgevī, au maturidisme, voir Yazıcıŏ̆lu, Le kalâm et son rôle dans la société turco-ottomane aux $X V^{e}$ et $X V I^{e}$ siècles, p. 8-9; El-Rouayheb, Islamic Intellectual History in the Seventeenth Century, p. 15-16, p. 143.

192 Messick, The Calligraphic State, p. 30. Une telle distinction est étayée par une étude quantitative proposée par Unan : sur 648 enseignants en poste dans la Șaḥn Medresesi au x ${ }^{\mathrm{e}}$ / $\mathrm{XVI}^{\mathrm{e}}$ siècle, 6 o ont produit 118 œuvres, dont $27 \%$ sont présentées comme originales et $73 \%$ comme des commentaires (Unan, «The Ottoman Ulema», p. 846). Au XII $/ \mathrm{XVIII}^{\mathrm{e}}$ siècle, les proportions sont respectivement de 41 et 59 \% (id., Kuruluşundan Günümüze Fâtih Külliyesi, p. 36o, p. 380).

193 Sur les ușūl al-figh, voir Atçıl, «Greco-Islamic Philosophy and Islamic Jurisprudence in the Ottoman Empire (130o-160o)», p. 36. 
pédagogiques essentielles aux yeux de leurs auteurs ; 3) à l'inverse, des commentaires et des gloses sont des œuvres à part entière ${ }^{194}$; du reste, les titres de la liste rendent compte d'une relation entre deux textes, et non du contenu de chacun d'eux, y compris au sein d'un même corpus. Je prends un exemple : le Durar al-h̆ukkām fi šarh Guurar al-ahkām, abrévié en Durar šarḥ al-Ġurar, n'est pas le commentaire (šarḥ) par Mollā Hüusrev de son précédent ouvrage, Gurar al-ậkām; alors que l'un est la synthèse des éléments que le jurisconsulte avait recueillis pendant sa carrière à partir de sa lecture d'ouvrages de figh et de ses expériences de juge, l'autre relève de l'adab al-qāḍ̄: c'est un manuel à l'usage des cadis sur toutes les questions qu'ils auraient à se poser dans l'exercice de leurs fonctions ${ }^{195}$; 4) il est des manuscrits dans lesquels se mèlent, parfois indistinctement, l'hypotexte et l'hypertexte qui en procède. Il est donc préférable d'envisager les commentaires comme des textes dont la construction dérive d'un texte plus ancien et qui en adoptent des termes particuliers « in structurally significant places ${ }^{196}$.

\section{$9 \quad$ Les langues}

Voici une autre difficulté : évaluer le projet d'ensemble, a priori ouvert et élargi, poursuivi par Halīl Hamīd à l'aune d'un public malgré tout restreint et peu lettré, qui bénéficie de la pratique de la lecture en commun, à la mosquée, en cercle plus ou moins fermé ou à la maison ${ }^{197}$. À Isparta, ville voisine de Burdur, où le $v a k f$ de Halīl Ḥamīd s'implante également, une école de quartier est attenante à la bibliothèque. Mais son enseignant et son assistant, aussi compétents et investis soient-ils dans l'accomplissement de leurs tâches, sont-ils en mesure de produire un vivier de lecteurs capables d'absorber les 440 volumes enregistrés dans la charte de la fondation pieuse ${ }^{198}$ ? Au XII ${ }^{\mathrm{e}} / \mathrm{XVIII}^{\mathrm{e}}$ siècle, la très

194 Spécialiste de Celāleddin Devvānī, Harun Anay invite à considérer que le développement de la pratique des commentaires sous les Ottomans n'est pas à interpréter comme la marque d'un recul des productions originales mais contribue au contraire au renouvellement des questions posées par ces productions (Anay, «Bir Osmanlı Düşüncesinden Bahsetmek Mümkün mü?», p. 13).

195 Muhammad Khalid Masud, «Adab al-qāḍī », EI ${ }^{3}$.

196 Van Lit, « Commentary and Commentary Tradition», p. 20.

197 Sabev, « The First Ottoman Turkish Printing Enterprise », p. 76 ; Zubčević, Book Ownership in Ottoman Sarajevo 1707-1828, p. 62-64, p. 194, p. 205-206.

198 Je ne vois pas bien à quoi correspond le chiffre de 449 manuscrits proposé par İ. Erünsal (Türk Kütüphaneleri Tarihi, p. 109). Pour l'époque républicaine, un livre de comptes (demirbaş defteri, registre matricule des cotes des manuscrits, sans doute) indique le chiffre de 554, ramené à 582 : Fehmi Aksu, «Sadrâzam Halil Hâmid Paşa'ya Dair », 
grande majorité des manuscrits en sciences islamiques continuent d'être écrits en arabe - c'est surtout au siècle suivant qu'ils sont traduits, et imprimés, en turc ottoman ${ }^{199}$. En revanche, les gloses et les commentaires en turc se multiplient ${ }^{200}$. Plusieurs ouvrages, longs et difficiles, font l'objet de versions réduites ou de vademecum. En page de garde des manuscrits, on relèvera la présence de notes et sceaux de propriété inscrits en arabe, puis, au fil des pages, la fréquence d'annotations en marge ${ }^{201}$. Ces marques manifestent-elles la continuité d'une pratique avérée de l'arabe autant que la prégnance d'une culture référencée, encore et toujours, aux trois langues (elsine-i s selāse) des savants ${ }^{202}$ ?

En vérité, le temps où un Țaşköprüzāde ( $\left.\mathrm{n}^{\circ} 53\right)$ pouvait rédiger en arabe l'ensemble de son œuvre est révolu ${ }^{203}$. Si l'on se sert du persan et de l'arabe, c'est surtout pour complexifier davantage encore les formulations ampoulées d'un ottoman compréhensible d'un nombre restreint de lettrés. En Anatolie occidentale et méridionale, qui connaît assez ces langues pour prendre possession de l'ensemble du corpus ${ }^{204}$ ? Qui est en mesure de se saisir de la «clé des sciences » (le Miftāh al-ulūm, no 33 ) façonnée par al-Sakkākī pour faire accéder le lectorat à la variété et la richesse des disciplines linguistiques, de la phonétique aux diverses formes du langage expressif? Qui pourra assimiler

$\ddot{U N}$ - Isparta Halkevi Mecmuası, 6/64-65 (1939), p. 9o8-913, p. 911. Lors d'un pointage ultérieur, Hikmet Turan Dağlıoğlu indique que 518 ouvrages de ce fond sont rédigés en arabe, 21 en persan et 43 en turc (Dağlıŏglu, « Isparta'da Halil Hamid Paşa Kütüphanesi », p. 1302).

199 Arzu Meral, "A Survey of Translation Activity in the Ottoman Empire», Osmanlı Araştırmaları, 42 (2013), p. 105-149 (surtout à partir des langues occidentales); Johann Strauss, «The Egyptian Connection in Nineteenth-Century Ottoman Literary and Intellectual History », Beyrouth Zokak El Bla(t), Beyrouth, Orient-Institut, 20 (2000).

200 El-Rouayheb, Islamic Intellectual History in the Seventeenth Century, p. 41-42.

201 Pour un inventaire de sceaux de bibliothèques fondées par 17 grands vizirs, dont Şehīd 'Alī (m. 1716), Dāmād İbrāhīm (m. 1730), Ḥekimoğlu 'Alī (m. 1758) et Meḥmed Rāg̀ıb (m. 1763), avec fac-similés, voir Günay Kut et Nimet Bayraktar, Yazma Eserlerde Vakıf Mühürleri, Ankara, Presses du ministère de la Culture, 1984, p. 67-99.

202 Adam Gacek, «Ownership Statements and Seals in Arabic Manuscripts », Manuscripts of the Middle East, 2 (1987), p. 88-95, p. 9o. Sur les manuscrits arabes, on trouvera une bibliographie très riche et régulièrement mise à jour sur le site de Jan Just Witkam : http:// janjustwitkam.nl/publications/index.html, consulté le 15 juillet 2020.

203 Agâh Sırrı Levend, Turk Edebiyatı Tarihi. Cilt 1, Ankara, Türk Tarih Kurumu, 1988³, p. 43 ; Strauss, «Who Read What in the Ottoman Empire (19th-2oth Centuries)? », p. 56-57.

204 Osman Horata, «The Turkish Literature from the Tulip Era to Tanzimat», dans The Turks, éd. H.C. Güzel et al., Ankara, Yeni Türkiye, 2002, III, p. 893-9o6, p. 894. Si İ. Erünsal (Ottoman Libraries, chapitre 8 ) parle d'un déclin des «bibliothèques de $v a k f$ » pour cause de manque de ressources et de traditionalisme, alors que des lecteurs seraient eux-mêmes en quête de «lumières » (enlightenment), je crois qu'il faut se poser également la question de leurs compétences linguistiques. 
les distinctions que l'auteur y propose et étaye entre șarf(morphologie), naḥw (syntaxe) et 'ilm al-ma'ānì wa-l-bayān (stylistique et théorie du langage figuratif) d'où fleurit un domaine riche de « douze sciences arabes » 205 ? Un étudiant devra sans doute chercher meilleure prise du côté des deux commentaires d'Ibn al-Ḥāğib $\left(n^{\circ} 75,76\right)$, grand classique de grammaire qui formalise davantage encore cette distinction sous la forme de volumes séparés ${ }^{206}$.

Bien sûr, la recherche de la transmission du savoir fondée sur la lecture attentive de textes de référence (muțāla'a) a certainement ses adeptes dans les madrasas anatoliennes ${ }^{207}$. Bien sûr, l'Empire compte en ses domaines de nombreux hauts lieux de savoir, de l'Anatolie (deux auteurs ont été formés à Tire $\left(n^{\circ} 16,63\right)$, ville active d'enseignement en sciences islamiques depuis la seconde moitié du VIII ${ }^{\mathrm{e}} / \mathrm{XIV}^{\mathrm{e}}$ siècle ${ }^{208}$ ) aux Balkans (selon O. Sabev, les livres en arabe étaient encore lus à Sofia au XII ${ }^{\mathrm{e}} / \mathrm{XVIII}^{\mathrm{e}}$ siècle et compris par ceux qui les manipulaient $\left.{ }^{209}\right)$. Bien sûr, les outils pédagogiques ne manquent pas: les commentaires d'al-Taftāzānī et d'al-Ğurğānī ( $n^{\circ}$ 61) s'imposent dans les programmes autant que le Miftāh al-úūm lui-même (no 64). D'abondantes ressources lexicographiques sont disponibles: à en croire l'énorme littérature critique qu'ils ont suscitée, les Șịăḥ d'al-Ǧawharī (no $\left.{ }^{\circ} 8\right)$ ne sont pas aussi impeccables qu'ils prétendent l'être; mais jusqu'à leur remplacement par le Qamūs d'al-Fīrūzābādī (m. 817/1415) au viII ${ }^{\mathrm{e}} / \mathrm{XIV}^{\mathrm{e}}$ siècle, ils constituent le dictionnaire arabe le plus utilisé, encore très apprécié par les Ottomans ensuite, puisque la traduction turque de Wānḳuli (m. 1000/1591-1592) compte parmi les quelques livres imprimés par Müteferriḳa $(\mathrm{m} .1158 / 1745)^{210}$. Un étudiant en difficulté pourra se rabattre sur le Muhtār al-Sịhăh (no ${ }^{\circ}$ 7), composé par le savant al-Rāzī (dont la méthode a hautement marqué les sciences ottomanes ${ }^{211}$ )

205 Mehmet Sami Benli, «Miftâhu'l-ulūm», Türkiye Diyanet Vakfi İslam Ansiklopedisi, 30 (2005), p. 20-21; Wolfhart P. Heinrichs, « al-Sakkākī », $E I^{2}$.

206 Sur les outils didactiques et les recueils destinés à l'enseignement d'un idiome savant et littéraire (l'allemand) au confluent de deux bassins linguistiques, voir Emmanuelle Chapron, «Enseigner l'allemand par les livres: Strasbourg et la librairie pédagogique au XVIII ${ }^{\mathrm{e}}$ siècle », Histoire et Civilisation du Livre, 11 (2015), p. 129-148.

207 Sur la notion de muțāla'a chez Müneccimbāşī (m. 1113/1702), voir Khaled El-Rouayheb, "The Rise of "Deep Reading" in Ottoman Scholarly Culture», CRASSH, Cambridge, 4 mai 2016, https://www.youtube.com/watch?v=eBposqiWFGs, consulté le 14 juillet 2019.

208 Gül, Osmanlı Medreselerinde Eğitim-Öğretim ve Bunlar Arasında Dâru'l-Hadîslerin Yeri, p. $32,87,111,114,115$.

209 Sabev, «Private Book Collections in Ottoman Sofia, 1671-1833 (Preliminary Notes)», p. 46. Sur Sarajevo, ville de poètes et d'écrivains, voir Zubčević, Book Ownership in Ottoman Sarajevo 1707-1828, p. 51-54.

210 Muhamammad b. Mușțafā l-Wānī, Tarğamat Șị̂ạḥ al-Ğawharī, Istanbul, 1141/1729.

211 Unan («The Ottoman Ulema», p. 842) va jusqu'à parler d'une «Razi school» constituée lors de l'ouverture des premières madrasas ottomanes. 
à partir du précédent dont il est l'un des dérivés les plus reconnus, en partie parce qu'il est conçu afin de contenir les seuls mots qu'un lettré digne de ce nom se devrait de mémoriser. Le problème est que l'auteur y note à la fois trop de mots et pas assez : il fait comme si les termes qu'il ne cite pas étaient connus, qui ne le sont pas nécessairement, a fortiori pour un jeune turcophone qui trouvera un faible recours auprès de rares et peu pratiques dictionnaires arabe-turc, celui de Kara Pīrī par exemple ( $\left.{ }^{\circ}{ }^{\circ} 59\right)$. Mais si le mouvement de fondation des bibliothèques vizirales ne fut que secondairement provincial, il y a des raisons culturelles à cela ${ }^{212}$. Hedda Reindl-Kiel explique pourquoi le grand vizir Hersekzāde Aḥmed Pacha (m. 922/1517), grand amateur de littérature, se résout à ne doter les vakf qu'il institue en province d'aucune bibliothèque : il sait que, dans les zones rurales où il répand une manne certes généreuse mais adaptée aux données du milieu, les lecteurs qualifiés se comptent sur les doigts d'une main ${ }^{213}$.

Faut-il ici tacler du bout du pied l'historiographie des bibliothèques ottomanes, celle qui traite des institutions et des règles qui s'y imposent davantage que de la forme des manuscrits et de l'usage qui en est fait, celle qui souligne l'utilité publique des bibliothèques plus qu'elle n'aborde la diversité des pratiques de lecture 214 ? La démarche de Henning Sievert est nouvelle qui

212 Comme exemples de grands vizirs fondateurs de bibliothèques en province, on citera Gedik Aḥmed (1477), Fāẓl Aḥmed Köprülü (1661), Dāmād İbrāhīm (1727) et Yeğen Mehmed (1728).

213 «As to the books, in Hersekzade's case it doesn't seem that he founded a library - his two vakfs were in more or less rural areas where libraries would not have had any customers. He was probably not very much interested in orthodox Islamic books; in case he received them as a gift, he would certainly have given them to one of his mosques. In Merzifonlu Kara Mustafa's case it is probable that he gave most of his books to his vakf library, because only a very small number of books (mostly luxury copies with miniatures) was confiscated by the royal palace» (courriel de H. Reindl-Kiel adressé à l'auteur).

214 Dans un compte rendu de Erünsal, Türk Kütüphaneleri Tarihi dans le Bulletin of the School of Oriental and African Studies, 54 (1991), p. 236-237, Caroline Finkel note que l'auteur n'évoque quasiment pas le contenu des collections. Dans son Ottoman Libraries, il y consacre deux pages (p. 136-138). Si dans sa dernière étude sur les livres au Moyen Âge, l'historien turc s'engage davantage du côté de la matérialité des pratiques savantes, il continue de laisser de côté l'étude des collections (İsmail Erünsal, «Kütüphâne Koleksyonları », Orta Çağ İslâm Dünyasında Kitap ve Kütüphane, Istanbul, Timaş, 2018, p. 417-419). Sur les pratiques de lecture dans Le Caire du XII $/ \mathrm{XVIII}^{\mathrm{e}}$ siècle, mais envisagées principalement sous l'angle de la sociologie professionnelle des propriétaires, voir Hanna, In Praise of Books, p. 96-98. Pour une réflexion générale sur les rapports entre pratiques de lecture et culture de l'écrit, voir Christoph Neumann, «Üç Tarz-ı Mütalaa: Yeniçağ Osmanlı Dünyası'nda Kitap Yazmak ve Okumak», Tarih ve Toplum Yeni Yaklaşımlar, 1 (2005), p. 51-75, p. 69, p. 59-69. Tout récemment, l'historiographie des bibliothèques ottomanes a connu de nouvelles ouvertures avec la publication de Cornell H. Fleischer, Cemal 
déplace l'objet de la réflexion vers les livres en tant que biens de consommation et d'échange ${ }^{215}$. Celle de Khaled El-Rouayheb l'est également qui, au-delà de l'approche de l'interraction individuelle entre un étudiant et son maître, propose une analyse de la transmission centrée sur le commentaire de texte $\left(m u t a \bar{l} l a^{\prime} a\right)^{216}$. Si l'on va dans ce sens, si l'on traite de front la question de la lecture, des possibilités qu'elle se donne et des contraintes qui s'imposent à elle, on se doit de poser celle, contiguë mais moins abordée par les études, des langues de lecture. Ce faisant, on en vient à laisser de côté deux orientations historiographiques opposées : 1) tirer de la consultation des curricula et de l'inventaire des ouvrages l'idée que l'arabe était la langue reine des madrasas; autrement dit, insister sur la maîtrise linguistique observée jusqu'au $\mathrm{X}^{\mathrm{e}} / \mathrm{XVI}^{\mathrm{e}}$ siècle et projeter celle-ci sur les siècles suivants, au motif, qu'avant les Tanzìmāt, l'enseignement reste «classique ${ }^{217} ; 2$ ) pointer au contraire du doigt la dégradation de l'enseignement des disciplines islamiques et, par voie de conséquence, l'érosion de l'apprentissage de l'arabe ${ }^{218}$. En marge de ces deux thèses, quelques historiens ottomanistes rejoignent des spécialistes d'autres parties du monde musulman quand ils essayent d'établir ce qui nous paraît être, au premier abord, du domaine de l'évidence mais qui, sauf erreur

Kafadar et Gülru Necipoğlu (éds), Treasures of Knowledge: An Inventory of the Ottoman Palace Library (1502/3-1503/4), Leiden-Boston, Brill («Studies and Sources in Islamic Art and Architecture », 14), 2019 (paru alors que le présent article était en cours d'examen par le comité d'Arabica).

215 Sur le développement de la production de livres dans Le Caire du XII ${ }^{\mathrm{e}} / \mathrm{XVIII}^{\mathrm{e}}$ siècle, lire Hanna, In Praise of Books, p. 85-9o. Sur les notes de lecture, voir Değirmenci, «Bir Kitabı Kaç Kişi Okur? », p. 39-42. Pour une démarche proche de celle de H. Sievert, voir l'étude des livres offerts à Evliya Çelebi et de leur usage par Neumann, «Üç Tarz-ı Mütalaa », p. 55-52, p. 69-70.

216 El-Rouayheb, «The Rise of "Deep Reading" in Ottoman Scholarly Culture ».

217 Richard Cooper Repp, The Müfti of Istanbul: A Study in the Development of the Ottoman Learned Hierarchy, Londres-Oxford, Ithaca-Faculty of Oriental Studies-Oxford University («Oxford Oriental Institute Monographs », 8), 1986, p. 29 ; Betül Can, « Fatih Döneminden Tanzimat'a Kadar Osmanlı Medreselerinde Arapça Öğretimi », 10. Uluslararası Dil, Yayın ve Deyişbilim Sempozyumu, Ankara Gazi Üniversitesi, 2010, p. 342-347 ; Atay, Osmanlılarda Yüksek Din Eğitimi, p. 214 (nuancé par Unan, Kuruluşundan Günümüze Fâtih Külliyesi, p. 349-350); Can Hızlı, Hüseyin Demir, «Osmanlı İlk Dönemi Medreselerinin Kuruluş Süreci ve Arap Dilinin Öğretimi », Bartın Üniversitesi Eğitim Fakültesi Dergisi, 6/2 (2017), p. 614-622.

218 İlyas Çelebi, «Osmanlı Medreselerinin Kuruluşu, Yükseliş ve Çöküş», dans Osmanlı, éd. Güler Eren, Ankara, Yeni Türkiye Yayınları, 1999, v [Toplum], p. 168-175, p. 174; Yazıcıoğlu, Le kalâm et son rôle dans la société turco-ottomane aux $X V^{e}$ et $X V I^{e}$ siècles, p. 8 ; Atay, Osmanlılarda Yüksek Din Eğitimi, p. 15-21; Yormaz, « Muhalif Bir Metin Nasıl Okunur?». 
de ma part, n'a pas encore été mesuré pour le XII ${ }^{\mathrm{e}} / \mathrm{XVIII}^{\mathrm{e}}$ siècle $^{219}$ : ce n'est pas parce qu'un enfant récite le Coran, sourate après sourate, qu'il en comprend le sens $^{220}$; ce n'est pas parce qu'un étudiant lit de l'arabe qu'il comprend ce qu'il lit; ce n'est pas parce qu'un bibliophile possède des livres écrits en arabe qu'il est apte à saisir les nuances qu'ils contiennent. Il faut cesser de penser que les livres sont toujours faits pour être lus ${ }^{221}$.

219 Pour ce qui est du XIII $\mathrm{e}^{\mathrm{e}} / \mathrm{XIX}^{\mathrm{e}}$ siècle, voir Olivier Bouquet, «Ce que l'on dit que l'on parle veut dire: réflexion sur les compétences linguistiques des derniers Ottomans », European Journal of Turkish Studies, 6 (2007), http://journals.openedition.org/ejts/1523, consulté le 15 juillet 2020 . Pour ce qui est $\mathrm{du} \mathrm{XI} / \mathrm{XVII}^{\mathrm{e}}$ siècle : «But it is important to keep in mind the difference between (1) being familiar with certain works and reading them, and (2) studying these works intensively as a regular part of madrasa education » (El-Rouayheb, Islamic Intellectual History in the Seventeenth Century, p. 38).

220 Pour le XIII $/{ }^{\mathrm{e}} / \mathrm{XX}^{\mathrm{e}}$ siècle, voir Gilbert Delanoue, Moralistes et politiques musulmans dans l'Égypte du XIXe siècle (1798-1882), Le Caire, Institut français d'archéologie orientale ( «Textes arabes et études islamiques », 15), 1982, p. 97-98, p. 110, p. 288, p. 394. Pour une présentation des différentes méthodes d'apprentissage de l'arabe en madrasa (sans réflexion sur leur effectivité respective et sans prise en compte des différences selon les périodes et les régions), voir Betül Can, «Tanzimat Öncesi Osmanlı Medreselerinde Arapça Öğretim Yöntemleri », Ekev Akademi Dergisi, 14/44 (2010), p. 305-320. Sur les difficultés de l'apprentissage de la lecture de l'arabe dans le contexte diglossique du Proche-Orient médiéval: Hirschler, The Written Word in the Medieval Arabic Lands, p. 91-99. Sur la transmission et la mémorisation des textes: Dale F. Eickelman, «The Art of Memory: Islamic Education and its Social Reproduction», Comparative Studies in Society and History, 20/4 (1978), p. 485-516, p. 493-495 ; Indira Falk Gesink, Islamic Reform and Conservatism: Al-Azhar and the Evolution of Modern Sunni Islam, Londres-New York, I.B. Tauris ( «ibrary of Modern Religion», 10), 2009, p. 18-19; Olivier Bouquet, Quand les Ottomans firent le point: histoire graphique, technique et linguistique de la ponctuation ottomane, Turnhout, Brepols («Miroir de l'Orient musulman», 8), 2019, p. 69-70 ; Benjamin Fortna, Learning to Read in the Late Ottoman Empire and Early Turkish Republic, Basingstoke, Palgrave Macmillan, 2014, p. 125; Messick, The Calligraphic State, p. 21-22; Rudolph T. Ware, The Walking Qur'an: Islamic Education, Embodied Knowledge, and History in West Africa, Chapel Hill, University of North Carolina Press («Islamic Civilization and Muslim Networks »), 2014, p. 49 ; Ismail Warscheid, Droit musulman et société au Sahara prémoderne : la justice islamique dans les oasis du Grand Touat (Algérie) aux XVII ${ }^{e}-X I X^{e}$ siècles, Leyde-Boston, Brill («Studies in the History and Society of the Maghrib », 9), 2017, p. 63-67.

221 Sur les livres comme biens du salut, voir Bernard Heyberger, «Premières imprimeries arabes en Orient: une histoire connectée», Circulations typographiques: imprimer les langues orientales entre Orient et Occident. $X V I^{\mathrm{e}}-X X^{\mathrm{e}}$ siècles, journée d'études organisée par Olivier Bouquet et Fabien Simon, Université Paris Diderot, le 25 janvier 2019. D'une liste de 145 ouvrages écrits en arabe, turc et persan, Heath Lowry deduit que « Hersekzâde Ahmed (who only began to learn Turkish, Persian and Arabic as an adult) had acquired sufficient mastery of all three languages, to allow him to purchase and read works written in them» (Heath W. Lowry, Hersekzâde Ahmed Paşa: An Ottoman Statesman's Career and Pious Endowments, Istanbul, Bahçeşehir University Press, 2011, p. 5). En l'absence de 
Que dire du persan? Son recul dans les pratiques de lecture a été identifié222. Il s'accentue davantage encore au XIII ${ }^{\mathrm{e}} / \mathrm{XIX}^{\mathrm{e}}$ siècle. Il est visible ici : deux auteurs cités, Ğāmī (no 45) et Hwwānd Amīr ( $\left.n^{\circ} 48\right)$, c'est tout. Et il faut attendre la toute fin de l'inventaire pour voir apparaître de la poésie. Trois titres seulement pour faire place, tout de même, au monument du gazal: Haāiż. Il y a de quoi rester songeur quand on sait à quel point, au bas Moyen Âge, le persan, non seulement imprima sa marque sur la personnalité du turc littéraire, mais devint une « lingua franca assurant la liaison entre le Bilād al-Rūm et le Bilād al-'Ajam ${ }^{223}$; quand on se souvient qu'au $\mathrm{x}^{\mathrm{e}} / \mathrm{XVI}^{\mathrm{e}}$ siècle la poésie persane ne connut nulle part ailleurs autant d'écho que dans l'Empire ottoman ; quand on se rappelle qu'aux $\mathrm{XI}^{\mathrm{e}} / \mathrm{XVII}^{\mathrm{e}}-\mathrm{XII} \mathrm{I}^{\mathrm{e}} / \mathrm{XVIII}^{\mathrm{e}}$ siècles la recension historique d'Ahmed Sūdī (m. ca 1008-1009/16oo) fit autorité sur les spécialistes notamment iraniens de Ḥāfiż, au point d'être traduite en persan ; quand, enfin, on lit, ici ou là, que le $\mathrm{XII}^{\mathrm{e}} / \mathrm{XVIII}^{\mathrm{e}}$ siècle ottoman fut le siècle par excellence de la poésie et des poètes ${ }^{224}$. Le fait est qu'à partir de la fin $\mathrm{du} \mathrm{XI}^{\mathrm{e}} / \mathrm{XVII}^{\mathrm{e}}$ siècle la copie des manuscrits persans décroît, alors que les traductions vers le turc ottoman se

données complémentaires, je conteste la validité du lien que présuppose l'auteur entre la possession de manuscrits et l'usage qui en est fait.

222 Recep Dikici, «Damad İbrahim Paşa'nın İstanbul'daki Kütüphanesi ve Nevşehirli Âlim ve Ediplerin Yazma Eserleri », dans 1. Uluslararası Nevşehir Tarih ve Kültür Sempozyumu Bildirileri, 16-19 Kasım 2011, Nevşehir, éd. Adem Öger, Ankara, 2012, vI, p. 371-388, p. 373 (34 volumes en persan et 1104 en arabe sur un total de 1153 manuscrits); Sabev, « Okuyan Taşralı Bir Toplum », p. 583 ( 7 livres en persan sur 1051 volumes recensés dans six inventaires après décès étudiés entre 1730 et 1747); Zubčević, Book Ownership in Ottoman Sarajevo 1707-1828, p. 102-103, p. 193-197 ; F. Richard estime que « la connaissance du persan était largement répandue et souvent indispensable à l'accomplissement d'une carrière de secrétaire ou de fonctionnaire dans l'administration » (Richard, «Lecteurs ottomans de manuscrits persans du XVI ${ }^{\mathrm{e}}$ au XVIII ${ }^{\mathrm{e}}$ siècles », p. 80). De même, Alexander Bevilacqua écrit: «most members of the educated elite spoke Arabic, Persian and Ottoman Turkish » (Alexander Bevilacqua, The Republic of Arabic Letters: Islam and the European Enlightenment, Cambridge, The Belknap Press of Harvard University Press, 2018, p. 21). J'ai établi le contraire pour la haute administration du $\mathrm{XIII}^{\mathrm{e}} / \mathrm{XIX}^{\mathrm{e}}$ siècle dans Olivier Bouquet, Les pachas du sultan : essai sur les agents supérieurs de l'État ottoman (1839-19og), Paris-Louvain-Dudley, Peeters («Collection Turcica», 12), p. 286-288. Pour ce qui est du $\mathrm{XII} \mathrm{e}^{\mathrm{e}} / \mathrm{XVIII}{ }^{\mathrm{e}}$ siècle, le débat reste ouvert.

223 Algar, «Jāmī and the Ottomans », p. 65, p. 125, ma traduction de l'anglais ; Johann Strauss, «Diglossie dans le domaine ottoman: évolution et péripéties d'une situation linguistique», Revue des mondes musulmans et de la Méditerranée, 75-76 (1995), p. 221-255, p. 224 ; Ahmet Kartal, « Anadolu'da Farsça Şiir Söyleyen Türk Şairler (XI.-XVI. Yüzylllar)», dans Türkler, éds Hasan Celâl Güzel, Kemal Çiçek et Salim Koca, Ankara, Yeni Türkiye Yayınları, 2002, VII, p. 682-695 (avec une liste des poètes actifs en Anatolie classés par siècle, p. 688-691).

224 Uluç, «Ottoman Book Collectors and Illustrated Sixteenth Century Shiraz Manuscripts », p. 87 ; Tahsin Yazıcı, « Hâfız-ı Şirâzî », Türkiye Diyanet Vakfi İslam Ansiklopedisi, 15 (1997), 
multiplient, notamment en Anatolie ${ }^{225}$, en sorte qu'à Burdur ${ }^{226}$ - c'est malheureux, mais c'est ainsi - Rūmī se lit en turc, au moyen des trois commentaires les plus employés par les Ottomans $\left(\mathrm{n}^{\circ} 104,105,106\right)$. Commentaire, c'est vite dit: celui de Şemiīi ( $\mathrm{m}$. ca 1011/16o2; $\mathrm{n}^{\circ}$ 104) consiste en une longue paraphrase ${ }^{227}$ du reste, on en parle comme d'une tercüme («traduction ») que Sūdī se fait fort d'égratigner $\left(\mathrm{n}^{\mathrm{o}}\right.$ 106). C'est bien peu au regard de l'importance qu'occupait la poésie persane dans la culture savante et religieuse des Ottomans et de l'intérêt que Halīl Hamīd, à l'instar de nombreux bureaucrates de son temps, portait au Mesnevi et au soufisme - le Rašaḥăt d'al-Ṣafī ( ${ }^{\circ}{ }^{102}$ ) figure également sous sa traduction en turc ottoman.

Pour la plupart d'entre eux, les ottomanistes et leurs collègues des facultés de théologie (ilahiyat) suivent une approche compilatrice des ouvrages plus qu'ils n'encouragent une démarche analytique des textes. Ils s'efforcent de recenser les manuscrits disponibles et de reconstituer les liens entre des originaux et leurs commentaires plus qu'ils ne s'attachent à circonscrire ce qui relève d'une «relation complexe d'intertextualité » (A.Q. Ahmed) 228 à situer au sein d'une «tradition du commentaire» $(\mathrm{E} \text {. Van Lit })^{229}$. En vérite, je ne sais

p. 103-106, p. 106; Georgii Michaelis Wickens, «Ḥāfiz », $E I^{2}$; Horata, «The Turkish Literature from the Tulip Era to Tanzimat », p. 895.

225 Özgüdenli, «Persian Manuscripts i. in Ottoman and Modern Turkish Libraries»; Osman G. Özgüdenli et Abdülkadir Erdoğan, «İstanbul Kütüphanelerinde Bulunan Farsça Tarih Yazmaları Hakkında Bazı Mülâhazalar », Osmanlı Araştırmaları, 23 (2003), p. 145-163. Chiffres à l'appui, ces deux études établissent une réduction du nombre des copies de manuscrits en persan à Istanbul aux XI ${ }^{\mathrm{e}} / \mathrm{XVII}^{\mathrm{e}}-\mathrm{XII} \mathrm{I}^{\mathrm{e}} / \mathrm{XVIII}^{\mathrm{e}}$ siècles, ce qui remet en question la thèse de $\mathrm{F}$. Richard d'une large pratique du persan après le $\mathrm{x}^{\mathrm{e}} / \mathrm{XvI}^{\mathrm{e}}$ siècle (Richard, «Lecteurs ottomans de manuscrits persans du XVI ${ }^{\mathrm{e}}$ au XVIII ${ }^{\mathrm{e}}$ siècles »).

226 Selon Özgüdenli, sur les 2312 manuscrits de la la bibliothèque municipale de Burdur, seuls 57 étaient composés en persan (Özgüdenli, «Persian Manuscripts i. in Ottoman and Modern Turkish Libraries»).

227 «A hypertext is a commentary in the true sense of the word when it shows structural textual correspondence and contains the complete hypotext. There are different types of commentaries. The two most common ones are the paraphrasing commentary and the running commentary ( Van Lit, « Commentary and Commentary Tradition », p. 15).

228 Ahmed, « Post-Classical Philosophical Commentaries/Glosses», p. 345, ma traduction.

229 "A "commentary tradition" is a set of different hypertexts and at least one hypotext, with the hypotexts (minus intermediary texts) all written by one author, and each hypertext has structural textual correspondence with one of the hypotexts » (Van Lit, « Commentary and Commentary Tradition », p. 17). 
pas d'équivalent en histoire ottomane à l'étude terminologique que Patrick Franke consacre à la comparaison de 182 titres associés au Mecquois 'Alī l-Qārī $\left(\mathrm{n}^{\mathrm{o}} 28,30\right)^{230}$. Il est vrai que le travail de catalogage des manuscrits arabes conservés en Turquie reste immense ${ }^{231}$ : prenons le Hidāyat al-hikma, ouvrage sur la philosophie scolastique d'al-Abharī (m. 663/1264; non cité ici mais possédé par des bureaucrates ${ }^{232}$ ): il existerait environ 800 manuscrits du texte, des commentaires et des gloses ${ }^{233}$. Il est vrai que les historiens arabisants qualifiés sont peu nombreux parmi les ottomanistes. Et il est vrai que l'insuffisance de l'histoire des textes va de pair avec les manques de l'histoire sociale: pour suivre les flux intellectuels qui irriguent la culture savante, il faudrait étudier de plus près les réseaux relationnels tissés entre les savants du temps ${ }^{234}$.

Il n'en reste pas moins que l'historiographie des manuscrits ottomans est assez avancée pour permettre de déterminer les traits principaux de la collection de Halīl Hamīd : celle-ci correspond pleinement aux fonds des madrasas ottomanes du XII ${ }^{\mathrm{e}} / \mathrm{XVIII}{ }^{\mathrm{e}}$ siècle - on le mesure en étudiant les programmes qui y étaient enseignés et les catalogues des manuscrits qui y étaient conservés ${ }^{235}$.

230 Franke, «The Ego of the Mullah», p. 199 (pour une correction des titres identifiés par Brockelmann et un remarquable tableau des références croisées au sein de l'œuvre de Qārī) ; voir aussi le compte rendu de C. Mayeur-Jaouen, «Deux livres pionniers sur les ego-documents dans les littératures du Moyen-Orient à l'époque moderne et contemporaine».

231 Pour une estimation précise du nombre de manuscrits répertoriés, voir Aynur, «Türkiye Kütüphaneleri Arap Harflı Basma Kitap Katalogları Üzerine Bibliyografik Bir Değerlendirme (1929-2009)». Au début du siècle, encore plus de 500 ooo manuscrits attendraient d'être catalogués: İsmail Erünsal et A. Oğuz İcimsoy, «The Legacy of the Ottoman Library in the Libraries of the Turkish Republic », Libri, 58 (2008), p. 47-57, p. 53 ; Aynur, «Türkiye'de Türkçe Yazma Eserlerin Kataloglanması Üzerine Bir Değerlendirme 1989-2002 », p. 37-38. Le catalogage des manuscrits au Proche-Orient arabe est particulièrement incomplet et déficient (Soler, compte rendu de Hirschler, Medieval Damascus, p. 236-237).

232 Sievert, « Eavesdropping in the Pasha's Salon », p. 175.

233 Yormaz, «Muhalif Bir Metin Nasil Okunur?», p. 186.

234 Voir les études quantitatives de Reichmuth, The World of Murtaḍa Al-Zabìdī, p. 16o-210; id., «Murtadâ al-Zabîdî (d. 1205/1791) and his Role in 18th Century Sufism », dans Le soufisme, éds Chih et Mayeur-Jaouen, p. 383-406 ; Atçll, « Mobility of Scholars and Formation of a Self-Sustaining Scholarly System in the Lands of Rūm during the Fifteenth Century ». Voir les nouvelles perspectives proposées dans Early Modern Trends in Islamic Theology, éds Demiri et Pagani.

235 Bilge, İlk Osmanlı Medreseleri, p. 40-63; Unan, Kuruluşundan Günümüze Fâtih Külliyesi, p. 322-38o ; Hüseyin Atay, «Fatih-Süleymâniye Medreseleri Ders Programları ve İcazetnameler»; Hızlı, «Osmanl Medreselerinde Okutulan Dersler ve Eserler»; Sievert, «Eavesdropping in the Pasha's Salon », p. 173-178; Bilici, «Les bibliothèques vaklf-s à Istanbul au XVI ${ }^{\mathrm{e}}$ siècle », p. 49-50. 
Elle est conforme aux exigences des canons de la 'ilmiyye. Ces exigences étaient à la fois précises et souples, arrêtées et fluctuantes: des ouvrages suspectés de sortir des limites de l'orthodoxie, reproduits et diffusés en grand nombre selon des versions variables et dynamiques, riches en interpolations $\left(\mathrm{n}^{\circ}{ }^{\circ}\right)^{236}$, ont été mis à l'index au XI $/ \mathrm{XVII}^{\mathrm{e}}$ siècle pour être réintroduits ensuite dans les programmes d'enseignement: on pense au manuel d'al-Īğì ( $\left.n^{\circ} 61\right)$ jadis taxé de bienveillance excessive à l'égard de la philosophie. Spécialisée et académique, la collection ne rend pas plus compte de la diversité et des richesses des modes d'expression littéraire (prose ou poésie ${ }^{237}$ ) que des champs de production intellectuelle (astronomie, médecine, histoire, géographie, musique, etc.) du siècle dans lequel a vécu celui qui l'a assemblée ${ }^{238}$ - ceci vaut également pour le spectre des sciences canoniquement approuvées (müstehab). Elle ne traduit que partiellement les orientations de la culture lettrée encouragée par la haute bureaucratie ottomane, celle qui fait la part belle aux « sciences utiles » ('ulūm-i nafía ${ }^{239}$, et l'intérêt, plus ciblé que général, porté par les gens de la

236 Francesca Bellino, «Sirāj al-Dīn ibn al-Wardī and the Harìdat al-'ajāìib: Authority and Plagiarism in a Fifteenth-Century Arabic Cosmography», Eurasian Studies, 12 (2014), p. 257-296, p. 258, p. 290 ; Feray Coşkun, « An Ottoman Preacher's Perception of a Medieval Cosmography: Maḥmūd al-Hațib's [sic] Translation of Kharīdat al-'Ajä̉ib wa-Farị̣̂t al-Gharāìb », Al-Masāq: Islam and the Medieval Mediterranean, 23/1 (2011), p. 53-66 (sur une traduction en turc ottoman du $\mathrm{x}^{\mathrm{e}} / \mathrm{XvI}^{\mathrm{e}}$ siècle par Mahmmūd al-Hațīb).

237 Hatice Aynur, «Ottoman Litterature», dans The Later Ottoman Empire 1603-1839, éd. Suraiya Faroqhi, Cambridge, Cambridge University Press («The Cambridge History of Turkey », 3), 2006, p. 481-528, p. 487-503, p. 506-507 ; Zubčević, Book Ownership in Ottoman Sarajevo 1707-1828, p. 241-259.

238 O. Sabev offre une étude comparée qui permet de mesurer cette diversité : Sabev, « Okuyan Taşralı Bir Toplum», p. 583. Sur l'intégration des sciences rationnelles ('ulüm-i 'aḳliyye) dans l'enseignement en madrasa, voir İhsanoğlu, «Institutionalisation of Science in the Medreses of Pre-Ottoman and Ottoman Turkey», p. 276, p. 280. Sur leur recul à partir de la fin du Xe/Xvi e siècle, voir Robinson, «Ottoman-Safawids-Mughals», p. 155, 173 (tirées de l'exploitation d'un nombre très réduit de curricula, les conclusions de l'auteur doivent être prises avec la plus grande circonspection). Sur leur renouveau à partir de la fin du $\mathrm{x}^{\mathrm{e}} /$ $\mathrm{xVI}^{\mathrm{e}}$ siècle (et en critique de la thèse précédente), voir El-Rouayheb, Islamic Intellectual History in the Seventeenth Century, p. 13-59. Sur la géométrie et l'astronomie, voir Salim Aydüz, «The impact of Al-Ṭūsī on the Ottoman science», International Review of Turkish Studies, 12/3 (2012), p. 8-30. Sur les productions médicales, voir Sabev, «Medical Books in Private and Public Ottoman Libraries », Proceedings of the 38 th International Congress on the History of Medicine (1-6 September 2002), Ankara, 2005, II, p. 615-628; Erünsal, « Kuruluşundan Tanzimatta Kadar Osmanlı Vakıf Kütüphanelerinde Yapılan Kataloglama Çalışmaları », p. 107.

239 Uluç, «Ottoman Book Collectors and Illustrated Sixteenth Century Shiraz Manuscripts », p. 89 (livres de Dāmād İbrāhīm Pacha, 1730); Reichmuth, «Bildungskanon und Bildungsreform aus der Sicht eines islamischen Gelehrten der Anatolischen Provinz », p. 500-503 (pour une classification des sciences selon Saçaklīzāde Meḥmed Efendī); Touati, L'armoire à sagesse, p. 203. 
plume et de l'épée aux disciplines islamiques - la présence marquée des hadiths fait penser davantage aux collections des institutions islamiques qu'aux bibliothèques des pachas ${ }^{240}$. La place des auteurs ottomans en madrasa est secondaire par la présence de leurs œuvres. Elle est importante par celle de leurs commentaires. Plutôt que d'y voir le signe d'une dévalorisation de savoirs classiques, il faut rappeler que le commentaire est le mode par excellence de l'activité pédagogique mais aussi intellectuelle ${ }^{241}$; il faut se dire que c'est à force de circuler sur les textes d'autrui, comme lecteurs et glosateurs, que les Ottomans ont produit leur littérature et qu'ils ont participé, à leur manière, à une république des lettres bien «plus vaste que n'importe quel corps politique ${ }^{242}$.

Dernière question : l'étude d'une bibliothèque de madrasa permet-elle d'approcher les goûts et les dispositions de celui qui l'a fondée ${ }^{243}$ ? Tout dépend des livres qu'on y trouve, mais aussi de ce que l'on sait par ailleurs du fondateur. J'ai cité le cas de Hersekzāde Ahmed Pacha. C'était un grand amateur de lettres et de poésie. Or sa bibliothèque était dotée d'un nombre restreint d'ouvrages consacrés aux sciences religieuses ${ }^{244}$. Mais elle était conçue à son image ${ }^{245}$.

240 Sievert, «Eavesdropping in the Pasha's Salon », p. 173. On trouvera une liste des ouvrages les plus cités dans des inventaires après décès de bureaucrates du milieu du XII $/$ XVIII $^{\mathrm{e}}$ siècle dans ibid., p. 19o-191. Voir aussi Nevzat Kaya, « Rāgıb Meḥmed Paşa and His Library », dans Theoretical Approaches to the Transmission and Edition of Oriental Manuscripts, éd. Judith Pfeiffer et Manfred Kropp, Beyrouth-Würzburg, Orient Institut-Ergon («Beiruter Texte und Studien », 111), 2007, p. 185-193.

241 Ahmed et Larkin, «The Häshiya and Islamic Intellectual History»; Walid Saleh, «The Gloss as Intellectual History: The Häshiyahs on al-Kashshäf », Oriens, 41/3-4 (2013), p. 217259, p. 248 ; Van Lit, « Commentary and Commentary Tradition », p. 201.

242 Al-Musawi, The Medieval Islamic Republic of Letters, p. 109, ma traduction de l'anglais. «Bien loin des écrivains, fondateurs d'un lieu propre, héritiers des laboureurs d'antan mais sur le sol du langage, creuseurs de puits et constructeurs de maisons, les lecteurs sont des voyageurs; ils circulent sur les terres d'autrui, nomades braconnant à travers les champs qu'ils n'ont pas écrits, ravissant les biens d'Égypte pour en jouir ». Michel de Certeau, L'invention du quotidien, Paris, Gallimard («Folio. Essais », 146), 1990, I [Arts de faire], p. 251.

243 Pour une étude sur les intérêts intellectuels d'un notable du XVIII ${ }^{\mathrm{e}}$ siècle proposée à partir d'un corpus de 307 volumes, voir Charles Wilkins, « The Self-Fashioning of an Ottoman Urban Notable: Ahmad Efendi Tahazâde (d. 1773)», Osmanlı Araştırmaları, 44 (2014), p. 393-425.

244 Lowry, Hersekzâde Ahmed Paşa, p. 6 ; Hedda Reindl-Kiel, «Some Notes on Hersekzade Ahmed Pasha, His Family, and His Books », Journal of Turkish Studies, 40 (2013), p. 315-326, p. 323 .

245 Voir aussi la bibliothèque constituée par le mufti de Sofia en 1777 (Sabev, «Bulgaristan'da Osmanlı Vakıf Kütüphanelerinde Bir Örnek», p. 300-303), ou celle d'un enseignant de la fin du $\mathrm{IX}^{\mathrm{e}} / \mathrm{Xv}^{\mathrm{e}}$ siècle (couvrant toutes les disciplines, à l'exception de l'histoire et de la géographie, avec des indications sur la maîtrise des trois langues). Halil Sahillioğlu, «Ottoman Book Legacies », dans Studies on Ottoman Economic and Social History, éd. id., Istanbul, IRCICA, 1999, p. 189-191, p. 190. 
Pour ce qui concerne la présente collection, les mentions de titres ne sauraient être interprétées autrement que comme les indications d'une culture générale du XII ${ }^{\mathrm{e}} / \mathrm{XVIII}^{\mathrm{e}}$ siècle, comme un «abrégé du monde » ottoman ${ }^{246}$. Je veux dire qu'elles ne sauraient être prises pour des indices de pratiques effectives: la présence du Qurrat al-'uyūn ( ${ }^{\circ}$ 43) ne fait pas du dignitaire un lecteur assidu de l'œuvre d'un Abū l-Layt al-Samarqandī. Pour tirer une telle conclusion, il faudrait que ce titre soit au moins flanqué des principaux travaux du juriste hanéfite, tels ses Nawāzil ou ses 'Uyūn al-masāìi247. Halīl Ḥamīd avait la réputation d'accorder une grande importance aux actions divinatoires et aux vertus miraculeuses ; il n'a sans doute pas acquis par hasard ce commentaire d'al-Hizb al-a zam de Qārī (no 30). Mais encore une fois, il faut penser au lieu de destination des ouvrages plus qu'à la personnalité du fondateur ${ }^{248}$ : si l'on trouve des livres de tarhīb ( $\left.\mathrm{n}^{\circ} 38\right)$, c'est peut-être que le pacha s'intéressait de près aux manuels eschatologiques; mais c'est surtout qu'il ne jugeait pas inutile que ses coreligionnaires, les jeunes gens des madrasas, fussent mis en garde contre les actes prohibés et les « grands péchés».

Si l'on ignore les circonstances précises et les motivations exactes de l'aquisition des ouvrages, on devine néanmoins les finalités de leur mise en $v a k f$ : former de jeunes clercs aux métiers auxquels ils se destinent; faire lire ceux qui, dans leur vie professionnelle, auront à parler et à écrire; offrir un lieu de savoir à une « communauté savante ${ }^{249}$, aussi circonscrite fût-elle, mais également au peuple plus ou moins différencié des imams de mosquée, artisans et commerçants, « chercheurs à temps partiel » ${ }^{250}$, témoins instrumentaires et maîtres d'école ; nourrir la piété des fidèles aux sources de grands classiques d'où la mention dans la collection de Qāḍī Tyāḍ (m. 544/1149; no 20), auteur d'un livre qui mèle soufisme, hadith et figh; faire en sorte que ce qui a été patiemment assemblé par un homme ne soit pas dispersé à sa mort ${ }^{251}$; offrir à la ville de Burdur de beaux ouvrages, aux calligraphies raffinées et aux reliures

246 Marie Lezowski, L'abrégé du monde: une histoire sociale de la bibliothèque Ambrosienne (v. 1590-v. 1660), Paris, Classiques Garnier («Bibliothèque d'histoire de la Renaissance», $9)$, 2015. Pour une réflexion sur une collection, riche en ouvrages de poésie et d'adab, qui reflète moins les intérêts disciplinaires d'oulémas qu'elle ne témoigne d'une culture de Damascènes éduqués, voir Hirschler, Medieval Damascus, p. 109, p. 117.

247 Abdur-Rahman Mangera, A Critical Edition of Abü'l-Layth al-Samarqandìs Nawāzil, $\mathrm{PhD}$ thesis, SOAS, University of London, 2013, p. 4-5, https://eprints.soas.ac.uk/17840/, consulté le 14 mai 2019.

248 Erünsal, Ottoman Libraries, p. 137.

249 Lezowski, L'abrégé du monde, p. 13, p. 123 ; Chartier, «Communautés de lecteurs », in id., Culture écrite et société, p. 133-154.

250 Hirschler, The Written Word in the Medieval Arabic Lands, p. 35, ma traduction de l'anglais.

251 Touati, «Entre dispersion et conservation », dans id., L'armoire à sagesse, p. 47-54. 
soignées ; tirer de cette action pieuse et utile une source de prestige et de salut pour une vie à venir. C'est sans doute cela que Halīl Ḥamīd, dignitaire navigant entre le pôle du désir et le principe de totalité252, aura souhaité pour sa bibliothèque anatolienne.

\section{Présentation du corpus}

La très grande majorité des titres de l'inventaire renvoie à des manuscrits rédigés en arabe. Or ils furent répertoriés par des scribes ottomans turcophones. Cela pose au moins deux problèmes. L'un tient à l'adaptation de l'arabe au turc ottoman, le second à la désignation des titres.

Les copistes ont une manière bien à eux de renommer les œuvres alaturca, une habitude prolongée jusqu'à aujourd'hui sous forme latine - j'ai constaté à quel point des collègues arabisants pouvaient être surpris à la lecture des transcriptions des noms et des titres indiqués dans les entrées de la Türkiye Diyanet Vakfi İslam Ansiklopedisi253. Ils écrivent certes comme ils lisent (en fonction du sens rigoureusement fixé par la grammaire arabe) mais aussi comme ils parlent (la phonétique du turc ottoman est soumise à la fois au respect de l'harmonie vocalique et aux contraintes d'une orthographe très conservatrice). Grammaticalement, ils substituent des annexions persanes à des annexions arabes: Manāqib al-imām devient Menāḳib-i imām ( $\left.\mathrm{n}^{\circ} 36\right)$. Phonétiquement, ils projettent leur système de voyelles antérieures et postérieures sur la graphie arabe. Je m'efforcerai d'en rendre compte dans les translittérations des titres cités : al-Ğawharī sera noté Cevherī. De même, je restituerai l'assimilation de l'article arabe à la première consonne du mot défini : je transcrirai معالم التنزيل me‘ālimü-t-tenzīl, car, là où la liste des ouvrages fut enregistrée, à Istanbul donc, c'était ainsi qu'on prononçait ma'ālim al-tanzïl.

À la différence de listes détaillées dans de nombreuses chartes et à l'instar de listes abréviées dans d'autres, l'inventaire est sommaire et imprécis, qu'il s'agisse des titres des ouvrages ou des désignations des auteurs ${ }^{254}$. Un scribe

252 Id., «Le désir et la totalité », dans id., L'armoire à sagesse, p. 39-47.

253 Sur les problèmes de translittération du turc ottoman dans les entrées des ouvrages biographiques turcs, voir Birnbaum, «The Transliteration of Ottoman Turkish for Library and General Purposes », p. 126-128.

254 Ainsi, une vakfiyye enregistrée par Rüstem Pacha apporte des précisions sur le nombre de volumes, la nature du papier, le style de l'écriture, la forme de l'ouvrage, la présence de couleurs et d'enluminures et le nombre de lignes : Aydın Yüksel, «Sadrazam Rüstem Paşanın Vakıfları », Ekrem Hakkı Ayverdi Hâtıra Kitabı, Istanbul, İstanbul Fetih Cemiyeti, 1995, p. 219-281, p. 269; Bilici, «Les bibliothèques vakıf-s à Istanbul au XVI e siècle», 
concilie deux objectifs. Il lui faut citer de nombreux livres : autant abréger les titres dans un contexte où les ouvrages mentionnés sont connus et diffusés et/ ou dont les auteurs sont renommés; autant indiquer la présence d'un commentaire par le seul terme 'alā («sur»). C'est une habitude générale, entretenue dans des firmans, fatwas et actes de cadi. C'est une pratique observable à la lecture de catalogues de bibliothèques ou d'inventaires après décès ${ }^{255}$. Mais comme tout bien mis en vakf, un livre doit être identifié. Il faut donc être relativement précis et éviter de possibles confusions. C'est le cas :j'ai identifié 93 des 106 manuscrits cités ${ }^{256}$. Il arrive que les intitulés correspondent à ceux qui sont inscrits en haut de première page de manuscrit, quand ils ne sont pas indiqués sous une forme plus réduite encore (Fetāvà-yı Üskübī, no 81 , noté sous le seul nom de l'auteur, Üskübīi257). Voici comment ils se présentent.

Tantôt seuls les premiers termes du titre sont cités: Kevkebü-r-Ravza li-es-Suyūṭi (no ${ }^{\circ}$ 1). Inutile d'en dire plus pour renvoyer au Kawkab al-rawda fì ta'rih al-Nül wa-ğazīrat al-rawḍ d'al-Suyūțī. Tantôt une épithète est modifiée, renvoyant au caractère éminent de l'ouvrage ou à l'importance de son statut scientifique. Ladjectif şerif est à cet égard particulièrement apprécié :

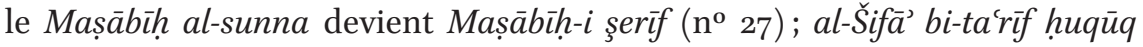
al-Muștafā passe à la postérité sous le simple nom de Şifā-yı şerîf ${ }^{258}$. Quoi d'autre ? 'Iyāụ al-Yaḥ̣subī l-Sabtī règne sur sa catégorie des şifă. De même que parler de La Recherche, c'est renvoyer à l'œuvre de Proust, qu'on en cite ou non l'auteur, mentionner al-Miftāh, c'est renvoyer au Miftāh al-'ulūm (La clé des sciences, $\mathrm{n}^{\circ}$ 33) d'al-Sakkākī plutôt qu'à d'autres titres contenant le même terme ${ }^{259}$. Ce qui est évident pour les Ottomans de l'époque ne l'est pas toujours

p. 52-53. Sur la précision des descriptions d'ouvrages, voir Erünsal, Ottoman Libraries, p. 156-157.

255 Sahillioğlu, «Ottoman Book Legacies», p. 19o; Ahmed Akgündüz (éd.), Osmanlı Kanunnâmeleri ve Hukukî Tahlilleri, Istanbul, Fey Vakfı, 1992, IV, p. 663; Aykan, Rendre la justice à Amid, p. 174; Erünsal, «Kuruluşundan Tanzimatta Kadar Osmanlı Vakıf Kütüphanelerinde Yapılan Kataloglama Çalışmaları », p. 107 ; Zubčević, Book Ownership in Ottoman Sarajevo 1707-1828, p. 159; Aynur, «I. Mahmûd'un (ö. 1754) Kütüphaneleri ve Tarih Manzumeleri », p. 723-734.

256 Pour un exposé très détaillé sur les problèmes et enjeux de l'identification de titres du catalogue d'une bibliothèque damascène, voir Hirschler, Medieval Damascus, p. 133-142. Pour un exemple de travail d'identification de titres sommairement indiqués dans des manuscrits arabes d'Afrique de l'Ouest, voir Jean-Louis Triaud, «Deux bibliothèques arabo-islamiques en Côte d'Ivoire au début du $\mathrm{XX}^{\mathrm{e}}$ siècle», dans Les non-dits du nom: onomastique et documents en terre d'islam. Mélanges offerts à Jacqueline Sublet, éds Christian Müller et Muriel Roiland, Damas-Beyrouth, Presse de l'Ifpo, 2013, p. 161-246.

257 Ms Konya, Konya Yazma Eserler Bölge Müdürlüğü, 4074/1.

258 «Delâilü’l-hayrât », Türkiye Diyanet Vakfi İslam Ansiklopedisi, 9 (1994), p. 113.

259 Erünsal, Ottoman Libraries, p. 5 ; Naguib, « Guiding the Sound Mind », p. 17 ; Uzunçarşll, Osmanlı Devletinin İlmiye Teşkilatı, p. 14. Sur l'importance de cette œuvre et le nombre 
pour les ottomanistes qui les lisent. Il faut tout de même faire attention: les Sịhāh ne renvoient pas communément au Muhtār al-ṣiḥạh d'al-Rāzī ( $\left.{ }^{\circ}{ }^{57}\right)$, mais au Tāğ al-lug̉a wa-șihạhh al-'arabiyya d'al-Ğawharī ( $\left.\mathrm{n}^{\circ}{ }^{58}\right)$ dont il est le résumé.

Tantôt l'auteur est à ce point identifié que le titre est rapporté à son nom. C'est une forme habituelle dans les vakfiyye que de citer par exemple « Tefsīr-i Ebu-s-su'ūd » ( $\left.\mathrm{n}^{\circ} 8\right)$. Le grand juriste ottoman du $\mathrm{X}^{\mathrm{e}} / \mathrm{XvI}^{\mathrm{e}}$ siècle a certes consacré plusieurs études à l'exégèse coranique. Mais on ne prend nul risque à penser que le titre qui figure dans la vakfyyye renvoie à son maître-ouvrage, celui qui l'a occupé pendant trente ans (Iršād al-'aql al-salìm ilā mazāyā l-kitāb al-karīm ${ }^{260}$ ). À noter que le nom est cité sous l'une de ses formes, mahlās șom de plume) ou nisba, parfois des plus réduites : 'Azmī (no 69), c'est 'Azmīzāde pour les ottomanistes, davantage Hâalitī pour les arabisants ${ }^{261}$. Parfois, on ne s'en sort pas. On lit « hāasşiye-i Beyḍāvī » ${ }^{262}$. Il s'agit d'un commentaire d'al-Bayḍāwī, l'ouvrage de tafsìr de référence chez les Ottomans, utilisé en particulier lors des séances de lecture (huzūr dersleri) ouvertes durant le mois de ramaḍān sous le règne de Mustafa III en 1172/1759 263 . Très bien, sauf que, du fait de son importance autant que des efforts de compréhension qu'il requiert, le Bayḍāwī a fait l'objet de dizaines de commentaires. Figurent dans la liste ceux de Şihāb ed-Dīn, Sa'dī, 'Ịsāâm ed-Dīn, Mollā Huüsrev et Kaạ̣̣ı Zekeriyyā. Qui donc, parmi eux et parmi d'autres, est l'auteur du commentaire auquel il est fait référence? On ne le saura pas. On ne peut même pas proposer d'hypothèse, car aucun de ces commentaires n'a surpassé les autres - tous se complètent et plusieurs d'entre eux sont des classiques ${ }^{264}$. De même, à quel ouvrage en particulier fait référence la mention Sünen fi-l-hadīs $\left(\mathrm{n}^{\circ}\right.$ 21) qui ne désigne rien d'autre que le genre auquel l'ouvrage appartient (les sünen/sunan, des recueils de traditions et de décisions juridiques) ? Parmi les six livres canoniques de la Tradition prophétique, quatre sont appelés sunan.

«stupéfiant » des commentaires qu'elle a suscités, voir al-Musawi, The Medieval Islamic Republic of Letters, p. 99, p. 109-110.

26o Imber, Ebu's-su'ud, p. 18-19.

261 Sur les mentions des auteurs arabes pour un ottomaniste, voir Erünsal, Orta Çağ İslâm Dünyasında Kitap ve Kütüphane, p. 165-169.

262 Sur les problèmes d'identification d'ouvrage du fait de l'absence du nom de l'auteur ou du caractère abrégé du titre, voir Colette Establet et Jean-Paul Pascual, « Les livres des gens à Damas vers 1700 ", Revue des mondes musulmans et de la Méditerranée, 87-88 (1999), p. 143-175, p. 154 ; Zubčević, Book Ownership in Ottoman Sarajevo 1707-1828, p. 151.

263 Ebül'ulâ Mardin, Huzur Dersleri, Istanbul, İsmail Akgün Matbaası, 1951, I, p. 13-15; Abay, «Osmanlı Döneminde Yazılan Tefsir ile İlgili Eserler Bibliyografyası », p. 25 o.

264 Difficile également d'identifier le commentaire du recueil de traditions Șaḥ̄ḥ-i Muslim $\left(n^{\circ} 29\right)$, alors qu'une demi-douzaine d'études au moins sont connues et très employées. 
Le catalogue général du тÜYAток ne permet généralement pas d'identifier plus précisément les références: la description des manuscrits proposée y est sommaire (état général de conservation, taille du volume, langue, script, encre et décorations, nombre de pages, nombre de lignes par page, phrase de début de manuscrit, phrase de fin). Quant à la charte, elle n'indique rien d'autre que le nombre de volumes. La plupart des manuscrits sont formés d'un seul volume («bir cild», est-il écrit). Il faut prendre cette indication au sens matériel : le scribe a légalement le devoir de caractériser ce qui est, physiquement, mis en vakf. Il a un volume sous les yeux, il écrit « un volume $»^{265}$. Or certains ouvrages comptent des milliers de pages. Des volumes peuvent certes dépasser le demi-millier de pages ${ }^{266}$. Mais il y a une limite au talent des relieurs ottomans : comment les 54 chapitres du Șaḥ̆h de Muslim (nº 19) pourraient-ils tenir en un seul volume ? Le Kitāb al-Aġānī (no $\left.{ }^{\circ} 37\right)$ n'est pas seulement « great» (H. Kilpatrick) : il est épais. Les manuscrits existants vont de 2 à 60 parties ${ }^{267}$. Il apparaît en fait que plusieurs ouvrages n'ont été qu'en partie copiés - la liste des 628 manuscrits de la Süleymaniye transférés à Konya en 2012 l'indique explicitement pour plusieurs d'entre eux ${ }^{268}$; la consultation des fonds numérisés des œuvres manuscrites conservées à Konya le confirme ${ }^{269}$. À l'inverse, un volume peut être composé de plusieurs titres différents (c'est mon hypothèse pour $\mathrm{n}^{\mathrm{o}} 7 \mathrm{O}$ ) ou de nombreux textes reliés, de varia (cāmi', mecma) consacrés à un même domaine ou, à l'inverse, à des sujets différents - souvent, le scribe (dans une liste de la vakfyye) comme le bibliothécaire (dans un catalogue) intitule le compendium en fonction de la discipline ou du titre qu'il estime le plus important ${ }^{270}$. Dans certains cas, l'indication mecmū'a renvoie au texte assorti de commentaires et gloses (le Kitāb Ițbāt al-wāğib d'al-Dawānī,

265 Sur le « one-text-one-title system of cataloguing » dans les bibliothèques arabes médiévales, voir Konrad Hirschler, «'Catching the Eel' - Documentary Evidence for Concepts of the Arabic Book in the Middle Period », Journal of Arabic and Islamic Studies, 12 (2012), p. 224-234, p. 227-228.

266 Pour ne donner qu'un exemple, un exemplaire du volumineux recueil de fatwas de Tātārhāāniyye ( $\left.n^{\circ} 85\right)$ jadis conservé à la mosquée Selīmiyye d'Edirne aurait comporté 1206 pages (Onur, Edirne Vakıf Kütüphaneleri, p. 47).

267 Hilary Kilpatrick, Making the Great Book of Songs: Compilation and the Author's Craft in Abū l-Faraj al-Ișbahānìs Kitāb al-Aghānī, Londres-New York, Routledge («Routledge Curzon Studies in Arabic and Middle Eastern Literature »), 2003, p. 30.

268 «Burdur Kitapları Süleymaniye'den Konya'ya Devir-Teslim Listesi, 21-6-2012», no 312. C'est le cas de manuscrits de la bibliothèque d'al-Azhar (fonds du XIX ${ }^{\mathrm{e}}$ siècle). Je remercie R. Soler pour cette indication.

269 C'est par exemple le cas du ms Konya, Konya Yazma Eserler Bölge Müdürlüğü, 38o3 qui correspond à une partie du Șaḥịh d'al-Buhāāī ( $\mathrm{n}^{\circ}$ 19; sommaire indiqué en début de manuscrit).

270 Zubčević cite des mecmūa mentionnés dans des vakfiyye de Sarajevo qui contiennent jusqu’à huit travaux différents (Zubčević, Book Ownership in Ottoman Sarajevo 1707-1828, 
$\mathrm{n}^{\circ}$ 66). Dans d'autres, il recouvre une désignation générique qui ne permet pas d'identifier le contenu du manuscrit: «Sünenü-l-hֵavāṣs fî̀-l-ḥadīs » (no 22),

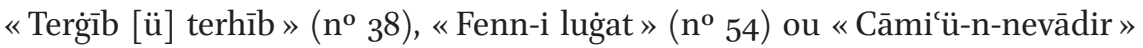
$\left(n^{\circ} 100\right)$.

12

Corpus

Les 106 titres du corpus sont présentés sous la forme suivante:

$\mathrm{N}^{\circ}$ de classement dans la vakfyyye [le signe * signifie que je n'ai pu identifier précisément l'œuvre correspondante]; « intitulé du manuscrit en ottoman tel qu'il figure dans la charte $»^{271}$; nombre de volumes ${ }^{272}$; titre de l'ouvrage correspondant dans la langue de composition et identification de l'auteur; présentation résumée. Bibliographie.

La bibliographie indiquée est celle qui m’a permis d'identifier les titres cités, de les situer dans l'ensemble de la collection, de les comparer à des manuscrits correspondants issus des bibliothèques de Burdur et de la bibliothèque Halīl Ḥamīd Pacha d'Isparta et, enfin, de les inscrire dans la littérature ottomane des madrasas. Elle ne vise ni à rendre compte des études, éditions et commentaires suscités par chacun des ouvrages, ni à suivre leur devenir après la constitution de la bibliothèque.

1. « Tefsīr-i kạḍī Beyḍāvī »; Anwār al-tanzīl wa-asrār al-tāìūl. Il s'agit de l'œuvre la plus importante d'al-Bayḍāwī, cadi en chef chaféite à Chiraz (m. ca 685/ 1286). Placée au sommet du genre exégétique, elle fut composée à partir d'al-Kaššă $f$ d'al-Zamahšarī ( $\left.{ }^{\circ}{ }_{56}^{6}\right)$, somme de connaissances pétries par des opinions mu'tazilites, en partie corrigées par al-Bayḍāwī. Des ottomanistes en ont repéré plus de 250 commentaires et études. Bibliographie : TÜYATOK, Burdur I, Ankara, Milli Kütüphane Basımevi («Kataloglar Dizisi», 15), 200o, p. 178 (15 H.K. 525); « Burdur Kitapları Süleymaniye'den Konya'ya Devir-Teslim Listesi, 21-6-2012 », no 580, 610, 611 ; İsmail Cerrahoğlu, « Envârü’t-tenzîl ve esrârü’t-te’vîl», Türkiye Diyanet Vakfı İslam Ansiklopedisi, 11 (1995), p. 26o-261;

p. 228). Voir aussi Erünsal, «A Brief Survey of the Development of Turkish Library Catalogues » ; id., Ottoman Libraries, p. 5.

271 Je n'indique des majuscules aux transcriptions que pour les initiales des noms de titre ou d'auteur. Le système de translittération adopté est celui de Nicolas Vatin, Initiation à l'ottoman.

272 Sauf précision contraire, je l'indique uniquement quand le manuscrit comporte au moins deux volumes. 
James Robson, «al-Bayḍāwī », $E I^{2}$, 1 (1960), p. 1163 ; Brockelmann, Geschichte der arabischen Litteratur, I, p. 530-533 et SI, p. 738-743.

2. «Tefsīr-i Hāzin »; Lubāb al-ta’wìl fı̀ ma'ānì l-tanzīl ; 2 vols; c'est l'œuvre principale de 'Alā' al-Dīn Ḩāzin al-Bag̉dādī (m. 741/134O-1341), lettré natif de Bagdad, formé en Syrie. Achevée en 725/1325, c'est principalement une émondation (tahdīib) de Máälim al-tanzïl (voir $\mathrm{n}^{\circ}$ 7), le fameux tafsìr d'al-Bag̉awī (m. 516/1122) assorti de quelques autres tafsirs. Souvent, le texte est publié avec, dans les marges, des éléments du tafsìr d'al-Nasafì, Madārikal-tanzīl (voir no 4) ; 2 vols. Bibliographie : Ms Konya, Konya Yazma Eserler Bölge Müdürlüğü, 3756 ; Brockelmann, Geschichte der arabischen Litteratur, I, p. 133; Ali Eroğlu, «Hâzin, Ali b. Muhammed», Türkiye Diyanet Vakfı İslam Ansiklopedisi, 17 (1998), p. 125-126.

3. «Tefsīr-i İbn 'Abbās »; Tanwìr al-miqbās min tafsìr Ibn 'Abbās. L'ouvrage est attribué à 'Abd Allāh b. al-'Abbās (m. ca 68/687), cousin paternel du Prophète et ancêtre des Abbassides. Le tafsìr auquel son nom est associé fut caractérisé comme la réunion de ses explications coraniques dans des recueils dont les chaînes de garants (isnād) remonteraient à l'un de ses élèves immédiats. Il fut difficile d'établir les différences entre ce que les lettrés ont transmis et ce qu'ils ont eux-mêmes ajouté. Bibliographie : TÜYATOK, Burdur I, p. 225-226 ; Sezgin, Geschichte des arabischen Schrifttums, I, p. 25-28; İsmail L. Çakan, Muhammed Eroğlu, « Abdullah b. Abbas », Türkiye Diyanet Vakfi İslam Ansiklopedisi, 1(1988), p. 76-79; İsaiah Goldfeld, «The Tafsìr of Abdallah b. 'Abbās », Der Islam, 58 (1981), p. 125-135.

4. « Tefsīr-i medārik»; Madārik al-tanzïl wa-ḥaqā̄iq al-ta’wīl. Il s'agit du Tafsìr al-Nasafí composé par Hââiz al-Dīn Abū l-Barakāt al-Nasafì (m. 710/1310), jurisconsulte et théologien hanafite, natif de Nasaf, surtout connu pour son ouvrage de droit, Kitāb al-Manār fì ușūl al-fiqh (voir no 69). Bibliographie: TÜYATOK, Burdur I, p. 196-197 (15 H.K. 1232); Brockelmann, Geschichte der arabischen Litteratur, II, p. 252 et SII, p. 267 ; Wilhelm Heffening, « al-Nasafì, Ḥāfiz al-Dīn Abū l-Barakāt », $E I^{2}, 7$ (1993), p. 969-970 ; Mustafa Öztürk, « Medârikü't-tenzîl ve Hakâiku't-te'vîl», Türkiye Diyanet Vakfı İslam Ansiklopedisi, 28 (2003), p. 292-293.

5. «Tefsīr-i celāleyn»; Tafsīr al-ğalālayn. L'ouvrage fut composé par Ğalāl al-Dīn al-Mahallī (m. 864/1459-146o) et son élève Ğalāl al-Dīn al-Suyūṭi (m. 911/1505). Il contient l'exégèse du « Hizb al-mufașsal » qui débute par la sourate 49 (al-Huğurāt: «Les appartements ») au lieu de la sourate 50, et se poursuit jusqu'à la fin du Coran (sourate 114), ainsi que le commentaire de la 
sourate al-Fātiḥa. Considéré comme l'un des ouvrages d'exégèse les plus accessibles du fait de son style bref et concis et de sa taille réduite, il fut très employé dans les madrasas ottomanes. Bibliographie : TÜYATOK, Burdur I, p. 223. (15 H.K. 1229); Ali Akpınar, «Tefsîrü'l-Celâleyn », Türkiye Diyanet Vakfi İslam Ansiklopedisi, 40 (2011), p. 294-295.

6. «Tefsīr-i lețāiif-i $L[\bar{a}] \mathrm{mi}^{\prime} \bar{»}$ ». Il s'agit probablement d'un commentaire du Lețāifnāme de Lāmi'î Çelebi (m. 938/1531-1532), poète, auteur de mesnevis et traducteur (notamment du poète persan Mollā Ğamī) néà Bursa. Le Lețẩifnāme est une œuvre satirique en prose en cinq parties appréciée pour ses traits d'humour et la finesse de ses descriptions de situations et de personnalités. L'œuvre est rédigée en turc, le commentaire l'est sans doute également. Bibliographie: Günay Kut Alpay, «Lamiî Chelebi and His Works », Journal of Near Eastern Studies, 35/2 (1976), p. 73-93, p. 82 ; Nuran Tezcan, «Bursalı Lāmiî îelebi », Türkoloji Dergisi, 8/1 (1979), p. 305-345 et 334-335 ; Yaşar Çalışkan (éd.), Lami î Çelebi, Latîfeler Kitabı. Letâif-i Lâmi î̀, Istanbul, Büyüyenay Yayınları, 2015.

7. «Tefsīr-i meālimü-t-tenzīl»; Macālim al-tanzīl. Abū Muḥammad Mas'ūd al-Bag̉awī (m. 510/1117, 515/1121 ou 516/1122), traditionniste et exégète chaféite, natif de la région de Hérat, est surtout connu pour ses recueils de hadiths. Bibliographie: Brockelmann, Geschichte der arabischen Litteratur, I, p. 449 et SI, p. 622 ; Eerik Dickinson, « al-Baghawī, Abū Muhammad », EI $I^{3}$.

8. «Tefsīr-i Ebu-s-su'ūd »; 3 vols ; Ebu-s-su'ūd (m. 982/1574) est souvent présenté comme l'un des şeyh̆ü-l-islām les plus importants de l'histoire ottomane. Le titre cité correspond à son maître-ouvrage : Iršăd al-'aql al-salīm ilā mazāya l-kitāb al-karìm. Considéré comme le livre ottoman de tafsìr le plus important, il s'inscrit dans la lignée méthodologique du Tafsìr d'al-Bayḍāwī $\left(\mathrm{n}^{\circ}{ }_{1}\right)$ et d'al-Kaššăf d'al-Zamahšarī ( $\left.{ }^{\circ}{ }^{6} 6\right)$. Bibliographie : Ms Konya, Konya Yazma Eserler Bölge Müdürlüğü, 4002; Brockelmann, Geschichte der arabischen Litteratur, II, p. 580 ; Shuruq Naguib, « Guiding the Sound Mind: Ebu's-su'ūd's Tafsir and Rhetorical Interpretation of the Qur'an in the Post-Classical Period », Osmanlı Araştırmaları, 42 (2013), p. 1-52 ; Repp, The Müfti of Istanbul, p. 272296 ; Colin Imber, Ebu's-su'ud: The Islamic Legal Tradition, Stanford, Stanford University Press, 1997, p. 18.

9. «Tefsīr-i nezīlü-t-tenzīl »; Nazīl al-tanzīl, également appelé Tafsìr al-Munšù, achevé en 999/1591 par Meḥmed Aḳ̣ișāiñ (dit Șarūḩanī ou Münşī ; m. ca 1oo1/ 1593), né à Manisa, dans le kaza de Akhisar. Il s'agit d'un commentaire très répandu du Coran dans lequel l'auteur mêle de précédentes analyses à ses propres interprétations. Bibliographie: Brockelmann, Geschichte der 
arabischen Litteratur, II, p. 580 ; Adem Yerinde, « Münşî̀, Türkiye Diyanet Vakfı İslam Ansiklopedisi, 32 (2006), p. 22-23.

10. «Ḥāşiye-i Şihāb ed-dīn 'alā-l-Beyḍāvī» ; 4 vols; Ināyāt al-qāộ̄ wa-kifāyāt al-rāḍ̄ 'alā Anwār al-tanzīl. Il s'agit d'un commentaire du Anwār al-tanzīl d'al-Bayḍāwī par Šihāb al-Dīn al-Hafāāīì (m. 1069/1658-1659), natif d'une bourgade proche du Caire. C'est son ouvrage le plus connu et le plus volumineux. L'auteur y suit une méthode fastidieuse qui consiste à expliquer chaque mot et à reproduire les explications des commentateurs précédents. Bibliographie: Ms Konya, Konya Yazma Eserler Bölge Müdürlüğü, 4028 et 4029 (32 H.K. 1653-1 et 2): vols 1 et 3 ; TÜYATOK, Isparta ( ${ }^{\circ}$ 288, p. 166); Brockelmann, Geschichte der arabischen Litteratur, SII, p. 396 ; Şahin, Rodos Fethi Pasa Vakfi, p. 43 ; Şükru Maden, «Osmanlılar'da el-Keş̧̧âf ve Envâru't-Tenzîl Hâşiyeleri », Türkiye Araştırmaları Literatür Dergisi, 9/18 (2011), p. 241-273 ; Ali Şakir Ergin, « Hafâcî, Şehâbeddin », Türkiye Diyanet Vakfi İslam Ansiklopedisi, 15 (1997), p. 72-73; Fritz Krenkow, «al-Khafādjī », $E I^{2}$.

11*. « Șādıḳ̂ 'alā-l-Beyḍāvī ». Il s'agirait d'un commentaire du chaféite Maḥmūd b. al-Ḥusayn al-Ṣaạdiqī plus connu sous le nom d'al-Ṣādiqiī (m. 970/1562-1563) ${ }^{273}$.

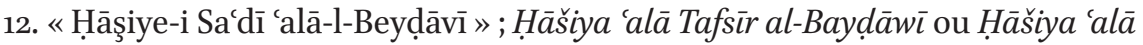
Anwār al-tanzīl. Ce commentaire de la sourate 67 (al-Mulk: «La royauté») par Sádī Çelebi (m. 945/1538), şeyhü̈-l-islām natif de la région de Kastamonu, est l'œuvre la plus diffusée de ce spécialiste de tafsìr et de fiqh. Bibliographie : TÜYATOK, Burdur I, p. 185 (15 H.K. 1530/3); Ms Konya, Konya Yazma Eserler Bölge Müdürlüğü, 4035; Mehmet İpşirli, Ziya Demir, «Sādī Çelebi », Türkiye Diyanet Vakfi İslam Ansiklopedisi, 35 (2008), p. 404-405; Demir, Osmanlı Müfessirleri ve Tefsir Calışmaları, p. 324-330 ; Şükrü Maden, «Osmanlı Tefsir Geleneğinde Haşiyeciliğin Önemi. Şeyhülislam Sa‘dî Çelebi'nin (ö. 945/1539) Haşiye-i sûre-i mülk 'ale'l-kâdî el-Beyzâvî İsimli Hâşiyesi Örneğinde Bir Değerlendirme », dans Tefsir: Osmanlı Toplumunda Kur’an Kültürü ve Tefsir Çalışmaları, éd. Bilal Gökkır et al., Istanbul, İlim Yayma Vakfı Kur’an ve Tefsir Akademisi, 2013, II, p. 57-89 ; Repp, The Müfti of Istanbul, p. 240-244.

13*. « 'Ịsām ed-Dīn 'alā-l-Beyḍāvī ». Il s'agit d'une glose de l'exégèse d'al-Bayḍāwī

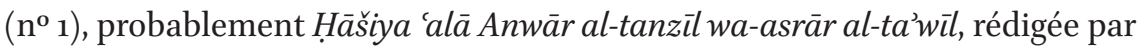

273 Je remercie L. Daaïf qui a tiré cette information de la référence suivante: Aḥmad b. Muḥammad al-Adnarwī, Ṭabaqāat al-mufassirīn, éd. Sulaymān b. Ṣaliḥ al-Ḩazzī, Médine, Maktabat al-'ulūm wa-l-hikam, 1970, p. 39o. 
'İșām al-Dīn Ibrāhīm al-Isfarāyīnī (m. 943/1536-1537), grammairien et rhétoricien originaire du nord-ouest du Khorasan, connu pour ses commentaires en diverses sciences islamiques. La glose de l'exégèse d'al-Bayḍāīi s'étend jusqu'à la sourate 7 (al-A'rāf). Il existe un autre commentaire, Anwār al-tanzīl par un homonyme, İṣām ed-Dīn İsmāīl b. Meḥmed ül-Ḳonevī (m. 1195/1781). À noter que 'Uşşāḳizāde 'Abd ül-Bāḳ̂̄ (m. 109o/1680) a rédigé une glose à partir

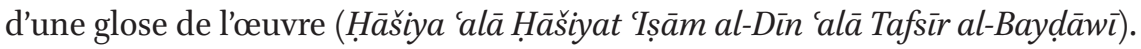
Bibliographie: TÜYATOK, Burdur I, p. 184 (15 H.K. 1311/1); Brockelmann, Geschichte der arabischen Litteratur, I, p. 531; İsmail Durmuş, «İsferâyînî, İsâmüddîn», Türkiye Diyanet Vakfı İslam Ansiklopedisi, 22 (2000), p. 516517 ; Şahin, Rodos Fethi Pasa Vakfi, p. 16 ; Maden, «Osmanlılar'da el-Keşşâf ve Envâru't-Tenzîl Hâş̧iyeleri », p. 253 et 266 ; Khaled El-Rouayheb, « al-Isfarāyīn̄i, 'Ișām al-Dīn », $E I^{3}$.

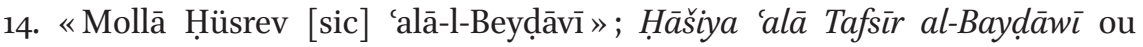
Hāašiya 'alā Anwār al-tanzīl par Mollā Hü̈srev, juriste ottoman natif de la région de Sivas-Tokat (m. 885/1480). La glose porte sur la partie du texte coranique qui s'étend jusqu'à la fin de la sourate al-Baqara. Bibliographie: TÜYATOK, Burdur I, p. 182 (15 H.K. 12/4); TÜYATOK, Isparta (32 H.K. 1673); MS Konya, Konya Yazma Eserler Bölge Müdürlüğü, 4056; Abay, «Osmanlı Döneminde Yazılan Tefsir ile İlgili Eserler Bibliyografyası», p. 286; Ferhat Koca, «Molla Hüsrev », Türkiye Diyanet Vakfı İslam Ansiklopedisi, 30 (2005), p. 252-254; Maden, «Osmanlılar'da el-Keşşâf ve Envâru't-Tenzîl Hâşiyeleri », p. 248-249; Repp, The Müfti of Istanbul, p. 155-166.

15. « Kạạ̣ı Zekeriyyā 'alā-l-Beyḍāvī »; Ta'lìqāt 'alā Tafsìr sūrat al-A'rāf min Anwār al-tanzīl de Bayrāmzāde Zekeriyyā Efendī, şeyhü̈-lislām (m. ca 1001/1593) natif d'Ankara. Il s'agit d'un commentaire du Tafsīr d'al-Bayḍāwī, Anwār al-tanzīl, consacré à la sourate 7 (al-A'rāf: «Les redans »). L'auteur est surtout connu pour ses commentaires de figh du Šarh al-Wiqāya de Șadr al-Šarīa (no 89) et son étude des Ma'ānī intitulée Hiāšiya 'alā Šarḥ al-Miftāḥ (en référence au Miftāḥ al-'ulūm d'al-Sakkākī, no 33). Bibliographie: Maden, «Osmanlılar'da el-Keş̧̧âf ve Envâru't-Tenzîl Hâşiyeleri », p. 264 ; Mehmet İpşirli, «Zekeriyyâ Efendi, Bayramzâde», Türkiye Diyanet Vakfı İslam Ansiklopedisi, 44 (2013), p. 211-212.

16. «Hâāşiye-i Beyḍāvī-i Bostān Efendī»; Hāšìiya 'alā Tafsìr sūrat al-An'ām. L'auteur est Bostān Çelebi (m. 977/1569-1570), lettré et historien ottoman natif de Tire. Il s'agit d'un commentaire du Tafsìr d'al-Bayḍ̂āī consacré à l'étude de la sourate 6 (al-An`ām: «Les bestiaux») qui s'appuie notamment sur de 
précédents commentaires par Șadr al-Šarīa ( $n^{\circ}$ 89) et Kemālpaşazāde $\left(n^{\circ}\right.$ 91). Bibliographie: Abay, «Osmanlı Döneminde Yazllan Tefsir ile İlgili Eserler Bibliyografyası », p. 266 ; Nezihi Aykut, « Bostan Çelebi », Türkiye Diyanet Vakfı İslam Ansiklopedisi, 6 (1992), p. 308.

17. «Maḳāṣıd-ı ḥasane-i müştehire ${ }^{274}$ fî-l-ḳırāat ». Il s'agit vraisemblablement d'al-Maquạsid al-hasana fì bayān kațìr min al-ậādît al-muštahara 'alā l-alsina composé par le traditionniste Šams al-Dīn al-Sahāwī (m. 902/1497). Tiré de l'exploitation d'un demi-millier de sources, ce volumineux recueil de hadiths fut l'un des plus utilisés par les savants ottomans. Il a suscité de nombreuses études. Bibliographie: Adil Yavuz, «el-Makāsidü'l-hasene», Türkiye Diyanet Vakfi İslam Ansiklopedisi, 27 (2003), p. 422-423.

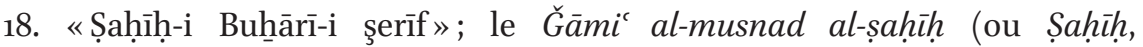
«L'authentique ») fut composé par le traditionniste de Transoxiane al-Buhārī (m. 256/870). C'est l'un des six recueils canoniques du hadith. Dans l'islam sunnite, il est considéré comme le livre le plus important après le Coran. Composé de 97 chapitres, ce volumineux recueil s'attache à classer par matière les traditions (entre 2602 et 4000 ) retenues comme valables. Estimé pour ses introductions en tête de chapitre, il aborde les sujets du rituel et du droit sous de multiples angles. Bibliographie : TÜYATOK, Isparta, p. 185 (32 H.K. 1468); TÜTATOK, Burdur I, p. 241 (15 H.K. 1831); Ms Konya, Konya Yazma Eserler Bölge Müdürlüğü, 3803 ; « Burdur Kitapları Süleymaniye'den Konya'ya Devir-Teslim Listesi, 21-6-2012 », nº 312, 400, 401, 481, 482, 540-544; Brockelmann, Geschichte der arabischen Litteratur, I, p. 163-166 et sI, p. 260-265; James Robson, «al-Bukhārī», $E I^{2}$; Mehmet Yaşar Kandemir, «El-Câmiu's-sahîh», Türkiye Diyanet Vakfi İslam Ansiklopedisi, 7 (1993), p. 114-123 (avec ses plus importants commentaires); Sezgin, Geschichte des arabischen Schrifttums, I, p. 115-134; Brown, The Canonization of al-Bukhārī and Muslim, p. 69-71; Lahcen Daaif, «L'extension du domaine du șaḥiḥ», Annales islamologiques, 50 (2016), p. 324-334.

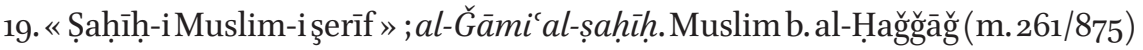
est un traditionniste né à Nichapour. Appelé al-Ṣaḥịh (L'authentique) à l'instar de celui d'al-Buhārī ( $\left.n^{\circ}{ }_{18}\right)$, l'ouvrage est l'un des six recueils canoniques du hadith. Volumineux, constitué de 12000 traditions environ avec 4 ooo répétitions, réparties en 54 chapitres et correspondant aux principales questions du figh et de la théologie, il se distingue par son introduction qui traite de la

274 Le copiste a noté « mükerrere » (« répétée »). C'est une erreur, semble-t-il. 
science des hadiths, un chapitre préliminaire sur la foi et le regroupement au sein d'un même chapitre des répétitions de traditions. Bibliographie: Brockelmann, Geschichte der arabischen Litteratur, I, p. 168-166 et SI, p. 265266; Gautier H.A. Juynboll, « Muslim b. al-Ḥadjādj », $E I^{2}$; Yaşar Kandemir, «El-Câmiu's-sahîh », Türkiye Diyanet Vakfi İslam Ansiklopedisi, 7 (1993), p. 124129; Brown, The Canonization of al-Bukhārī and Muslim, p. 82-86; Lahcen Daaïf, « L'extension du domaine du șaḥịh».

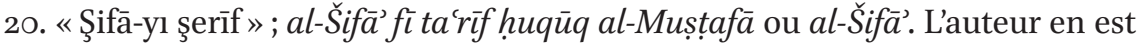
'Iyāọ al-Yaḥ̣ubī l-Sabtī, farouche défenseur du malékisme, appelé Qāḍī 'Iyāọ (m. 544/1149). Cet ouvrage d'éthique célèbre les mérites du Prophète et traite des règles de bonne conduite sur la base de l'étude de sa vie. Très empreint de mystique soufie, le recueil connaît une grande diffusion et joue un rôle important dans le renouveau de la piété aux XI ${ }^{\mathrm{e}} / \mathrm{XVII}^{\mathrm{e}}-\mathrm{XII}^{\mathrm{e}} / \mathrm{XVIII}^{\mathrm{e}}$ siècles. Bibliographie : Mohammed Talbi, «'Iyāḍ b. Mūsā », $E I^{2}$; Yaşar Kandemir, « eş-Şifā », Türkiye Diyanet Vakfi İslam Ansiklopedisi, 39 (2010), p. 134-138 (cite 16 commentaires de l'époque ottomane); Ruggero Vimercati Sanseverino, «Transmission, Ethos and Authority in Hadith Scholarship: A Reading of al-Qāḍī 'Iyāḍ's (476544/1083-1149) Handbook of Hadith Science The Elucidation of the Principles of Transmission and of the Transcription of Audition », Mélanges de l'Institut dominicain d'études orientales (à paraître ; non consulté).

21*. «Sünen fì-l-ḥadīs ». Quatre des six recueils de hadiths dits canoniques (al-kutub al-sitta) sont désignés sous la forme générique de Sunan. Composés par Abū Dāwūd (m. 275/888), al-Tirmid̄ī (m. 279/892, no 28), al-Nasầī (m. 303/915) et Ibn Māğā (m. 273/887), ils recueillent des dits, actes et gestes du Prophète (aqwāl wa-af'āl) en chapitres distincts divisés en paragraphes relatifs aux « actes cultuels d'adoration » ( $i b \bar{a} d \bar{a} t$ ) et aux «relations sociales» entre musulmans (mu'āmalāt). Bibliographie: Yaşar Kandemir, «Sünen», Türkiye Diyanet Vakfi İslam Ansiklopedisi, 38 (2010), p. 141-142; Gautier H.A. Juynboll, «Sunan»,EI $I^{2}$.

22*. «Sünenü-l-hַavāṣs fî̀-l-ḥadīs ». Il s'agit peut-être de l'œuvre de Yūsuf Šams al-Dīn Abū l-Muẓaffar, plus connu sous le nom de Șibṭ Ibn al-Ğawzī (m. 654/1256), Tadkiratal-hawāsș qui traite des mérites des Gens de la maison (la famille du Prophète, Āl al-Bayt), à commencer par le calife 'Alī b. Abī Ṭālib (m. 40/661), puis les deux fils de ce dernier et leur martyre ${ }^{275}$.

275 Cette possibilité m’a été suggérée par L. Daaïf. Je l'en remercie vivement. 
23. « Şerḥ-i cāmi 'ü-ṣ-ṣagīr-i Münāvī » ; 2 vols ; il s'agit du commentaire d'al-Ğāmic al-ṣagìr d'al-Munāwī, docteur de la loi et soufi égyptien (m. 1031/1621-1622), lequel Ğāmic est un résumé de l’œuvre inachevée du Ğam 'al-ğawāmic du célèbre savant égyptien al-Suyūṭi (m. 911/1505), dernière grande compilation de la tradition prophétique. Quatre commentaires sont identifiés. S'agit-il du plus populaire d'entre eux, le Fayḍ al-qadìr šarh al-Ğāmi al-ṣag̀ìr ? Bibliographie : Saleh Hamdan, «al-Munāwī », $E I^{2}$; Mücteba Uğur, «el-Câmi's-sagīr», Türkiye Diyanet Vakfı İslam Ansiklopedisi, 7 (1993), p. 113-114; Éric Geoffroy, « al-Suyūțī »,EI $I^{2}$.

24. «Şerḥ-i şifă’ li-'Alī el-Ḳārī ». Il s'agit d'un commentaire d'al-Šifă’ de Qāọī 'Iyāọ al-Sabtī (no 20) par 'Alī b. Sulțān Muḥammad al-Qārī (m. 1014/16o5, no 28), molla mecquois originaire de Hérat, dans le Khorasan, jurisconsulte et traditionniste hanéfite, l'un des auteurs les plus prolifiques de l'époque moderne. Achevé à La Mecque en 1011/16o2-1603, c'est le plus important de ses sept travaux identifiés de prophétologie. Bibliographie : Yaşar Kandemir, «eş-Şifā », Türkiye Diyanet Vakfi İlam Ansiklopedisi, 39 (2010), p. 134-138, p. 136; Ahmet Özel, « Ali el-Kârî», Türkiye Diyanet Vakfi İslam Ansiklopedisi, 2 (1989), p. 403405 ; Patrick Franke, « The Ego of the Mullah: Strategies of Self-Representation in the Works of the Meccan Scholar 'Alī al-Qārī (d. 16o6) », dans Mary Ways of Speaking about the Self: Middle Eastern Ego Documents in Arabic, Persian, and Turkish (14th-2oth Century), éd. Ralf Elger et Yavuz Köse, Wiesbaden, Harrassowitz («Mîzân », 18), 2010, p. 185-200.

25. «Şerḥ-i hadīisüül-erbaīn Nevevī ve et-Ṭavāfì [sic] ». Il s'agit du commentaire par Nağm al-Dīn al-Ṭūfi (m. 716/1316-1317), savant hanbalite, intitulé Kitāb al-Ta'yin fi šarh al-arbaìn et abrévié Šarh al-arbaìn, tiré du Kitāb al-arbaìn (al-Arbaün al-nawawiyya), recueil de quarante hadiths choisis par al-Nawawī (m. 676/1277; İmām Nevevī pour les Ottomans). Dans son commentaire, al-Ṭūî bâtit une théorie audacieuse sur le principe d'utilité (mașlaha a) que des réformistes de la fin du XIX ${ }^{\mathrm{e}}$ siècle redécouvrent et adaptent au principe d'intérêt public. Bibliographie : Leila Demiri, «Tūfì », Türkiye Diyanet Vakfi İslam Ansiklopedisi, 41 (2012), p. 324-327, p. 326 ; Wolfhart P. Heinrichs, «al-Ṭüfï, Nadjm al-Dīn », $E I^{2}$; Wilhelm Heffening, «al-Nawawī », $E I^{2}$; Yaşar Kandemir, « Nevevî », Türkiye Diyanet Vakfı İslam Ansiklopedisi, 33 (2007), p. 45-49, p. 47.

26. « Kitābü-l-kāşifi-z-ZZehebī ». Šams al-Dīn al-Dַhahāi (m. 753/1352-1353), historien et théologien, est l'auteur du Kitāb al-Kāšiif fı̀ márifat man lahu riwāya fì l-kutub al-sitta wa-hāšsiyatuhu. Il s'agit d'un recueil de biographies résumées de savants traditionnistes. Bibliographie: «al-Dhahabī, Shams al-Dīn », $E I^{2}$; 
Tayyar Altıkulaç, «Zehebî», Türkiye Diyanet Vakfı İslam Ansiklopedisi, 44 (2013), p. 180-188.

27. « Mașābīḥ-i şerīf »; il s'agit probablement de Mașābịh al-sunna ${ }^{276}$ composé par le savant chaféite al-Baġawī (m. 516/1122) natif de la région de Hérat $\left(\mathrm{n}^{\circ} 3^{2}\right)$. Classé par sujets, ce recueil de traditions différencie soigneusement, dans chaque chapitre, les traditions « authentiques » (șaḥịh, celles d'al-Buhāāī et Muslim), bonnes (hașan, relevées chez Abū Dāwūd ou Tirmid̄ī) et faibles (daîf). L'auteur précise qu'il n'en inclut aucune qui soit rejetée ou apocryphe. Bibliographie : James Robson, «al-Baghawī », $E I^{2}$; İbrahim Hatiboğlu, «Mesâbîhu's-Sünne », Türkiye Diyanet Vakfı İslam Ansiklopedisi, 29 (2004), p. 258-26o.

28. «Şerḥ-i şemā’il li-'Alī el-Kāāī »; Ğam`al-wasā̉il fì šarh al-šamā’il par al-Qārī $\left(n^{\circ} 24\right)$. C'est l'un des commentaires les plus importants et les plus diffusés dans les bibliothèques de madrasa de l'ouvrage de sìra d'al-Tirmidīi (m. 279/892), Kitāb al-Šamäil al-nabawiyya, collection de traditions traitant uniquement des caractères et pratiques visibles du Prophète. Bibliographie: Ms Konya, Konya Yazma Eserler Bölge Müdürlüğü, 3997; TÜYATOK, Isparta, p. 569, no 971 (32 H.K. 1624); Brockelmann, Geschichte der arabischen Litteratur, I, p. 170 ; Gautier H.A. Juynboll, « al-Tirmidhī », $E I^{2}$; « eş-Şemâilü'n-Nebeviyye », Türkiye Diyanet Vakfi İslam Ansiklopedisi, 38 (2010), p. 500-501; Ahmet Özel, « Ali el-Kârî», Türkiye Diyanet Vakfi İslam Ansiklopedisi, 2 (1989), p. 403-405.

29*. « Şerḥ-i Ṣaḥịh-i Muslim »; 5 vols ; il s'agit d'un ou de plusieurs commentaires du recueil Șahịh de Muslim ( $\mathrm{n}^{\circ}$ 19). Parmi les nombreux commentaires connus des Ottomans, une demi-douzaine sont très employés. Bibliographie: Gautier H.A. Juynboll, «Muslim b. al-Hadjâdj », $E I^{2}$; M. Yaşar Kandemir, «El-Câmiu's-sahîh », Türkiye Diyanet Vakfı İslam Ansiklopedisi, 7 (1993), p. 124129 ; Sezgin, Geschichte des arabischen Schrifttums, I, p. 136-143.

30* « Şerḥ̂-i ḥizb-ü-l-a àzam li-'Alī el-Ḳārī ». C’est un commentaire de l'œuvre d'al-Qārī (ñ 24, 28), al-Hizb al-a'zam wa-l-wird al-afham qui rassemble des litanies et oraisons à réciter quotidiennement tirées de versets coraniques et de hadiths authentiques. Imprégné d'une piété soufie transconfrérique, riche en poésie, l'ouvrage traite largement des vertus miraculeuses. Alors que les « deux

276 De la même manière, le Dalāil al-hayrāt $\left(\mathrm{n}^{\circ}{ }_{31}\right)$ est souvent appelé par les lettrés ottomans Delāill-i şerîf. Voir « Delâilü'l-hayrât », Türkiye Diyanet Vakfi İslam Ansiklopedisi, 9 (1994), p. 113 . 
saints sanctuaires » étaient placés sous l'autorité ottomane, l'ouvrage était lu à 'Arafāt par le cadi de La Mecque. Bibliographie : Ahmet Özel, «Ali el-Kârî», Türkiye Diyanet Vakfi İslam Ansiklopedisi, 2 (1989), p. 403-405; Patrick Franke, «Querverweis als Selbstzeugnis. Individualität und Intertextualität in den Schriften des mekkanischen Gelehrten Mullā 'Alī al-Qārī (gest. 1014/16o6) », dans Zwischen Alltag und Schriftkultur: Horizonte des Individuellen in der arabischen Literatur des 17. und 18. Jahrhunderts, éds Stefan Reichmuth et Florian Schwarz, Beyrouth-Würzburg, Orient-Institut-Ergon Verlag ( «Beiruter Texte und Studien », 110), 2008, p. 131-164 (non consulté).

31. «Şerḥ-i delāilü̈-l-hayrāt-ı Fāsī»; Mațālic al-masarrāt bi-ğalāi Dalāil al-hayrāt. Ce commentaire fut rédigé par le mystique et historien Muhammad Mahdī al-Fāsī (m. 1052/1642 ?), originaire de Fès, à partir du Dalāil al-hayrāt, prestigieux recueil de prières à l'intention du Prophète (avec des développements sur les noms de ce dernier et les noms de Dieu) composé par al-Ğazūlī (m. 869/1465), membre de la tribu berbère Ğazūla au Maroc et cheikh de la Šādiliyya. Bibliographie: Ms Konya, Konya Yazma Eserler Bölge Müdürlüğü, 3999 ; TÜYATOK, Isparta, nº 810, p. 481 ; Süleyman Uludağ, « Delâilü'l-hayrât », Türkiye Diyanet Vakfi İslam Ansiklopedisi, 9 (1994), p. 113-114 ; Mohammed Ben Cheneb, « al-Djazūlī », $E I^{2}$.

32* . "Miftāḥ 'alā-l-mașābīḥ ». Il s'agit probablement d'un livre d'exercices destiné à l'apprentissage de la collection de hadiths intitulée Maṣābịh al-sunna composée par le traditionniste chaféite Mas'ūd al-Bag̉awī ( $\left.n^{0} 27\right)$. Bibliographie: Brockelmann, Geschichte der arabischen Litteratur, I, p. 448 et SI, p. 620 ; Sezgin, Geschichte des arabischen Schrifttums, I, p. 155 ; James Robson, « al-Baghawī », EI ${ }^{2}$; İbrahim Hatiboğlu, « Mesâbîhu's-Sünne », Türkiye Diyanet Vakfi İslam Ansiklopedisi, 29 (2004), p. 258-26o.

33. «Miftāḥü-l-'ulūm »; Miftāḥ al-'ulūm. Célèbre et très employé, cet ouvrage du rhétoricien Muhammad al-Sakkākī (m. 626/1229), natif du Khwarizm, vise à englober toutes les disciplines linguistiques, à l'exception de la lexicographie (lugia). Il développe une distinction entre șarf (morphologie), naḥw (syntaxe) et 'ilm al-ma'ānì wa-l-bayān (stylistique et théorie du langage figuratif). Bibliographie : « Burdur Kitapları Süleymaniye'den Konya'ya Devir-Teslim Listesi, 21-6-2012 », no 4; Brockelmann, Geschichte der arabischen Litteratur, I, p. 352-354; Bilge, İlk Osmanlı Medreseleri, p. 55-56; William Smyth, « Some Quick Rules Ut Pictura Poesis: The Rules for Simile in Miftāh al-Ulüm», Oriens, 33 (1992), p. 215-229; Mehmet Sami Benli, «Miftâhu'l-ulūm », Türkiye 
Diyanet Vakfi İslam Ansiklopedisi, 30 (2005), p. 20-21; Wolfhart P. Heinrichs, «al-Sakkākī », $E I^{2}$; Seeger Adrianus Bonebakker, « al-Macānī wa-l-bayān », $E I^{2}$.

34*. «Ṭabakạat-ı Kānī»; Toḳadlı Kānī Ebūbekir Efendī (m. 1206/1792) a rédigé des ouvrages de composition et de poésie. Mais, sauf erreur, il n'est l'auteur d'aucun recueil de țabaqāt.

35. «Şerḥ-i şir'a li-es-Seyyīd 'Alīzāde »; il s'agit d'un commentaire du Šir'at al-islām par Yáḳūb b. Seyyīd 'Alī el-Bursevī (m. 931/1524). Šir'at al-islām correspond possiblement à un ouvrage d'adab écrit par Imāmzāde Muḥammad b. Abū Bakr (m. 573/1177), savant de Samarcande.

36. « Menāḳib-i imām Aḥmed Ḥanbal»; Manāqib al-imām Aḥmad b. Hanbal. Aḥmad b. 'Alī b. al-Ğawzī (m. 597/1201), savant et prédicateur hanbalite né à Bagdad, est l'un des auteurs les plus prolifiques du monde arabe. L'ouvrage est une hagiographie d'Ahmad b. Ḥanbal (m. 241/855), fondateur présumé de l'école juridique hanbalite. Bibliographie : Angelika Hartmann, «Les ambivalences d'un sermonnaire ḥanbalite: Ibn al-Ğawzī (m. en 597/1201), sa carrière et son ouvrage autographe, le Kitāb al-Hawātìm », Annales islamologiques, 22 (1986), p. 51-115; Vanessa van Renterghem, Les élites bagdadiennes au temps des Seldjoukides : étude d'histoire sociale, Beyrouth-Damas, Presses de l'Ifpo, 2015, I, p. 42-44.

37. «Ag̀ānī»; Kitāb al-Aġānī. C'est l'œuvre la plus importante d'Abū l-Farağ al-Ișfahānī (m. 356/967), érudit, poète et généalogiste chiite actif à Bagdad. Ce recueil en 24 volumes de poèmes mis en musique, riche en commentaires sur les vers des poèmes chantés, la vie des auteurs de mélodies, mais aussi sur les usages de la cour des Omeyyades, fut un ouvrage de référence en stylistique, utilisé comme une encyclopédie du monde arabe pour la période allant de l'époque pré-islamique au III $/ \mathrm{IX}^{\mathrm{e}}$ siècle. Bibliographie: Maria Nallino, «Abū l-Faradj 'Alī b. al-Ḥusayn b. Muḥammad b. Aḥmad al-Ḳurashī al-Iṣbahānī »,EI ${ }^{2}$; Hilary Kilpatrick, Making the Great Book of Songs: Compilation and the Author's Craft in Abū l-Faraj al-Ișbahānī’s Kitāb al-Aghānī, Londres-New York, Routledge («Routledge Curzon Studies in Arabic and Middle Eastern Literature »), 2003.

38. «Tergīib [ü] terhīb ». Il peut s'agir d'études et de sélections sur les hadiths concernant ce qu'il convient de rechercher et ce qu'il faut fuir. La référence la plus importante et la plus prestigieuse dans le domaine des « recommandations et avertissements » est l'ouvrage du traditionniste al-Mundirī (m. 656/1258), 
al-Targīb wa-l-tarhīb. Bibliographie: Mehmet Görmez, «Tergīb ve terhīb», Türkiye Diyanet Vakfi Islam Ansiklopedisi, 40 (2011), p. 508-509; Yaşar Kandemir, « Münzirî», Türkiye Diyanet Vakfi İslam Ansiklopedisi, 32 (2006), p. 35-37.

39. « Kitābü-l-muẓāf ve-l-mensūb »; Timimār al-qulūbfí l-muḍāfwa-l-mansūb est un lexique classé par ordre alphabétique d'expressions et de clichés formés de deux mots dont l'auteur est Abū Manșūr al-Táālibī (m. 429/1038), natif de Nishapur, auteur prolifique d'anthologies et d'ouvrages d'érudition littéraire. Bibliographie : Everett K. Rowson, « al-Tha'ālibī », $E I^{2}$; Bilal Orfali, « The Works of Abū Mansūr al-Tha'ālibī (350-429/961-1039) », Journal of Arabic Literature, 40 (2009), p. 273-318, p. 294.

40. «Mevāhibü-l-Ledüniyye »; 2 vols; al-Mawāhib al-laduniyya fì l-minaḥ al-muhammadiyya, ouvrage de sira du traditionniste et théologien Ahmad b. Muhammad al-Ḩațīb al-Qasțallānī (m. 923/1517-1518). Bibliographie: Abdülkadir Şenel, « Kastallânî », Türkiye Diyanet Vakfı İslam Ansiklopedisi, 24 (2001), p. 583-584; Carl Brockelmann, « al-Ḳasțāllānī », $E I^{2}$.

41. « Kevkebü-r-Ravẓa li-es-Suyūțī »; Kawkab al-Raw da fíta’rīh al-Nül wa-ğazìrat al-Rawḍa d'al-Suyūṭi $\left(\mathrm{n}^{\circ}{ }_{23}, 5^{2}\right)$. Il s'agit d'un traité d'histoire générale sur lîle de Rawḍa au Caire où le savant égyptien vécut et écrivit. Il retrace l'histoire de l'île sur le temps long depuis l'installation des musulmans, souligne les avantages de sa situation et le rôle de sa citadelle, évoque les travaux d'aménagement et de restauration engagés par les États successifs et décrit le Nilomètre. Puisant dans les vers d'une dizaine de poètes égyptiens, syriens, irakiens et andalous et exposant l'ensemble des connaissances acquises chez les voyageurs et les géographes arabes, entre évocations poétiques du paysage, correspondance personnelle et saillies polémiques, il pose les éléments d'une histoire plus globale, à la fois du Nil et du fait urbain. Bibliographie: Brockelmann, Geschichte der arabischen Litteratur, II, p. 202 et SII, p. 196 ; Marouane Slama, Lîle de Rawḍ selon al-Suyūțī, mémoire de $2^{\mathrm{e}}$ année, Lyon, Université Lumière, 2017, p. $17-20^{277}$.

$42^{*}$. «Mecma'ü-l-ahyāar». Il s'agit sans doute d'un recueil de tabaqāt. Parmi les titres possibles: Lawāqih al-anwār fì tabaqāt al-ahyār de l'érudit soufi et hagiographe 'Abd al-Wahhāb al-Anșārī l-Ša'rānī (m. 973/1565-1566). Il peut s'agir également de l'œuvre de Mağd al-Dīn b. al-Ațīr, al-Muhtār min Manāqib

277 Je remercie M. Slama et R. Seignobos pour leurs indications concernant cet ouvrage. 
al-ahyā ${ }^{278}$.Bibliographie :https://data.bnf.fr/fr/12116993/_abd_al-wahhab_ibn _ahmad_ibn_ali_al-ans_ari_al__sa_rani/, consulté le 8 juillet 2019 .

43. « Kurratü-l-'uyūn »; Qurrat al-'uyūn wa-mufarrih al-qalb al-maḩzūn. Le juriste Abū l-Layt al-Samarqandī (m. 373/983-984) a composé ce manuel eschatologique (à ne pas confondre avec son célèbre 'Uyūn al-Masāìl) concernant principalement la mise en garde contre les actes prohibés et l'encouragement au respect des obligations, et précisant les peines encourues pour ceux qui commettraient de grands péchés. Bibliographie : «Semerkandî, Ebü'l-Leys », Türkiye Diyanet Vakfi İslam Ansiklopedisi, 36 (2009), p. 473-475; Muhammad Haron, «Abū'l-Layth Al-Samarqandì's Life and Works with Special Reference to His al-Muqaddimah», Islamic Studies, 33/2-3 (1994), p. 319-340; AbdurRahman Mangera, A Critical Edition of Abü'l-Layth al-Samarqandì's Nawāzil, $\mathrm{PhD}$ thesis, Londres, School of Oriental and African Studies-University of London, 2013, p. 40 ; consultable en ligne: https://eprints.soas.ac.uk/17840/, consulté le 17 juillet 2020.

44. «El-esbāb ve-l-'alāmāt »; al-Asbāb wa-l-alāmāt. Rédigé par Naḡīb al-Dīn al-Samarqandī (m. 619/1222), ce traité classe, dans la tradition médicale de l'époque, les maladies, d'une part, en pathologies spécifiques à chacun des organes du corps et, d'autre part, en affections générales et fièvres affectant l'ensemble du corps. Dans un esprit d'exhaustivité, il y traite aussi de la cosmétologie et des poisons, des maladies de la peau, des blessures, des fractures et des luxations. Bibliographie: Mahmut Kaya, « Necîbüddin es-Semerkandî », Türkiye Diyanet Vakfi İslam Ansiklopedisi, 32 (2006), p. 490 ; Zouhour Chaabane, Les causes et les symptômes (al Asbāb wa-l-'alāmāt) d'al-Samarqandī: édition critique avec présentation et annotations, thèse de doctorat, Paris, Université Paris Sorbonne, 2013.

45. « Nefahātü-n-üns »; Nafahăàt al-uns est un riche recueil de biographies de mystiques, hommes et femmes, rédigé en persan et précédé d'un exposé sur le soufisme, par Mawlānā Ğāmī (m. 898/1492), illustre savant et poète persan naqšbandi. Cette œuvre précieuse sur la vie et la personnalité de Ğāmī eut un important écho dans l'Empire ottoman. Elle fut traduite en turc ottoman dès 915/1509 par Lāmi'ī Çelebi qui y ajouta plusieurs compléments. De très nombreux manuscrits en existent. Bibliographie: Henri Massé, «Djāmī», $E I^{2}$; Ömer Okumuş, «Câmî, Abdurrahman », Türkiye Diyanet Vakfi İslam Ansiklopedisi, 7 (1993), p. 94-99; Süleyman Uludă̆, « Nefehâtü'l-Üns », Türkiye

278 Je remercie L. Daaïf pour cette suggestion. 
Diyanet Vakfi İslam Ansiklopedisi, 32 (2006), p. 521-522; Algar, «Jāmī and the Ottomans », p. 91, p. 117, p. 124.

46. « Fethüün-niāal »; Fath al-muta'āl fı madh al-nicāl fut composé par Aḥmad b. Muhammad al-Maqqarī (m. 1041/1632), littérateur et biographe né à Tlemcen. Tiré de hadiths, vers et citations de textes de poètes et d'écrivains, marocains notamment, cet ouvrage porte sur le Prophète, en particulier sur ses sandales. Bibliographie : Évariste Lévi-Provencal [révisé par Charles Pellat], «al-Makkạarī», $E I^{2}$.

47. « 'Avārifü-l-me‘ārif »; 'Awārif al-ma'ārif. 'Umar Šihāb al-Dīn al-Suhrawardī (m. 632/1234-1235) est l'un des soufis les plus importants de l'islam sunnite médiéval. Composé de 63 chapitres et incorporant des éléments de tafsirr, son manuel généraliste aborde une multiplicité de thèmes autour de l'adab soufi. Il a influencé des millions de croyants dans leur approche du religieux et a fait l'objet de plusieurs traductions turques. Bibliographie: Angelica Hartmann, «al-Suhrawardī», $E I^{2}$; Hasan Kâmil Yllmaz, «Sühreverdī, Şehâbeddin», Türkiye Diyanet Vakfi Íslam Ansiklopedisi, 38 (2010), p. 40-42; Süleyman Uludağ, « Avârifü'l-Maârif», Türkiye Diyanet Vakfi İslam Ansiklopedisi, 4 (1991), p. 109-110.

48. « Habīib-i siyer »; Habīb al-siyar. C'est l'ouvrage le plus important de Huwānd Amīr (m. 942/1535-1536), historien persan, également auteur d'éthique politique, de biographies, de géographie et d'épistolographie. Il s'agit d'une histoire générale, composée de trois livres, traitant respectivement de l'époque préislamique, de l'histoire islamique jusqu'à la fin du califat abbasside et des périodes de domination mongole et timouride jusqu'à la fondation de l'État séfévide en Iran. À noter l'innovation, largement reprise ensuite, qui consiste à insérer des biographies à la fin de chaque grande période historique. Bibliographie : «Hândmîr », Türkiye Diyanet Vakfı İslam Ansiklopedisi, 15 (1997), p. 550-552; Henry Beveridge [révisé par Johannes Thomas Pieter de Bruijn], « Kh̄āndamīr », $E I^{2}$.

$49^{*}$. «Fetḥ-i mecīd ». Il s'agit possiblement de Fath al-mağìd fı̈ ahkām al-taqlìd, ouvrage de fiqh composé par le jurisconsulte chaféite 'Alī b. Abū Bakr b. al-Ğammāl al-Ȟazrağī (m. 1072/1661-1662).

50. « Harițatü-l-'acāīb »; Harìdat al-'ağàìb wa-farīdat al-ġarāib. L'ouvrage est généralement attribué au lettré chaféite syrien Sirāğ al-Dīn b. al-Wardī ( $\mathrm{m}$. après 822/1419). Mêlant géographie, histoire naturelle et cosmographie, l'étude a suscité l'intérêt de lettrés ottomans et d'orientalistes européens (Joseph de Guignes). 
Largement diffusée du fait des informations sur l'Europe, l'Afrique et le monde arabe qui s'y trouvent, elle a fait l'objet de traductions en turc ottoman, notamment celle de Maḥmūd al-Hูațîb. Bibliographie : «İbnü'l-Verdî, Sirâceddin », Türkiye Diyanet Vakfi İslam Ansiklopedisi, 21 (2000), p. 238-239; Francesca Bellino, «Sirāj al-Dīn ibn al-Wardī and the Harìdat al-ajāi ib: Authority and Plagiarism in a Fifteenth-Century Arabic Cosmography», Eurasian Studies, 12 (2014), p. 257-296 ; Feray Coşkun, «An Ottoman Preacher's Perception of a Medieval Cosmography: Mahmūd al-Hațib's [sic] Translation of Kharìdat al'Ajā̉ibwa Farīdatal-Gharā’ib »,Al-Masāq:Islamand the MedievalMediterranean, 23/1 (2011), p. 53-66 (sur la traduction précitée datée du $\mathrm{X}^{\mathrm{e}} / \mathrm{XVI}^{\mathrm{e}}$ siècle).

51. « Tenbīhü-l-muġterrīn li-eş-Şa'rānī »; Tanbīh al-muġtarrīn. 'Abd al-Wahhāb al-Ša'rānī, savant et soufi égyptien, historien du soufisme, est l'auteur de ce manuel à l'intention des soufis sur le bon comportement à adopter face aux princes. Bibliographie: Michael Winter, "al-Sha'rānī », $E I^{2}$; id., Society and Religion in Early Ottoman Egypt: Studies in the Writings of 'Abd al-Wahhāb al-Sha'rānī, New Brunswick, Transaction books («Studies in Islamic Culture and History »), 1982, p. 7 .

52. « Muḥaẓarāt li-es-Suyūțī »; Husn al-muḥādara fì aḩbār Mișrwa-l-Qāhira. Ce manuel d'histoire aborde l'Égypte islamique à travers les grandes lignes de son évolution politique et l'intègre à une histoire plus vaste, celle du califat auquel l'auteur, al-Suyūțī $\left(n^{\circ} 23,41\right)$, apporte un indéfectible soutien. Bibliographie : Jean-Claude Garcin, «Histoire, opposition politique et traditionaliste dans le Husn al-muhâậara de Suyūțī », Annales islamologiques, 7 (1967), p. 33-9o.

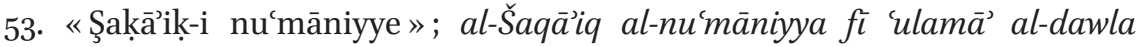
l-ựmāniyya. Rédigé par Ahmed Țaşköprüzāde (m. 968/1561), c'est l'un des plus importants ouvrages biographiques ottomans. Il est divisé en dix classes, chacune correspondant au règne d'un sultan, celui de Soliman le Magnifique coïncidant avec l'apogée de l'histoire impériale. Bibliographie : Barbara Flemming, «Ṭashköprüzāde », $E I^{2}$; Ali Uğur, «Taşköprî-zâde Ahmed Efendi », Osmanlı Araştırmaları, 7-8 (1988), p. 419-437.

$54^{*}$. «Fenn-i luğāt »; ouvrage de lexicologie.

55. «Mugiribü-l-lugiat»; sans doute al-Mugirib fi tartīb al-Múrib rédigé par al-Muțarrizī (m. 610/1213), philologue et juriste égyptien. Il s'agit d'un lexique conçu afin d'expliciter les expressions problématiques et étranges du figh hanéfite, classé selon les deux premiers caractères pour les racines trilitaires et le dernier pour les racines dotées de plus de trois caractères. Bibliographie: 
Rudolf Sellheim, «al-Muțarrizī», $E I^{2}$; Mehmet Sadi Çöğenli, «Mutarrizî̀», Türkiye Diyanet Vakfi İslam Ansiklopedisi, 31 (2006), p. 375-376.

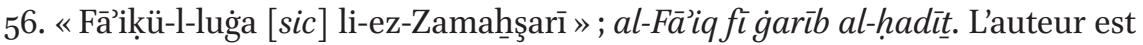
Mahmūd al-Zamahš̌arī (m. 538/1143-1144), dont la nisba dérive de sa ville de naissance, située dans le Khwarizm. Spécialiste de sciences linguistiques, ardent défenseur de la langue arabe contre la šucúbiyya, il est également illustre pour le caractère dogmatique et philosophique de son exégèse du Coran, le célèbre Kaššăf. L'ouvrage cité est une liste de locutions usitées dans les hadiths. Bibliographie: Kees Versteegh, «al-Zamakhsharī », $E I^{2}$; Ibrahim Lutpi, «Az-Zamakhshari: His Life and Works», Islamic Studies, 19 (1980), p. 95-110, p. 105 .

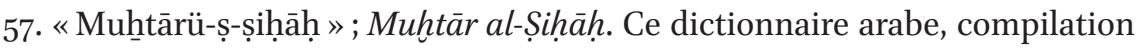
de Muhammad b. Abī Bakr al-Rāzī (m. 666/1267-1268), fut en partie composé à partir des Șịhạh (n $\left.{ }^{\circ} 5^{8}\right)$ d'al-Ğawharī. Il est conçu afin de contenir les seuls mots qu'un lettré digne de ce nom se devait de mémoriser. Bibliographie: MS Konya, Konya Yazma Eserler Bölge Müdürlüğü, 4353; «Râzî, Muhammed b. Ebû Bekir», Türkiye Diyanet Vakfı İslam Ansiklopedisi, 34 (2007), p. 487-488; Hulûsi Kılıç, « Tâcül'-luga », Türkiye Diyanet Vakfi İslam Ansiklopedisi, 39 (2010), p. 356-357.

58. «Ṣị̂āḥ-i Cevherī » al-Ğawharī (m. ca 396/10o5), lexicographe arabe d'origine turque, est renommé pour son dictionnaire intitulé Tăğ al-lug̉a wa-șihăḥ al-arabiyya. L'ouvrage entend ne contenir que des données lexicographiques authentiques, issues de leur transmission à travers une chaîne continue de traditions dignes de foi. Il a suscité une littérature lexicographique considérable, pour partie critique des erreurs qu'il contient. Il est le dictionnaire arabe le plus employé jusqu'au VIII ${ }^{\mathrm{e}} / \mathrm{XIV}^{\mathrm{e}}$ siècle. Il propose un classement selon la « rime » : les racines sont classées suivant l'ordre de la dernière radicale, puis de la première et des intermédiaires. Dans ce cadre, l'ordre alphabétique normal est suivi. Les Sịhạh d'al-Ğawharī sont le premier ouvrage important à employer ce système qui ne tarde guère à s'imposer dans des dictionnaires généraux. La traduction turque de Meḥmed b. Mușțafà l-Wānī (Wanqulu) fut publiée par Müteferriḳa (Tarğamat Șiḩạh al-Ğawharī, 1141/1729). Bibliographie : MS Konya, Konya Yazma Eserler Bölge Müdürlüğü, 4598; TÜYATOK, Isparta, p. 62O, $\mathrm{n}^{\mathrm{o}} 1062$ (32 H.K. 2069); Lothar Kopf, «al-Djawharī», $E I^{2}$; John A. Haywood et al., « Kāmūs », $E I^{2}$; Hulûsi Kılıç, « Tâcül'-luga », Türkiye Diyanet Vakfi İslam Ansiklopedisi, 39 (2010), p. 356-357. 
59. «Lugiat-ı Kara Pīrī »; 2 vols; il s'agit du dictionnaire arabe-turc de Pīr Meḥmed b. Yūsuf el-Anḳaravī (m. 866-867/1462 ?), actif à Ankara et en Anatolie centrale. L'auteur a notamment exploité l'ouvrage de Mugirib ( $\left.{ }^{\circ} 55\right)$. Une trentaine d'exemplaires en ont été identifiés. Il a également composé un dictionnaire arabe à partir de celui de Rāzī. Les mots arabes sont disposés en chapitres $(b \bar{a} b)$ qui correspondent soit à la première lettre du mot, soit à la dernière, et chaque $b \bar{a} b$ est divisé en sous-chapitres (fașl) correspondant à la deuxième lettre et aux suivantes. Bibliographie: Tahsin Özcan, «Pîr Mehmed», Türkiye Diyanet Vakfi İslam Ansiklopedisi, 34 (2007), p. 275-276 ; Țāhir, 'Oșmānlı Müellifleri, I, p. 26o.

60. « Lug̉at-ı miṣbāḥ-ı münīr »; Kitāb al-Mișbāḥ al-munirrfígarīb al-šarh al-kabìr composé par Aḥmad b. Muḥammad b. 'Alī l-Muqri' al-Fayyūmī (m. ca 770/ 1368). C'est un glossaire de termes légaux islamiques, dérivé d'une glose du commentaire de 'Abd al-Karīm al-Rāfici (m. 623/1226) consacré à l'étude de al-Wağiz fì l-furū' par al-Gazālī (m. 505/1111) et intitulé Fath al-'azìz 'alā kitāb al-Wağız.

61. «Şerḥ-i mevāḳıf». Il s'agit d'un commentaire du Kitāb al-Mawāqif fì 'ilm al-kalām, d'al-Ǐ̆̄ì, juriste chaféite et théologien aš́arite (m. 756/1355-1356). Destiné à l'enseignement de la théologie sunnite, cet ouvrage de base expose de manière concise les principes dominants de son temps, dans la lignée des propositions de Faḩr al-Dīn al-Rāzī (m. 606/1210) et al-Āmidī (m. 631/1233). Populaire et pratique, le texte a suscité de très nombreuses copies et une quarantaine de commentaires identifiés. Celui dont il est question ici est probablement le plus connu d'entre eux, le Šarh al-mawāqif du célèbre savant timouride Sayyīd Šarīf al-Ğurğānī (m. 816/1413-1414). Enseigné aux niveaux supérieurs du cursus en madrasa, ce dernier offre la particularité d'être largement consacré à la philosophie. Il a suscité de multiples commentaires. Bibliographie: Arthur Stanley Tritton, «al-Djurdjānī », $E I^{2}$; Josef Van Ess, «al-Īdjī », $E I^{2}$; Mustafa Sinanoğlu, « el-Mevākıf », Türkiye Diyanet Vakfi İslam Ansiklopedisi, 29 (2004), p. 422-424; Sadreddin Gümüş, «Cürcânî, Seyyid Şerif» Türkiye Diyanet Vakfi İslam Ansiklopedisi, 8 (1993), p. 134-136; Yakuboğlu, Osmanl Medrese Eğitimi ve Felsefesi, p. 69, p. 168-184; Yazıcıoğlu, Le kalâm et son rôle dans la société turco-ottomane aux XV $V^{e}$ et XVI ${ }^{e}$ siècles, p. 51, p. 55, p. 63-68; Unan, Kuruluşundan Günümüze Fâtih Külliyesi, p. 373.

62. « Şerḥ-i maḳāṣıd »; le Kitāb Šarh al-maqāṣid fut composé à Samarcande par 'Umar al-Taftāzānī (m. 792/139o), savant polygraphe en grammaire, rhétorique, 
théologie, logique, droit et exégèse, enseignant estimé pour la qualité de ses commentaires utilisés et glosés en madrasa. Loué pour la finesse de ses réflexions philosophiques et métaphysiques, l'ouvrage est un manuel de théologie constitué d'une courte introduction et de six parties. Bibliographie: MS Konya, Konya Yazma Eserler Bölge Müdürlüğü, 4436; TÜYATOK, Isparta, p. 513 (32 H.K. 1884); Wilferd Madelung, «al-Taftāzānī», $E I^{2}$; Şükrü Özen, «Teftāzānī », Türkiye Diyanet Vakfı İslam Ansiklopedisi, 40 (2011), p. 299-308; Mustafa Sinanoğlu, «el-Makāsıd», Türkiye Diyanet Vakfı İslam Ansiklopedisi, 27 (2003), p. 420-421; Yakuboğlu, Osmanlı Medrese Eğitimi ve Felsefesi, p. 59-63.

63. « Şerḥ-i meşāriḳ li-İbn-i Melek ». L'auteur est Firiştezāde 'Abdü-l-Lațîf (à ne pas confondre avec son frère, également lettré, 'Abdü-l-Mecīd), connu sous le nom de İbn Melek, lettré et jurisconsulte (m. après 821/1418-1419), formé dans les territoires égéens des Aydınoğlu. Le Mabārik al-azhār fi šarh mašāriq al-anwār est un commentaire du Mašāriq al-anwār al-nabawiyya du lexicographe et traditionniste Raḍī l-Dīn al-Ṣāgāāī (m. 650/1252), première contribution indienne à la littérature du hadith. Très employé parmi les oulémas ottomans, il donne des éclaircissements sur 2500 hadiths tirés des recueils d'al-Buhārī $\left(\mathrm{n}^{\circ} 18\right)$ et de Muslim ( $\mathrm{n}^{\circ}$ 19). Bibliographie: Ms Konya, Konya Yazma Eserler Bölge Müdürlüğü, 3936 ; TÜYATOK, Isparta, p. 204, no $35^{2}$ (32 H.K. 1697); Ṭāhir, 'Oșmānlı Müellifleri, I, p. 219-220 ; Ömer Faruk Akün, «Firishte-oghlu », $E I^{2}$; Mustafa Baktır, «İbn Melek », Türkiye Diyanet Vakfi İslam Ansiklopedisi, 20 (1999), p. 175-176.

64. «Şerḥ-i miftāḥ » : le Miftāḥ al-ulūm (no 33) d'al-Sakkākī, ouvrage central de l'enseignement de rhétorique, a fait l'objet d'un très grand nombre de commentaires par les savants les plus illustres. Dans les madrasas ottomanes, les plus étudiés d'entre eux étaient le Šarh al-Miftāḥ d'al-Taftāzānī (no ${ }^{\circ}$ ) et le Miftāḥ al-ulūm d'al-Ğurğānī ( $\mathrm{n}^{\circ} 61$ ) appelé également al-Miṣbạh (ce qui le distinguait du précédent). Dans ces commentaires, a été particulièrement étudiée la troisième partie de l'ouvrage consacrée à la stylistique et au langage figuratif dont la littérature rhétorique ('ilm al-baläga) a fait fond. Ces deux commentaires ont fait l'objet de nombreux commentaires. Bibliographie : TÜYATOK, Isparta, p. 768 (32 H.K. 2038; commentaire d'al-Taftāzānī); TÜYATOK, Burdur I (15 H.K. 1956 ; idem); Mehmet Sami Benli, « Miftâhu'l-ulūm », Türkiye Diyanet Vakfi İslam Ansiklopedisi, 30 (2005), p. 20-21; Wolfhart P. Heinrichs, « al-Sakkākī », $E I^{2}$; Azmi Şerbetçi, « Kutbüddîn-i Şirâzî », Türkiye Diyanet Vakfı İslam Ansiklopedisi, 26 (2002), p. 487-489.

65. «Şerḥ-i 'akâàid». Il s'agit du commentaire de 'Aqāìd al-Nasafí, un catéchisme chargé de démontrer rationnellement tous les aspects du credo et de 
l'eschatologie (le caractère incréé du Coran). Il porte également les conceptions maturidites de la foi contre la critique ašcarite par le savant Nağm al-Dīn al-Nasafî (m. 537/1142). L'auteur du commentaire est 'Umar al-Taftāzānī (nº 62), à la fois adhérant à l'école hanéfite et champion d'un islam tolérant. Très employé en madrasa, le commentaire est marqué par la progression des réflexions onthologiques sous l'influence d'Avicenne. C'est l'une des œuvres les plus diffusées d'al-Taftāzānī. Elle a suscité de très nombreux commentaires notamment dans l'Empire ottoman. Bibliographie : TÜYATOK, Burdur I, p. $302(15$ H.K. 108/1) ; Brockelmann, Geschichte der arabischen Litteratur, I, p. 548-55० ; Wilferd Madelung, «al-Taftāzānī», $E I^{2}$; Şükrü Özen, «Teftāzānī », Türkiye Diyanet Vakfi İslam Ansiklopedisi, 40, (2011), p. 299-308; Nathan Spannaus, «Theology in Central Asia », dans Oxford Handbook of Islamic Theology, éd. Sabine Schmidtke, Oxford, Oxford University Press («Oxford Handbooks»), 2016, p. 587-6o5; Yakuboğlu, Osmanlı Medrese Eğitimi ve Felsefesi, p. 163-168; Yazıcioğlu, Le kalâm et son rôle dans la société turco-ottomane aux $X V^{e}$ et $X V I^{e}$ siècles, p. 51, p. 307-325 (traduction du commentaire d'al-Taftāzānī); Unan, Kuruluşundan Günümüze Fâtih Külliyesi, p. 373.

66. « Mecmūa-1 iṣbātü-l-vācib ». Le Kitāb It thāat al-wāăğib est un ouvrage du théologien Ğalāl al-Dīn al-Dawānī (m. 908/1502-1503), né en Iran, dans le district de Kāzarūn. Il est possible que le mecmūa $a$ cité ici contienne le texte de l'auteur ainsi que des commentaires et gloses. Connu et étudié dès le règne de Beyazıd II (r. 886/1481-918/1512), al-Dawānī devient un auteur de base du cursus au XI ${ }^{\mathrm{e}}$ / $\mathrm{XVII}^{\mathrm{e}}$ siècle, comme à Damas à la même époque; des auteurs persans, kurdes et azéris glosent le texte. Des gloses en turc ottoman sont produites à partir de la fin du XI $/ \mathrm{XVII}^{\mathrm{e}}$ siècle. Bibliographie: Ann Katharine Swynford Lambton, « al-Dawānī », $E I^{2}$; Hülya Terzioğlu, « Celâleddîn ed-Devvânînnin İsbât-ı Vâcib Anlayışı ve Osmanlı Düşünce Dünyasına Etkileri », İnsan ve Toplum Bilimleri Araştırmaları Dergisi, 7/1 (2018), p. 330-343; Harun Anay, « Devvânî», Türkiye Diyanet Vakfi İslam Ansiklopedisi, 9 (1994), p. 257-262; Khaled el-Rouayheb, Islamic Intellectual History in the Seventeenth Century: Scholarly Currents in the Ottoman Empire and the Maghreb, Cambridge, Cambridge University Press, 2015, p. 37-42.

67. « Mecmū'a-ı hikmetü-l-'ayn ». Il pourrait s'agir de varia réunissant plusieurs des nombreux commentaires de Hikmat al-ayn de Nağm al-Dīn al-Kātibī (m. 657/1276-1277), philosophe et logicien de l'école chaféite, connu sous le nom de Dabīrān. L'ouvrage traite de sciences naturelles et de métaphysique. Le plus célèbre commentaire est celui de Mīrak al-Buhārī (m. 740/1339-1340), objet de commentaires notamment par al-Ǧurǧānī et Kamāl al-Dīn al-Šīrāzī. Bibliographie: TÜYATOK, Isparta, p. 109 (32 H.K. 2097); Mahdi Mohaghegh, 
«al-Kātibī», $E I^{2}$; «Kâtibî, Ali b. Ömer», Türkiye Diyanet Vakfı İslam Ansiklopedisi, 25 (2002) p. 41-42 ; Robert G. Morrison, « Mīrak al-Bukhārī », EI ${ }^{3}$; Mustakim Arıcı, « Gelenek Oluşturan Bir Felsefe Klasiği Olarak Hikmetü'l-Ayn ve Etkileri », dans Uluslararası 13. Yüzyılda Felsefe Sempozyumu Bildirileri, éds Murat Demirkol et M. Enes Kala, Ankara, Ylldırım Beyazit Üniversitesi, 2014, p. 332-349 (pour une liste très riche de commentaires).

68. «Ușūl-ı mirāat 'alā-l-mirḳāt »; le Mir'àt al-uṣūl fı̌ šarh mirqāt al-wuṣūl de Mollā $\underline{\text { Hüsrev }}\left(\right.$ voir n $\left.^{\circ} 14,86\right)$ est une œuvre dogmatique d'ușūl al-figh, composée d'une introduction et de deux parties (maqșad). Utilisé comme manuel dans les madrasas ottomanes, l'ouvrage a suscité de multiples gloses. Bibliographie: «Burdur Kitapları Süleymaniye'den Konya'ya Devir-Teslim Listesi, 21-6-2012 », $\mathrm{n}^{\circ}$ 406, 415, 577; Ferhat Koca, «Mirâtü'l-usûl », Türkiye Diyanet Vakfı İslam Ansiklopedisi, 30 (2005), p. 148; Ferhat Koca, «Molla Hüsrev », Türkiye Diyanet Vakfi İslam Ansiklopedisi, 30 (2005), p. 252-254.

69. «'Azmī 'alā-l-menār»; 'Azmīzāde Ḥāletī Mușțafà (m. 1040/1631), né à Istanbul, surtout connu pour ses œuvres poétiques, ses rubāi en particulier, a rédigé un commentaire sur le Šarh Manār al-anwār d'İbn Melek (no 63), lequel est un commentaire (dont la prise en compte de points de vue malékites ou chaféites introduit des éléments critiques) du Kitāb al-Manār, exposé condensé de principes de droit (ușūl) d'al-Nasafî (voir no 4). Bibliographie : TÜYATOK, Burdur I, p. 517-518 (15 H.K. 656); Halûk İpekten, «Azmîzâde Mustafa Hâletî », Türkiye Diyanet Vakfi İslam Ansiklopedisi, 4 (1991), p. 348-349; «İbn Melek», Türkiye Diyanet Vakfi İslam Ansiklopedisi, 20 (1999), p. 175-176; Fahir İz, «Hāaletī », $E I^{2}$; Ṭāhir, 'Oșmānlı Müeellifleri, II, p. 311-312 ; Murteza Bedir, « Nesefî, Ebü'l-Berekât », Türkiye Diyanet Vakfı İslam Ansiklopedisi, 32 (2006), p. 567-568; Wilhelm Heffening, « al-Nasafī, Ḥāfiz al-Dīn Abū l-Barakāt », $E I^{2}$.

$70^{*}$. «Tehżīb-i mīrī ma'-l-Celāl »; le manuscrit comprend deux titres, semble-t-il.

71. «Şerḥ-i Çag̉minī ». Il s'agit du commentaire de l'abrégé d'astronomie (Šarh al-Mulahhas fi l-hay'a) d'al-Ğaġmīnī (m. ca 745/1344), natif du Khwarizm, par Mūsā Kạạīzāde Rūmī, mathématicien originaire de Bursa (m. ca 835/1432), surtout connu pour l'ouvrage cité, manuel d'enseignement populaire, qui a fait l'objet de nombreuses copies. Bibliographie: TÜYATOK, Isparta, p. 728 (nº 1240 ; autre ex. : 32 H.K. 1952) ; F. Jamil Ragep, « Kāạ̣ī-zāde Rūmī », EI ${ }^{2}$; İhsan Fazlığlu, «Kadızâde-i Rûmî», Türkiye Diyanet Vakfı İslam Ansiklopedisi, 24 (2001), p. 98-100; Ekmeleddin İhsanoğlu et al., Osmanlı Matematik Literatürü Tarihi, İstanbul, IRCICA, 1999, I, p. 3-18. 
$72^{*}$. « Ḥāşsiye-i mīr-i Ḳara Mūsā ».

73. « Kara Hַalīl ‘alā Ḳara Dāvūd ». Il s’agit du commentaire par Birgili Ḳara Hַalīl Efendī (m. 1123/1711), ḳāzı́asker d'Anatolie et commentateur de philosophie, dialectique et logique, du Ḥāšiya 'alā Šarḥ Mațāli' al-anwār de Kara Dāvūd (m. 948/1541), lequel est une glose du Šarḥ Mațāic al-anwār de Maḥmūd b. 'Abd al-Raḥmān al-Iṣfahānī (m. 749/1349), lequel est un commentaire du Mațālic al-anwār également appelé Ṭaraf al-manțiq, ouvrage de logique de Sirāğ alDīn al-Urmawī (m. 682/1283). Après le VIII ${ }^{\mathrm{e}} / \mathrm{XIV}^{\mathrm{e}}$ siècle, l'étude de ce dernier décline: est surtout étudiée la première partie qui expose les problèmes introductifs, l'acquisition des conceptions (tașawwurāt) et le commentaire qu'en propose al-Rāzī l-Tahtānī (m. 766/1364). Bibliographie : Hatice Kelpetin Arpaguş, «Kara Dâvud İzmitî », Türkiye Diyanet Vakfı İslam Ansiklopedisi, 24 (2001), p. 359-36o ; Muhsin Demirci, « İsfahânî, Mahmûd b. Abdurrahman », Türkiye Diyanet Vakfi İslam Ansiklopedisi, 22 (2000), p. 509-510.

74. « Kitābü-l-lübāb »; al-Lubāb fí 'ulūm al-kitāb. C'est une étude de tafsīr hanbalite par Sirāğ al-Dīn b. 'Ādil al-Ḥanbalī (m. après 88o/1475) dont la biographie et l'œuvre sont peu déterminées. L'ouvrage traite d'une multitude de sujets, de la terminologie et de l'írāb (différence dans la finale du mot) à l'interprétation des versets à partir du figh ou du kaläm. Évoquant les interprétations d'autres madhabs, il s'appuie sur les travaux d'auteurs tel Fahr al-Dīn al-Rāzī. Les Ottomans en possédaient de nombreuses copies. Bibliographie : Brockelmann, Geschichte der arabischen Litteratur, II, p. 138 ; Ahmet Özel, «Ibn Âdil», Türkiye Diyanet Vakfi İslam Ansiklopedisi, Ek-1 (2016), p. 583-585.

75. «Çārperdī 'alā-l-şāfiyye »; Šarh al-šăfiyya fut composé par Fahr al-Dīn al-Ğārabardī (m. 746/1345-1346), juriste chaféite natif de l'Arran (dans l'actuel Azerbaïdjan). Ce commentaire porte sur la célèbre grammaire, al-Šăfiyya fì 'ilmay al-tașrīf wa-l-hațț, objet de très nombreux commentaires, de Ğamāl al-Dīn b. al-Hāăğib (m. 646/1249), né en Haute-Égypte. Son opuscule distingue la morphologie (șarf) de la syntaxe (naḥw). Le commentaire d'al-Ğārabardī porte sur le premier sujet. Bibliographie : Mehmed Șener, « Çârperdî», Türkiye Diyanet Vakfi İslam Ansiklopedisi, 8 (1993), p. 230-231; Henri Fleisch, «Ibn al-Ḥādjib », $E I^{2}$.

76. «Hindī 'alā-l-Kāfiyye »; Šarḥ al-Hindī, par 'Umar al-Sāwūli l-Dawlatābādī (m. 849/1445), exégète, jurisconsulte et grammairien natif de Dawlatābād, dans le Deccan. Ce commentaire porte sur le second volume (la syntaxe, naḥw) de la célèbre grammaire de Ğamāl al-Dīn b. al-Ḥāğib, al-Šāfiyya fi í imay al-tașrīf wa-l-hatț, objet de commentaires plus nombreux encore que pour le premier 
volume et publiée à Rome en 1512. Bibliographie: Brockelmann, Geschichte der arabischen Litteratur, sII, p. 310 ; Khaliq Ahmad Nizami, «Devletâbâdî », Türkiye Diyanet Vakfi İslam Ansiklopedisi, 9 (1994), p. 242-243.

77. «Cevāmi'ü-l-kelim»; Ǧāmi` al-ulüm wa-l-hikam fì šarh hamsīn hadìt min ğawāmi al-kalim du savant hanbalite Ibn Rağab (m. 795/1392-1393), jurisconsulte, traditionniste et historien natif de Bagdad. L'ouvrage élève au nombre de 5 o la collection des 42 hadiths rassemblés dans le Kitāb al-Arba'in d'al-Nawawī ( $\left.\mathrm{n}^{\circ} 25\right)$. Il discute du degré d'authenticité des hadiths pourtant rassemblés par un traditionniste de haute réputation particulièrement sévère et mentionne les décisions de figh qui y sont rattachées. Bibliographie: Yaşar Kandemir, « Cevâmiü'l-kelim », Türkiye Diyanet Vakfi İslam Ansiklopedisi, 7 (1993), p. 440 ; Cengiz Kallek, «İbn Receb», Türkiye Diyanet Vakfı İslam Ansiklopedisi, 20 (1999), p. 243-247; Wilhelm Heffening, «al-Nawawī», $E I^{2}$; Yaşar Kandemir, « Nevevî », Türkiye Diyanet Vakfi İslam Ansiklopedisi, 33 (2007), p. $45-49$, p. 47 .

78. «Telbīs-i iblīs»; Talbīs Iblīs fut composé par Abū l-Farağ b. al-Ğawzī (m. 597/1201), jurisconsulte, traditionniste, historien et sermonnaire hanbalite de Bagdad. C'est «l'une des œuvres majeures du Hanbalisme de combat» (Henri Laoust), qui s'en prend, outre à des sectes plus ou moins extérieures au sunnisme, à l'intérieur du sunnisme à des traditionnistes, hommes d'État et surtout cheikhs soufis accusés d'avoir introduit de condamnables innovations dans le dogme de l'islam. Bibliographie : Bekir Topaloğlu, «Telbīsü iblis », Türkiye Diyanet Vakfı İslam Ansiklopedisi, 40 (2011), p. 394-395; Henri Laoust, «Ibn al-Djawzī », $E I^{2}$.

79. «Fetāvā-yı 'Ațầullah ». 'Ațā̉ullah Meḥmed Efendī, şeyhূü-l-islām (m. 1127/ 1715), formé par Minkāāīzāde Yahyaa Efendī, auteur d'un recueil de fatwas émises en 1072-1073/1662-1084-1085/1674. Dans celui-ci, il est surtout question de mu'āmalāt, mais aussi de purification canonique, prière, jeune et aumône. Minḳārīzāde a repris ce recueil en validant les sources à partir desquelles Yahyāā Efendī avait rendu ses avis, à telle enseigne que, sur plusieurs copies, la mention « Fetāvā-yı Minkārizāde » a été remplacée par celle de « Fetāvā-yı 'Ațāullah ». Bibliographie: «Burdur Kitaplanı Süleymaniye'den Konya'ya Devir-Teslim Listesi, 21-6-2012», no 533 (recueil en turc); Ms Konya, Konya Yazma Eserler Bölge Müdürlüğü, 4034; Mustafa Yayla, «Fetâvâ-yı Minkârizâde», Türkiye Diyanet Vakfi İslam Ansiklopedisi, 12 (1995), p. 444-445; Mehmet İpşirli, "Atâullah Mehmed Efendi», Türkiye Diyanet Vakfi İslam Ansiklopedisi, 4 (1991), p. 46-47; Ahmet Özel, Hanefi Fıkıh Âlimleri, Ankara, Türkiye Diyanet Vakfi, 199o, p. 141 ; Özen, « Osmanlı Döneminde Fetva Literatürü », p. 366-367. 
80. « Hulāṣatü-l-fetāvā»; Hulāṣat al-fatāwā est une compilation de fatwas tirées de Hizānat al-fatāwā de Țāhir b. Aḥmad al-Buhārī (m. 542/1147), jurisconsulte hanéfite natif de Boukhara. Bibliographie: Brockelmann, Geschichte der arabischen Litteratur, sI, p. 640-641; Özel, Hanefi Fıkı Âlimleri, p. 5 ० ; M. Esat Kılıçer, «Buhârî, Tâhir b. Ahmed », Türkiye Diyanet Vakfi İslam Ansiklopedisi, 6 (1992), p. 376.

81. « Fetāvā-yı Üskübī »; Muìn al-muftī fì l-ğawāa 'alā l-mustaftī fut composé par le mufti et enseignant Pīr Meḥmed Üskübī (m. 1020/1611), né à Istanbul. L'ouvrage rassemble les fatwas émises alors que celui-ci était mufti d'Üsküp pendant de longues années. Elles furent compilées par son fils Ahmed, cadi de Baypazarı, en 1039/1630, sous le titre Mu'in al-muftī. Les fatwas rédigées en turc sont doublées de traductions arabes systématiquement classées selon les ouvrages de $f i q h$. Elles ont servi de sources à des recueils ultérieurs. Bibliographie : MS Konya, Konya Yazma Eserler Bölge Müdürlüğü, 4074/1; TÜYATOK, Isparta, p. 466 ; Şükrü Özen, «Pîr Mehmed Üskübî», Türkiye Diyanet Vakfi İslam Ansiklopedisi, 34 (2007), p. 276-277; id., «Osmanlı Döneminde Fetva Literatürü », p. 307.

82. «Mü'eyyedzāde »; Mü’eyyedzāde 'Abd al-Raḥmān Efendī, théologien et juriste natif d'Amasya (m. 922/1516), a composé de nombreux traités en théologie et en droit, spécialement sur l'exégèse du Coran. Son œuvre la plus lue et la plus reproduite est un recueil d'une centaine de fatwas (Mağma' al-fatāwa $\bar{a})$; une partie est consacrée aux 'amal, «actes humains » faisant l'objet de degrés de qualification ou hukm dans le langage juridique ; l'autre porte sur les mu'ämalät et munāsabāt. Bibliographie: Țāhir, 'Oșmānlı Mü̉ellifleri, I, p. 355; Theodor Menzel, «Mu'ayyad-zāde », $E I^{2}$; Hasan Aksoy, « Müeyyedzâde Abdurrahman Efendi », Türkiye Diyanet Vakfi İslam Ansiklopedisi, 31 (2006), p. 485-486 ; Tayyib Gökbilgin, « Müeyyed-zâde », İslam Ansiklopedisi, 8 (1979), p. 786-79o ; Erünsal, Türk Kütüphaneleri Tarihi, p. 37-40.

83. «Fetāvā-yı Kadrī Efendī»; al-Fatāwāa l-qādiriyya. Kadrī Efendī (m. 1084/ 1674), ǩäzı́asker d'Anatolie et de Roumélie, est l'auteur d'un recueil de fatwas dont la composition est organisée selon les problèmes juridiques auxquels se rapportent les cas traités. Cette œuvre concise, qui s'en tient aux questions traitées sans en livrer les analyses détaillées, fut un instrument de travail très utilisé par des cadis et des muftis. Il en existerait 70 copies environ. Bibliographie: Ahmet Özel, «Kadri Efendi», Türkiye Diyanet Vakfı İslam Ansiklopedisi, 24 (2001), p. 140-141; Özel, Hanefi Flkıh Âlimleri, p. 133; Özen, «Osmanlı Döneminde Fetva Literatürü », p. 361-362. 
84. «Fetāvā-yı Feyẓ Kerekī »; Fayd Karakī, version abrégée de Fayḍ al-mawlā l-karìm 'Alī Ubayda Ibrāhìm par Ibn al-Karakī (m. 922/1516), cadi hanéfite, natif de Karak en Jordanie, est l'auteur d'un recueil de fatwas qui a suscité de très nombreuses copies.

85. «Fetāvā-yı Tātārhnāniyye »; al-Fatāwā l-tātārhhāniyya est une œuvre attribuée à 'Ālim b. 'Alā' al-Ḥanafì (m. 786/1384-1385), jurisconsulte hanéfite indien, savant de la cour du sultan Muhammad II Tugiluq (r. 724/1324-752/1351). Rédigé en arabe, ce recueil de fatwas est organisé selon les livres de fur $\bar{u}$, reprenant la forme du célèbre Hidāya de Burhān al-Dīn al-Margīnānī (m. 593/1197), l'un des juristes les plus importants du figh hanéfite (voir $\mathrm{n}^{\circ}$ 91, 92). Le Tätārhāniyyya compte de nombreux volumes qui résument les ouvres de maitres d'autorité de l'école hanéfite. Bibliographie: ms Konya, Konya Yazma Eserler Bölge Müdürlüğü, 4O54; TÜYATOK, Isparta, p. 350 (32 H.K. 1672/1); Wilhelm Heffening, « al-Marghīnānī », $E I^{2}$.

86. «Dürer-i g̈urer »; Durar al-ḥukkāmfišarh Ġurar al-ậkām, abrévié en Durar Šarh al-Ġurar, est un commentaire de Mollā Hü̈srev, juriste ottoman $\left(\mathrm{n}^{\circ}{ }_{14}, 68\right)$ tiré de son propre ouvrage, Gurar al-ậkām, lequel est une synthèse des éléments qu'il avait lui-même recueillis pendant sa carrière à partir de sa lecture d'ouvrages de figh et de ses expériences de juge. Son but était de produire un manuel à l'usage des cadis sur toutes les questions qu'ils auraient eu à se poser dans l'exercice de leurs fonctions, et il fut utilisé comme tel. Composé à la manière des ouvrages de $f i q h$, l'ensemble est constitué de 55 livres (kitāb) et 120 parties $(b \bar{a} b)$. Il traite de toutes les questions de droit en matière de 'ibādāt et de mu'āmalāt et livre les analyses des autres madhab sur des problèmes de droit. Il a suscité une vingtaine de commentaires. Bibliographie : «Burdur Kitapları Süleymaniye'den Konya'ya Devir-Teslim Listesi, 21-6-2012 », no 458, 469; Ferhat Koca, «Molla Hüsrev », Türkiye Diyanet Vakfi İslam Ansiklopedisi, 30 (2005), p. 252-254; « Dürerü'l-hükkâm », Türkiye Diyanet Vakfı İslam Ansiklopedisi, 10 (1994), p. 27-28; Unan, Kuruluşundan Günümüze Fâtih Külliyesi, p. 367.

87. «Ḥalebī-i kebir»; Gunyat al-mutamallī fì šarh Munyat al-muṣallī est un commentaire d'Ibrāhīm al-Halabī, né à Alep (m. 956/1549-1550), savant hanéfite, tiré de Munyat al-mușallī wa-g்nnat al-mubtadī, de Sadīd al-Dīn al-Kāšğarī (m. 705/1305-1306), qui traite une à une des pratiques religieuses élémentaires, notamment les ablutions. Le commentaire enrichit les domaines des șalāts abordés dans Munyat al-muṣallī, notamment les modes des différentes prières (surérogatoires, accomplies postérieurement, pour les défunts, à l'occasion des fêtes religieuses, etc.). Il cite les hadiths correspondants, discute de leurs dates et de leur fiabilité. Il accorde une grande importance aux questions 
lexicologiques. Il explicite dans un style simple les comparaisons proposées avec les autres madhabs. Bibliographie: TÜYATOK, Burdur I, p. 511-512 (15 H.K. 347); Hüseyin Kayapınar, «Münyetü'l-mușallî» Türkiye Diyanet Vakfı İslam Ansiklopedisi, 32 (2006), p. 32-33.

88. « Kuhistānī-i kebir »; Šams al-Dīn Muḥammad al-Ḳuhistānī (m. 962/15541555), jurisconsulte hanéfite, né au Kohistan, dans le Khorasan, est connu pour son ouvrage $\breve{G} \bar{a} m i i^{\prime}$ al-rumūz. Son petit-fils en a rédigé un résumé (muhtașar) appelé șaḡìr. Il s'agit d'un commentaire de la Niqāya de Șadr al-Šarīa (no 89). Bibliographie: Ahmet Yaman, «Kuhistânî», Türkiye Diyanet Vakfı İslam Ansiklopedisi, 26 (2002), p. 348.

89. «Ṣadrü-ş-şerīa »; Șadr al-Šarīa (m. 747/1346-1347) était un jurisconsulte hanéfite et théologien issu d'une famille de grands oulémas de Boukhara. Il est connu pour son commentaire (Niqāya) consacré au Wiqāyat al-riwāaya fimasāàil al-hidāya appelé en turc Vikāye, composé par son grand-père Tāğ al-Šarī‘a (m. 673/1274-1275) et qui est l'un des quatre livres de base mu'tabar (tenus en haute estime) appelés dans le figh hanéfite mutūn al-arba'a. Les deux ouvrages ont fait l'objet de nombreuses gloses et d'innombrables copies. Bibliographie: «Burdur Kitapları Süleymaniye'den Konya'ya Devir-Teslim Listesi, 21-6-2012 », $\mathrm{n}^{\mathrm{o}}$ 305, 523; Brockelmann, Geschichte der arabischen Litteratur, I, p. 644; Murteza Bedir, «Vikâyetü'r-rivâye », Türkiye Diyanet Vakfı İslam Ansiklopedisi, 43 (2013), p. 106-108; Şükrü Özen, « Șadr üş-şerīa », Türkiye Diyanet Vakfi İslam Ansiklopedisi, 35 (2008), p. 427-431.

90. «Enfa'ü-l-mesā’il »; Anfa al-wasāil ilā tahrīr al-masāill, appelé al-Fatāwwā l-tarsūsiyya, fut composé par Nağm al-Dīn al-Ṭarsūsī (m. 758/1357), jurisconsulte hanéfite né dans un village du nord de Damas. Ce recueil de fatwas fut compilé à l'usage des cadis afin de résoudre les problèmes auxquels ils étaient régulièrement confrontés dans l'exercice de leurs fonctions. Bibliographie: Brockelmann, Geschichte der arabischen Litteratur, sII, p. 87 ; Muharrem Kılıç, «Tarsûsî, Necmeddin », Türkiye Diyanet Vakfı İslam Ansiklopedisi, 40 (2011), p. 114-115.

91. «İbn Kemāl 'alā-l-hidāye ». Şems ed-Dīn Kemālpaşazāde ou İbn Kemāl (m. 940/1534), şeyhü-l-islām, écrivain fécond, est connu pour son œuvre d'historien, mais aussi pour ses travaux de philosophie, droit, grammaire et théologie. Son commentaire du Hidāya d'al-Margiinānī (voir no 85, 92) nommé Hāšiyat al-Hidāya porte sur les parties de l'œuvre consacrées notamment à la purification canonique, l'aumône, le jeune, le pèlerinage, le mariage et la vente. Bibliographie: Şerafettin Duran, «Kemalpaşazâde », Türkiye Diyanet 
Vakfi İslam Ansiklopedisi, 25 (2002), p. 238-240 ; İlyas Çelebi, « Kemalpaşazâde. Eserleri», Türkiye Diyanet Vakfi İslam Ansiklopedisi, 25 (2002), p. 245-247, p. 247; Heffening, «al-Marghīnānī », $E I^{2}$; Süleyman Hayri Bolay et al. (éd.), Şeyhülislām İbn Kemâl Sempozyumu (26-29 Haziran 1985, Tokat), Tebliğler ve Tartısmalar, Ankara, Türkiye Diyanet Vakfi, 1986 ; Repp, The Müfti of Istanbul, p. 224-244.

92. «Ekmel 'Alī 'alā-l-hidāye»; al-'Tnāya šarh al-Hidāya (ou simplement alInāya), composé par Akmal al-Dīn al-Bābartī (m. 786/1384), natif d'un village de la région de Bagdad, est l'un des commentaires les plus célèbres du Hidāya de Burhān al-Dīn al-Margīinānī (m. 593/1196-1197). L'auteur appuie ses analyses sur l'ușūl, la lexicologie et la grammaire, tout en procédant à la critique d'autres commentaires. Il mobilise l'iğtị̣ad de Abū Ḥanīfa et ses élèves, mais convoque également les analyses d'autres madhabs. Plusieurs commentaires de l'œuvre ont été rédigés, notamment celui du şeyhhü-l-islam Sa'dī Çelebi ( $\left.{ }^{\circ} 12\right)$. Bibliographie: Heffening, «al-Marghīnānī», $E I^{2}$; Arif Aytekin, «Bābertī », Türkiye Diyanet Vakfi İslam Ansiklopedisi, 4 (1991), p. 377-378; Mehmet İpşirli, Ziya Demir, « Sâdî Çelebi », Türkiye Diyanet Vakfi İslam Ansiklopedisi, 35 (2008), p. 404-405.

93. «Cāmi'ü-l-fușūleyn »; al-Fușūl fì l-mu'āmalāt fut rédigé par Mağd al-Dīn al-Usrūšanī (m. après 637/1240), jurisconsulte hanéfite. Composé de 30 chapitres, c'est un compendium de figh à l'usage des cadis et des muftis sur des sujets comme le mariage, la répudiation, la vente, la location ou la succession. Fușūl al-ị̣kām fì ușūl al-aḥkām d'al-Margì̄nānī ( $\mathrm{n}^{\circ}$ 92) complète l'ouvrage précédent de quelques chapitres et commentaires. Badr al-Dīn al-Simāwī (m. 823/1420) fait la synthèse des deux. Il traite des mu'āmalāt et des questions de jugement, inclut des résumés des parties des deux œuvres, des points laissés de côté et des ajouts. Traitant de problèmes liés aux kazāa et aux fatwas, il fut, également pour cette raison, très utilisé par des muftis et des cadis comme livre de cas d'espèce discutés (murāğa'āt). Bibliographie: Brockelmann, Geschichte der arabischen Litteratur, II, p. 290-291 ; Ali Bardakoğlu, « Câmiu'l-fusûleyn », Türkiye Diyanet Vakfi İslam Ansiklopedisi, 7 (1993), p. 108-109; Murteza Bedir, « Üsrûşenî », Türkiye Diyanet Vakfi İslam Ansiklopedisi, 42 (2012), p. 392-393.

94. « Fuṣūl-i 'imādī »; Fuṣūl al-'imādì d'al-Margīinānì (nº 92, 93). Ce compendium fut largement composé à partir du Fușūl fì l-mu'āmalāt d'al-Usrūšanī $\left(\mathrm{n}^{\circ}\right.$ 93). Ce dernier aborde les problèmes juridiques afférants aux rapports sociaux (mu'ämalāt), mais en se focalisant sur la dimension ascétique de la vie d'un musulman dans ses rapports à ses semblables, aussi bien musulmans que non-musulmans, et en insistant, par delà l'aspect prohibé (ḥarām), sur l'aspect 
répréhensible ( $m a k r u ̄ h)$ dont il convient également de se prémunir. Ce type de figh intègre les valeurs ascético-mystiques pour élever les conduites au rang de l'excellence du caractère ${ }^{279}$. Bibliographie: Murteza Bedir, «Üsrûşenî », Türkiye Diyanet Vakfi İslam Ansiklopedisi, 42 (2012), p. 392-393.

95. «Keşf 'alā-l-Pezdevī»; Kašf al-asrār 'an ușūl faḩr al-islām al-Bazdawì. Abū l-Yusr al-Bazdawī (m. 493/1099-110o) était un jurisconsulte hanéfite de Samarcande. Son livre est un classique qui marque un aboutissement de la littérature des ușūl. Il connut un grand succès et servit de modèle à des manuels, parmi lesquels le Manār al-anwār d'al-Nasafì (nº 69) et le Tanqīh al-ușūl de Șadr al-Šarīa (no 89). Par la somme des uṣūl qu'il réunit, le commentaire de 'Alā' al-Dīn 'Abd al-'Azīz al-Buhārī (m. 730/1329-1330) est sans doute le plus riche et le plus abouti. Bibliographie : Murteza Bedir et Ferhat Koca, « Pezdevî, Ebü'l-Usr », Türkiye Diyanet Vakfi İslam Ansiklopedisi, 34 (2007), p. 264-266.

96. «Şerḥ̈̈-l-kenz li-el-Aynī»; 2 vols; l'ouvrage de figh, Kanz al-daqā̇iq d'al-Nasafi (m. 710/1310-1311), jurisconsulte et théologien hanéfite ( $\left.n^{\circ} 4, n^{\circ} 69\right)$, compte parmi les mutūn al-arba'a. Parce qu'il est à la fois bref et ardu, très estimé tout en laissant des points difficilement compréhensibles des non spécialistes, il a suscité de très nombreux commentaires. Parmi eux, Ramz al-haqā̉iq fišarḥ kanz al-daqāiq est un court commentaire rédigé par Badr al-Dīn al-'Aynī (m. 855/1451-1452), jurisconsulte, traditionniste et historien natif de 'Ayıntāb, dont l'œuvre, principalement rédigée en arabe, comporte aussi des titres en turc. Bibliographie : TÜYATOK, Burdur I, p. 531-532 (15 H.K. 2068, manuscrit du Kanz al-daqā̇iq) ; «Burdur Kitapları Süleymaniye'den Konya'ya Devir-Teslim Listesi, 21-6-2012 », no 506 (idem); Murteza Bedir, «Nesefî, Ebü'l-Berekât», Türkiye Diyanet Vakfı İslam Ansiklopedisi, 32 (2006), p. 567-568; Heffening, «al-Nasafì, Ḥāifiz al-Dīn Abū l-Barakāt», $E I^{2}$; «Aynî, Bedreddin», Türkiye Diyanet Vakfı İslam Ansiklopedisi, 4 (1991), p. 271-272 ; William Marçais, «al'Aynī», $E I^{2}$; Ahmet Yaman, «Kenzü'd-dekâik », Türkiye Diyanet Vakfı İslam Ansiklopedisi, 25 (2002), p. 261-262.

97. «Muhtelifü-l-rivāyet»; Muhtalif al-riwāya fut composé par Abū l-Layt al-Samarqandī (m. 373/983), théologien et jurisconsulte hanéfite. Il discute et réorganise plusieurs points du fiqh qui ont suscité des opinions divergentes parmi des muğtahid et d'anciennes autorités hanéfites. L'auteur est identifié, mais sur plusieurs copies, quatre autres noms sont cités. Bibliographie: Brockelmann, Geschichte der arabischen Litteratur, I, p. 210 ; Joseph Schacht, «Abū l-Layth », EI $I^{2}$; İshak Yazıcl, «Semerkandî, Ebü'l-Leys », Türkiye Diyanet

279 Je remercie L. Daaïf pour ses indications très précises. 
Vakfi İslam Ansiklopedisi, 36 (2009), p. 473-475; Josef van Ess, «Abu'l-Layt Samarqandī», Encyclopaedia Iranica, 1/3 (1983), p. 332-333; Muhammad Haron, « Abü'l-Layth Al-Samarqandì's Life and Works with Special Reference to His al-Muqaddimah », Islamic Studies, 33/2-3 (1994), p. 319-340.

98. «Mu'īnü-l-kuzāāt ve tenvīrü-l-ebșār ». Mu'inn al-quḍāt est le titre d'un ouvrage d'Abū 'Abd Allāh Muḥammad b. Sulaymān al-Nafì l-Uțmānī (m. 974/ 1566-1567) mentionné par Ḥāğğì Hualīfa dans son Kašf al-zunūn, précisant que ce traité fut composé pour «al-Mawlā Ahmmad, connu sous le nom de Mu'allim Zāde» (m. 980/1572). La seconde expression correspond à un autre titre identifié: Tanwīr al-abșār wa-ğāmic al-bihāar, achevé en 995/1586-1587 par Šihāb al-dīn Aḥmad b. al-Tumurțāšì (m. 10o6/1597-1598), natif de Ghaza. C'est une compilation de problèmes traités dans des ouvrages de figh hanéfite. Considéré comme solide et fiable, cet ouvrage fut utilisé comme un manuel de référence par quantité de muftis et cadis. De très nombreuses copies en existent. Bibliographie : Ḥăğğḡi Halīfa, Lexicon bibliographicum et encyclopaedicum a Mustafa ben Abdallah Katib Jelebi dicto et nomine Haji Khalfa celebrato compositum. Ad codicum vindobonensium, parisiensium et berolinensium fidem primum edidit, latine vertit et commentario indicibusque instruxit Gustavus Fluegel, éd. Gustav Flügel, Leipzig, R. Bentley, 1835-1858, 6 vols, v, p. 644 ; Ahmet Özel, «Timurtaşî, Muhammed b. Abdullah», Türkiye Diyanet Vakfı İslam Ansiklopedisi, 41 (2012), p. 188-189.

99. « Hāâşiye-i Sinān 'alā-ṣ-șadrü-ş-şerīa ». Un grand nombre de lettrés ottomans ont rédigé un commentaire de la Wiqāya de Șadr al-Šarīa (no 89). Kara Sinān ed-Dīn Yūsuf (Kara Hiṣār ; m. ca 885/1480), lettré natif de la région d'Akhisar en fait partie. C'est l'un de ses écrits les plus importants. Bibliographie : Țāhir, 'Oșmānlı Mü̉ellifleri, I, p. 397; Şükrü Özen, «Sadrüşşerîa », Türkiye Diyanet Vakfi İslam Ansiklopedisi, 35 (2008), p. 427-431; Tahsin Özcan, « Kara Sinan», Türkiye Diyanet Vakfi İslam Ansiklopedisi, 24 (2001), p. 365-366.

100*. «Cāmi ü-n-nevādir»; 2 vols; Ğami‘ al-nawādir. Abū Misḥal al-Árābī (m. 230/845) est l'auteur d'un Kitāb al-Nawādir. Il s'agit d'un lexique de locutions rares et inusitées. Il est possible qu'il s'agisse d'un autre ouvrage, d'un anecdotier ou d'un répertoire de raretés religieuses ${ }^{280}$. Bibliographie: İsmail

280 Nawādir (litt. «chose rare, rareté») désigne une anecdote plaisante contenant un trait d'esprit. Mais des auteurs ont intitulé leurs ouvrages Kitāb al-Nawādir souvent sans autre spécification. Dans ce cas, nawādir a généralement le sens de « curiosités, originalités, raretés » et s'applique aux études religieuses, philologiques, mathématiques, astrologiques, 
Durmuş, «Nevadir», Türkiye Diyanet Vakfı İslam Ansiklopedisi, 33 (2007), p. 29-30; Ch. Pellat, « Nādira », $E I^{2}$.

101. «Dürrü-l-müntekāa fî şerhü̈-l-mültekāā. Il s'agit d'un commentaire de Multaqā l-abḥur, manuel de furū d'Ibrāhīm al-Ḥalabī (m. 956/1549), né à Alep, savant hanéfite, par Muḥammad al-Haskafī (m. 1088/1677), jurisconsulte natif de Damas. C'est l'un des commentaires les plus connus de l'œuvre, traduite en turc et commentée dans cette langue dès le $\mathrm{XI}^{\mathrm{e}} / \mathrm{XVII}^{\mathrm{e}}$ siècle. Lauteur examine les différentes sources de la littérature du figh. Bibliographie : TÜYATOK, Burdur I, p. 56o-561 (15 H.K. 65, manuscrit du Multaqā l-abhur) ; Has, « The Use of Multaqa'-abhur in the Ottoman Madrasas and in Legal Scholarship »; id., « Mülteka'l-ebhur », Türkiye Diyanet Vakfi İslam Ansiklopedisi, 31 (2006), p. 549$55^{2}$; Joseph Schacht, «al-Ḥalabī », $E I^{2}$; « Haskefî̀ », Türkiye Diyanet Vakfi İslam Ansiklopedisi, 16 (1997), p. 387-388; Özel, Hanefi Flkıh Âlimleri, p. 133-134.

102. «Tercüme-i reşahāāt »; Tarğama al-rašahăàt 'ayn al-hayāt. Il s'agit d'une traduction (en turc, sinon en arabe) de Rašahạt 'ayn al-hayāt, ouvre principale, écrite en persan et achevée en 909/1503-1504, de l'éminent prédicateur soufi naqšbandi, Faḩr al-Dīn 'Alī l-Ṣafî̀ (m. 939/1532-1533), né à Sabzawār (Khorasan occidental). C'est une œuvre importante de mystique (tașawwuf), estimée pour les informations qu'elle livre sur cet ordre avant le $\mathrm{x}^{\mathrm{e}} / \mathrm{XvI}^{\mathrm{e}}$ siècle et pour ce qui y est dit des actes et propos de soufis naqšbandis que l'auteur a côtoyés ou d'éléments qui lui ont été rapportés. Bibliographie : Necdet Tosun, Türkiye Diyanet Vakfi İslam Ansiklopedisi, 35 (2008), p. 470 ; William L. Hanaway, « Șafì », $E I^{2}$.

$103^{*} \cdot$ «Mu'innü-l-ḳuẓāt »; voir nº 98 .

104. « Şemi'ī 'alā-l-Ḥāflż ». Şemi'ī (m. ca 1011/16o2) est connu pour ses commentaires de divan en turc. Celui-ci est tiré du divan de ghazals de Ḥāfiż-1 Şīrāzī (Šams al-Dīn Muḥammad Ḥāfiẓ, m. 792/139o), le plus populaire et le plus commenté des poètes persans. Rédigé pour son patron Aḥmad Ferīdūn, il s'agit d'une paraphrase turque intégrale du texte, assortie de courtes notices explicatives. $3^{2}$ copies de la traduction du Ḥāıż ont été identifiées. Celui-ci est le plus employé des commentaires rédigés en turc avec ceux de Sürūrī et de Sūdī. Bibliographie: Şeyda Öztürk, «Şemiî̀», Türkiye Diyanet Vakfi İslam Ansiklopedisi, 38 (2010), p. 503-504 ; Johannes Thomas Pieter de Bruijn,

botaniques, médicales, etc. F. Sezgin cite au total 144 titres dans lesquels nawädir n'a jamais le sens d'anecdotes. Charles Pellat, «Nādira " $E I^{2}$. Voir aussi Fuat Sezgin, Geschichte des arabischen Schriftums, Leyde, Brill, 1967-1984, 9 vols. 
«Shem'ī», $E I^{2}$; Ehsan Yarshater, «Hafez i. An overview», Encyclopaedia Iranica, 11/5 (2002), p. 461-465 ; Tahsin Yazıcı, « Hâfız-ı Şîâazî », Türkiye Diyanet Vakfi İslam Ansiklopedisi, 15 (1997), p. 103-106.

105. «Sürūrī 'alā-l-Ḥāfiż ». Mușțafà Sürūrī (m. 969/1562), philologue et commentateur natif de Gallipoli, est l'auteur du plus ancien des commentaires en turc du divan de Ḥāfiż. Bibliographie: Ms Konya, Konya Yazma Eserler Bölge Müdürlüğü, 4409; TÜYATOK, Isparta, p. 795, nº 1353 (32 H.K. 1861); İsmail Güveç, «Sürūrī, Muslihuddin Mustafa», Türkiye Diyanet Vakfı İslam Ansiklopedisi, 38 (2010), p. 170-172; Tahsin Yazıcı, «Hâfız-ı Şîrâzî», Türkiye Diyanet Vakfı İslam Ansiklopedisi, 15 (1997), p. 103-106; Georgii Michaelis Wickens, « Hâafiz », EI ${ }^{2}$; Ömer Faruk Akün, «Sürûrî», İslam Ansiklopedisi, 11 (1979), p. 249-250 ; Edith Ambros, «Surūrī», $E I^{2}$.

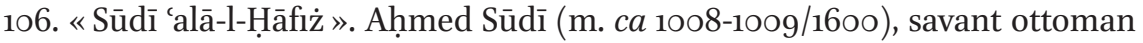
natif de la région de Foça (en Bosnie), est célèbre pour ses commentaires de divan. Celui-ci est le plus réputé des commentaires en turc du divan de Ḥāfiż. Il éclipse les deux précédents (dont il fait la critique), mais l'auteur est accusé d'avoir supprimé du poème des pièces à tendance chiite. Pendant plusieurs siècles, la recension historique de Sūdī domine les études biographiques de Ḥāfıż. Bibliographie : Wickens, « Hāfiz », $E I^{2}$; Kathleen Burrill, «Sūdī », $E I^{2}$; Hellmut Ritter, « Hâfız », İslam Ansiklopedisi, 5/1 (1988), p. 65-71. 
Annexe : extraits de la charte de la fondation pieuse de Halīl Ḥamīd Pacha (Vakıflar Genel Müdürlüğü, VGM-D-1929)

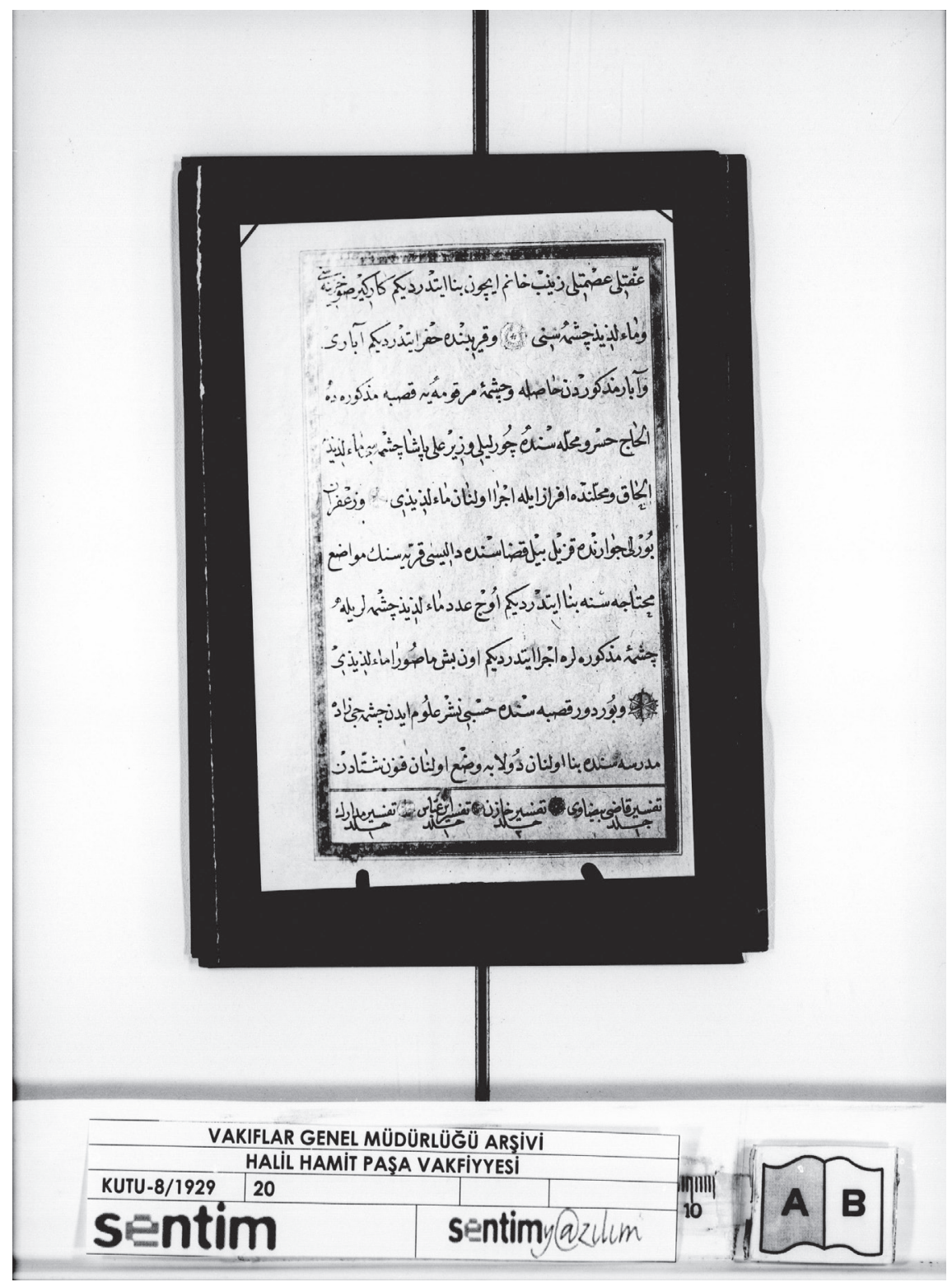

FIGURE 1 


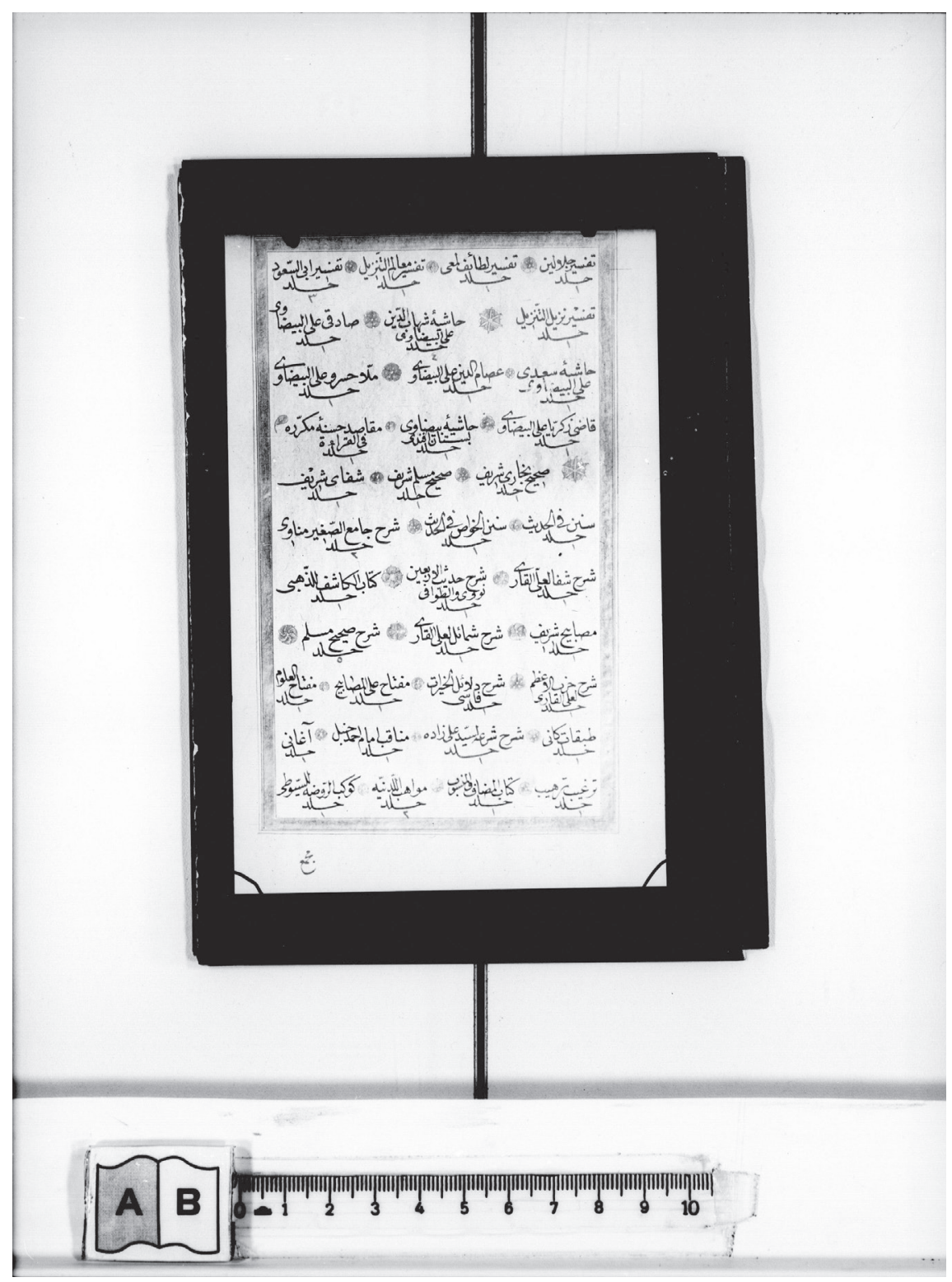

FIGURE 2 


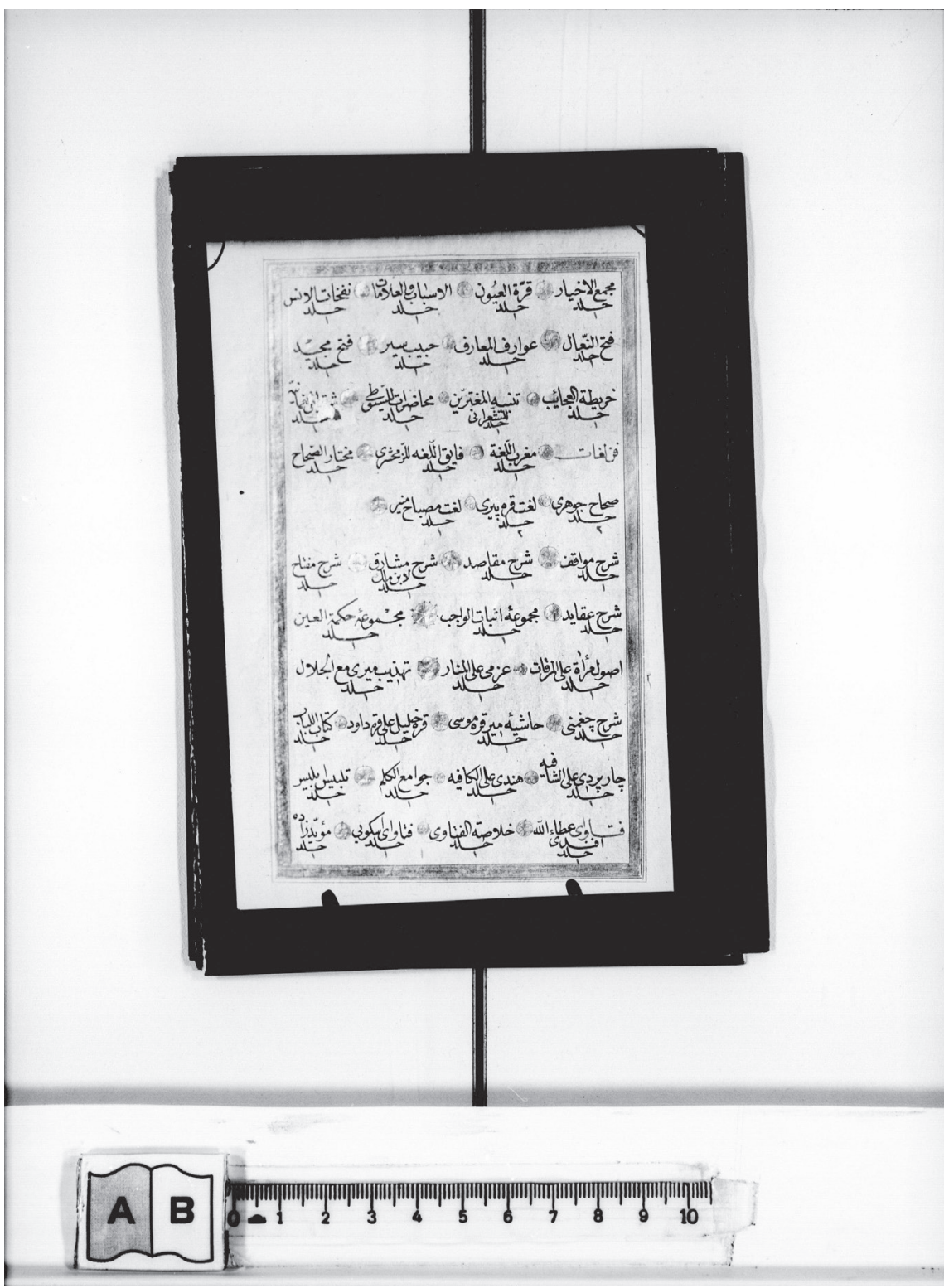

FIGURE 3 


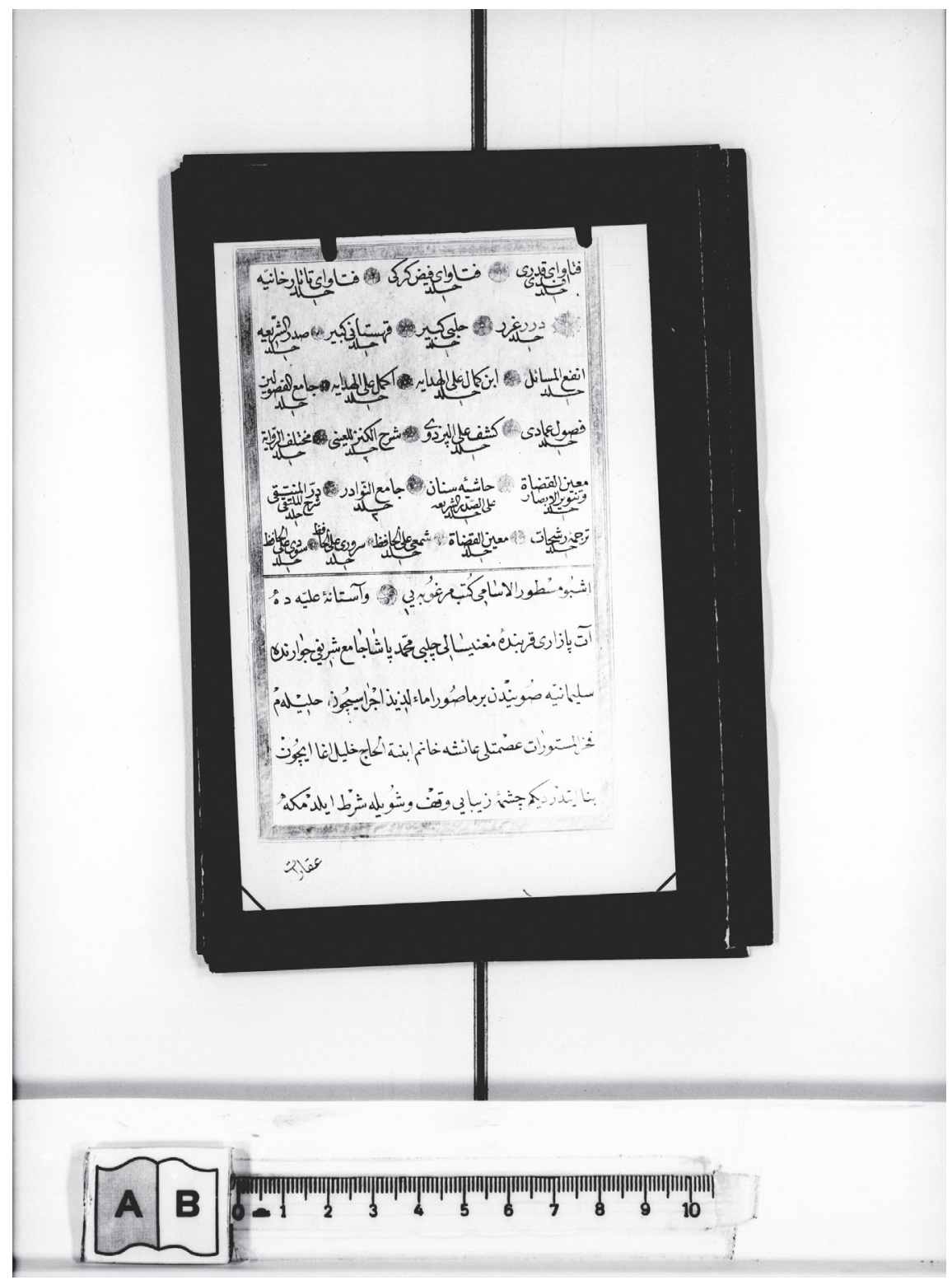

FIGURE 4 